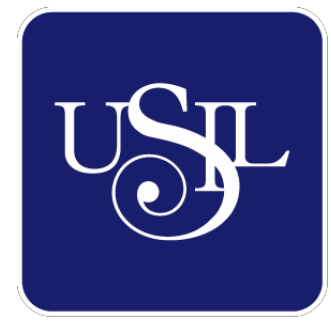

UNIVERSIDAD

SAN IGNACIO

DE LOYOLA

ESCUELA DE POSTGRADO

\title{
ELABORACIÓN DEL PLAN ESTRATÉGICO PARA LA INSTITUCIÓN EDUCATIVA SANTIAGO APOSTOL DE CUSCO PARA EL PERÍODO 2018 - 2023
}

Trabajo de Investigación para optar el grado de:

KATIA RODRIGUEZ VILLAGARCIA

Maestro en Ciencias Empresariales con Mención en Gestión del Capital Humano

\section{SERGIO GUSTAVO PUELLES PUELLES \\ Maestro en Ciencias Empresariales con Mención en Gestión del Capital Humano}

\author{
Asesor: \\ Julio Enrique de la Puente de la Borda \\ Lima - Perú \\ 2019
}




\section{RESUMEN EJECUTIVO}

El presente trabajo de investigación desarrolla el Plan Estratégico de la institución educativa particular Santiago Apóstol del distrito de Santiago de la ciudad del Cusco en un horizonte de tiempo de cinco años. El problema identificado se origina en la capacidad instalada insuficiente para cubrir la demanda de estudiantes, el inmueble donde actualmente opera la institución educativa es alquilado y los precios de la competencia directa reducen las posibilidades de incrementar la mensualidad.

El objetivo general es incrementar la rentabilidad a través de la selección de estrategias idóneas para que dicha institución logre contribuir con la formación académica y moral de sus estudiantes, potenciando sus capacidades, conocimientos y habilidades con el fin de que se puedan integrar y adaptar a la sociedad con valores. Para el logro de este propósito, se ha considerado tres objetivos estratégicos orientados al incremento de rentabilidad, lograr mayor participación de mercado y contar con plana docente idónea para el servicio educativo asimismo se ha formulado diez objetivos específicos, diseñados con indicadores del cuadro de mando integral para alcanzar la visión de ser reconocida como una institución educativa que propone educación personalizada con calidad, para contribuir al desarrollo personal y social de los estudiantes. Respecto a las estrategias seleccionadas, se formula adicionar al currículo de estudios vigente actividades extra curriculares de acuerdo a los intereses particulares de cada estudiante y mejorar los procesos internos optimizando la distribución correcta de costos y gastos.

Para el desarrollo del planeamiento estratégico, se consideró el modelo integral del proceso de administración estratégica planteado por Fred David, para describir y operativizar estrategias, 
así como el análisis de las oportunidades de mejora que sean aplicables para hacer frente al entorno de la industria educativa. 


\section{TABLA DE CONTENIDO}

RESUMEN EJECUTIVO

TABLA DE CONTENIDO

$\begin{array}{ll}\text { ÍNDICE DE TABLAS } & 7\end{array}$

$\begin{array}{ll}\text { ÍNDICE DE FIGURAS } & 7\end{array}$

CAPÍTULO I. GENERALIDADES

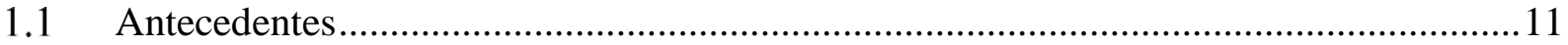

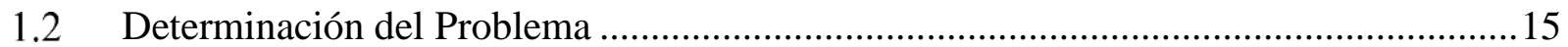

1.3 Justificación del Proyecto ................................................................................... 19

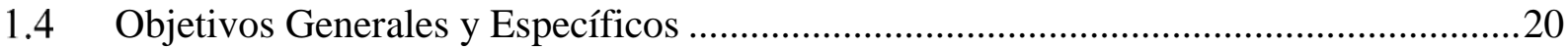

1.4.1 Objetivo General. ........................................................................................ 20

1.4.2 Objetivos Específicos................................................................................ 20

1.5 Alcances y Limitaciones de la investigación ........................................................21

1.5.1 Alcances de la IEP Santiago Apóstol................................................................ 21

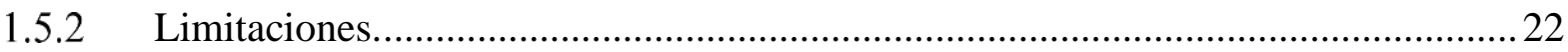

CAPÍTULO II. LA EMPRESA

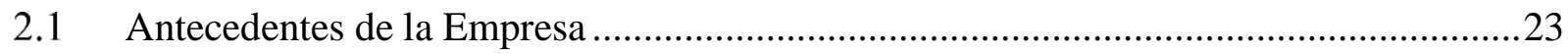

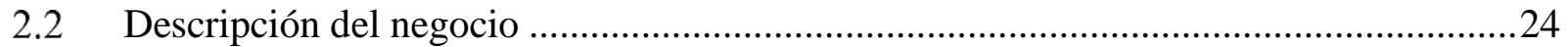

2.3 Ciclo de vida de la Industria ..................................................................................24

2.4 Estructura organizacional actual de la empresa....................................................29

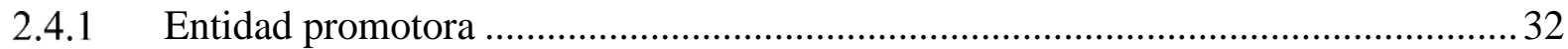

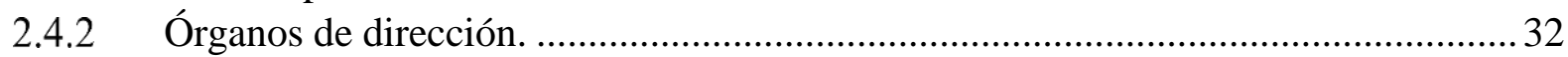

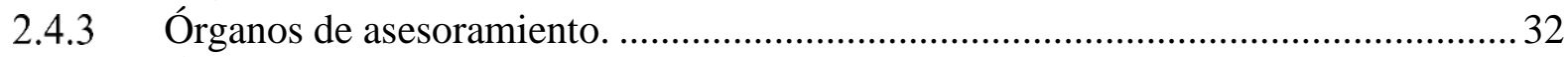

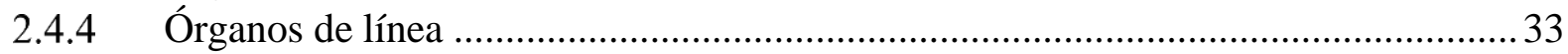

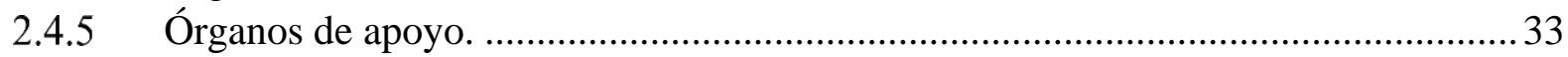

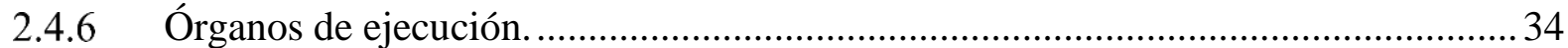

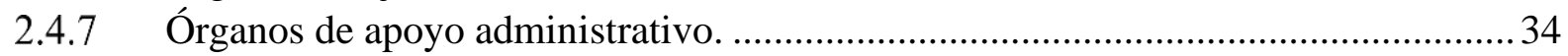

2.5 Situación de Mercado y Financiera actual de la Industria ..........................................35

\section{CAPÍTULO III. FORMULACIÓN DE VISIÓN, MISIÓN Y VALORES DE LA} EMPRESA 37

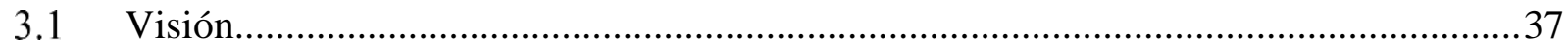

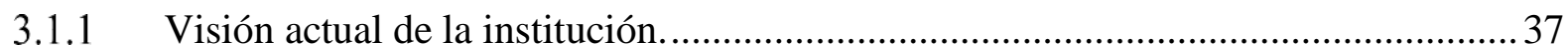

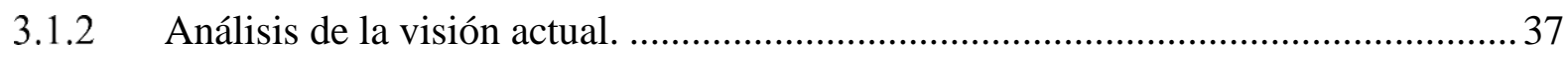

3.1.3 Matriz de la visión propuesta para la institución. ............................................... 38

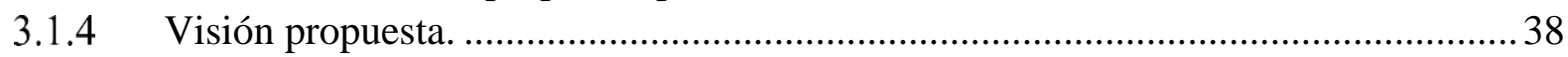

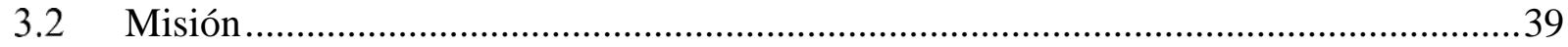

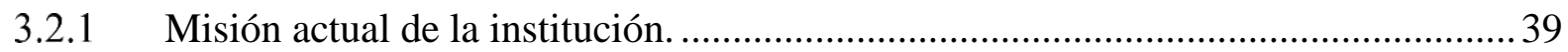

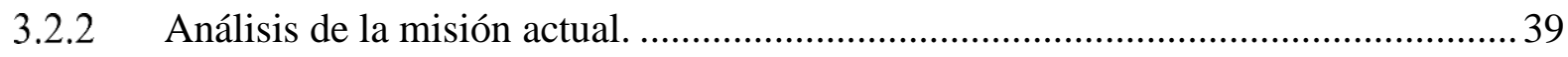

Elementos de la misión propuesta para la institución. 


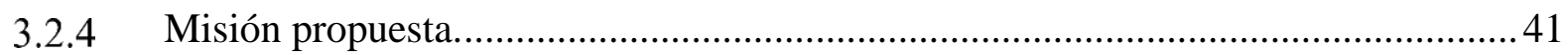

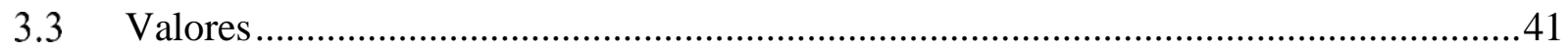

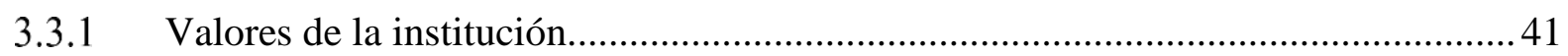

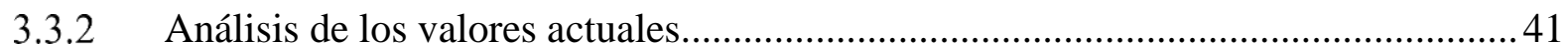

3.3.3 Elementos de los valores propuestos para la institución............................................. 41

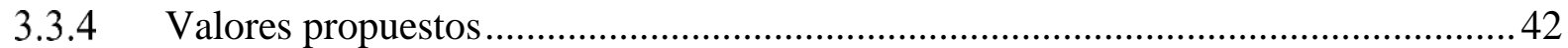

3.4 Alineamiento estratégico de la visión, misión y valores de la institución.........................42

CAPÍTULO IV. ANÁLISIS EXTERNO 44

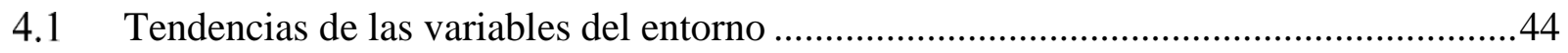

4.1.1 Análisis político-gubernamental y legal. ................................................................ 44

4.1.2 Análisis Económico. ……………………….......................................................4

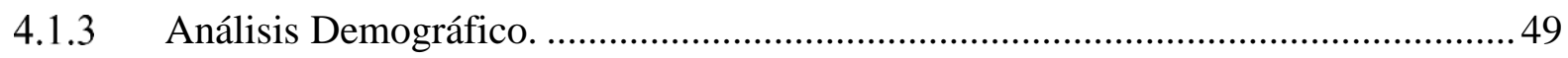

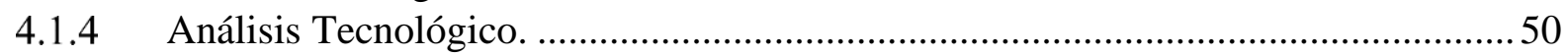

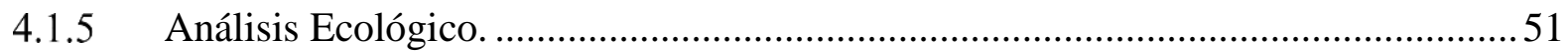

4.2 Impacto en clientes / proveedores de cada una de las variables del entorno ...................52

4.3 Efecto en la IEP de cada una de las variables del entorno............................................54

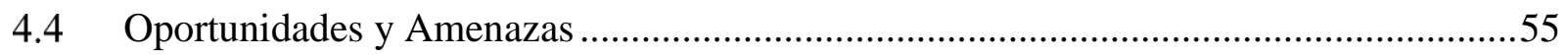

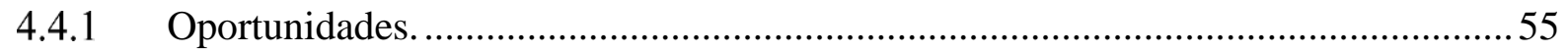

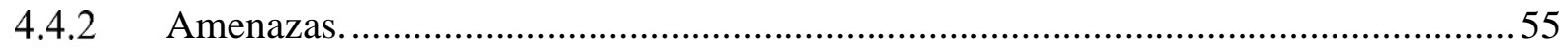

4.5 Matriz de Evaluación de los Factores Externos EFE .....................................................56

CAPÍTULO V. ANÁLISIS DE LA INDUSTRIA 59

5.1 Descripción del Mercado (demanda) e Industria (oferta)...............................................59

5.2 Descripción de las cinco fuerzas competitivas de la industria .........................................60

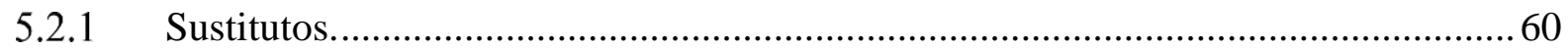

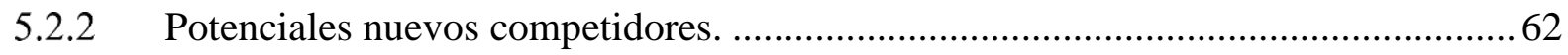

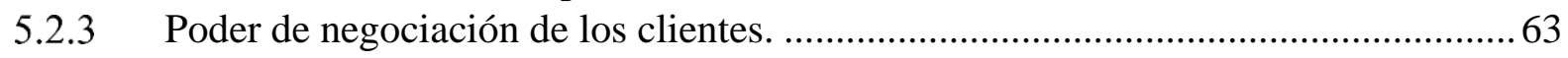

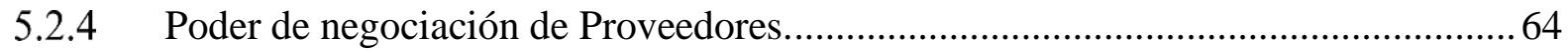

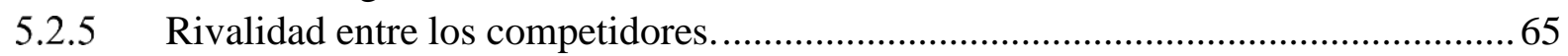

5.3 Matriz de Atractividad de cada una de las cinco fuerzas..................................................67

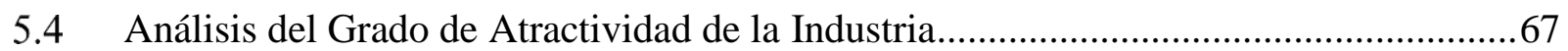

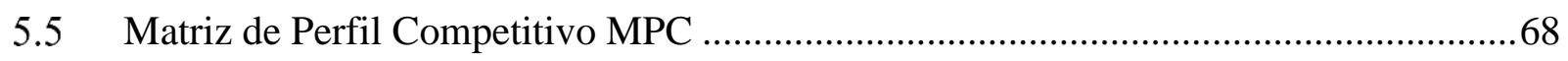

CAPÍTULO VI. ANÁLISIS INTERNO

6.1 Descripción de las actividades de la Cadena de Valor ...................................................72

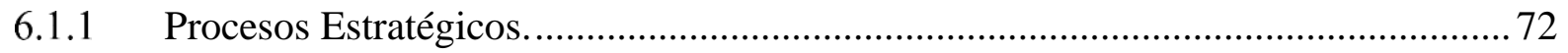

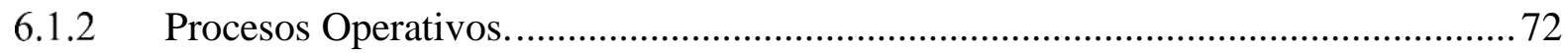

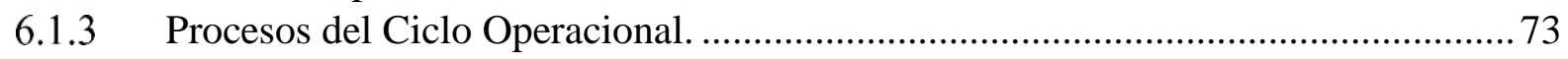

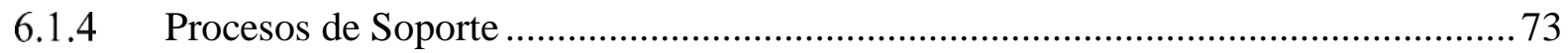

6.1.5 Procesos de medición, análisis y mejora.................................................................. 74

6.2 Indicadores de cada una de las Actividades de la Cadena de Valor .................................76

6enchmarking y comparación con los líderes de la industria de cada una de las

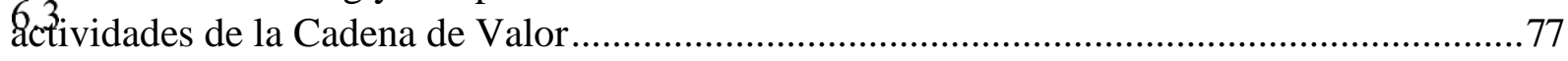

6.4 Determinar las Competencias de la Institución ............................................................78 
6.5 Identificación y determinación de las Ventajas Competitivas de la Institución .............80

6.6 Lista de Fortalezas y Debilidades ....................................................................... 81

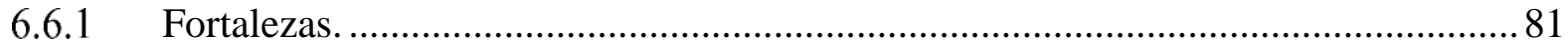

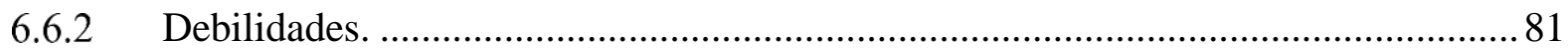

6.7 Matriz de Evaluación de los Factores Internos EFI..................................................81

CAPÍTULO VII. FORMULACIÓN DE LOS OBJETIVOS Y DISEÑO DE LAS ESTRATEGIAS 84

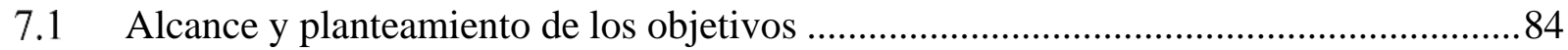

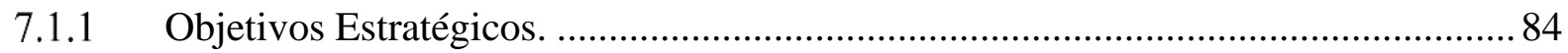

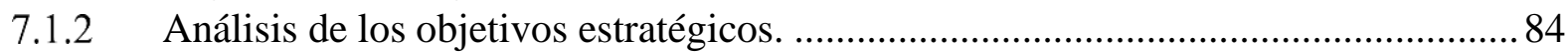

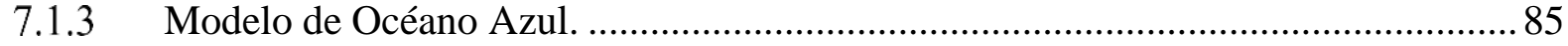

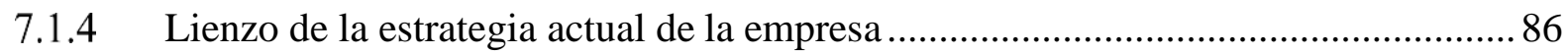

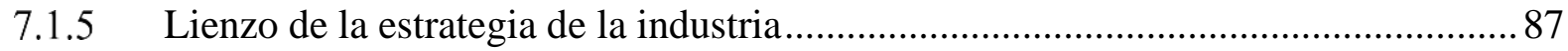

7.1.6 Matriz (Eliminar, Reducir, Incrementar, Crear). ............................................... 88

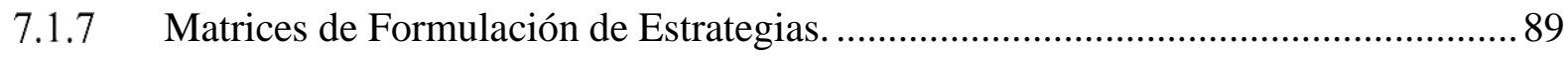

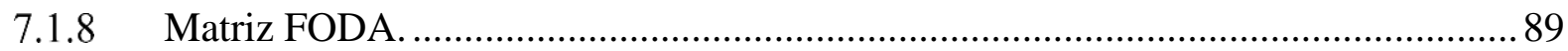

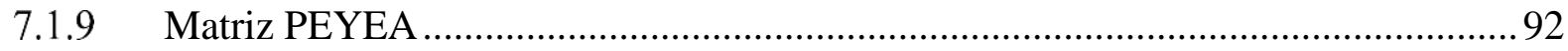

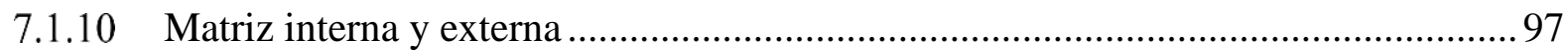

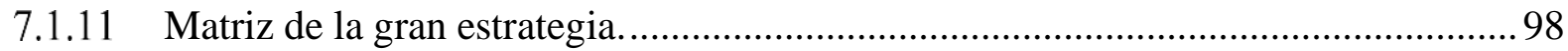

CAPÍTULO VIII. SELECCIÓN DE LA ESTRATEGIA 101

8.1 Método Factores Estratégicos Clave .................................................................... 101

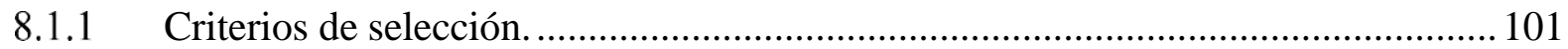

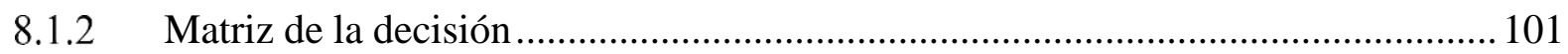

8.1.3 Matriz cuantitativa del planeamiento estratégico................................................ 104

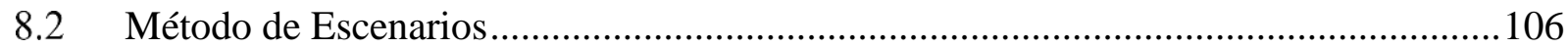

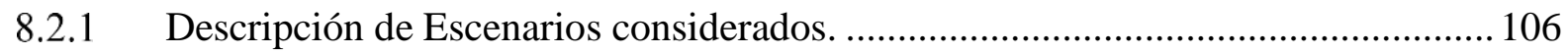

8.3 Descripción de Estrategia Seleccionada ................................................................ 108

CAPÍTULO IX. IMPLEMENTACIÓN DE LA ESTRATEGIA 110

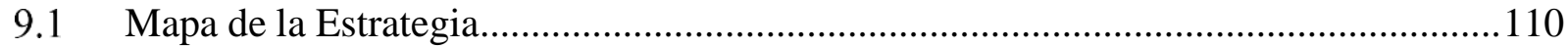

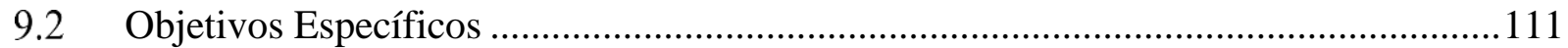

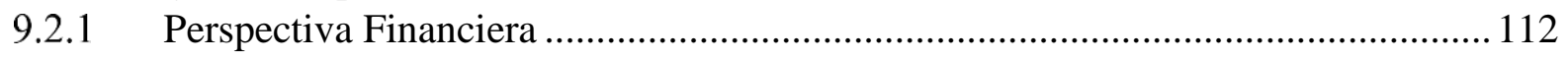

9.2.2 Perspectiva del Cliente................................................................................ 112

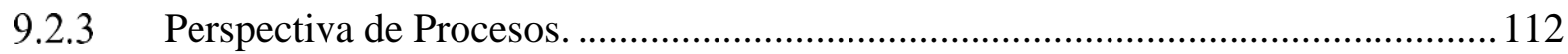

9.2.4 Perspectiva de Aprendizaje.......................................................................... 112

CAPÍtULO X. EVALUACIÓN

Evaluación Financiera de la Estrategia ................................................................. 116

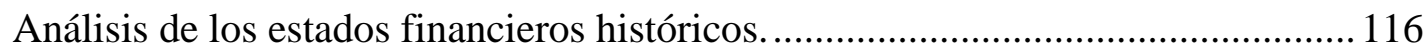

18:1:2 Proyección de los ingresos anuales (sin estrategia y con estrategia)..................... 117

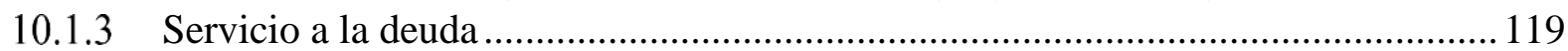

10.1.4 Gastos Administrativos, Operativos y de Implementación. .................................. 120

10.1.5 Proyección del estado de resultados (sin estrategia y con estrategia).................... 1225 
10.1.6 Proyección del estado de situación ...................................................................... 123

10.1.7 Proyección del Flujo de caja con y sin estrategia. .............................................. 123

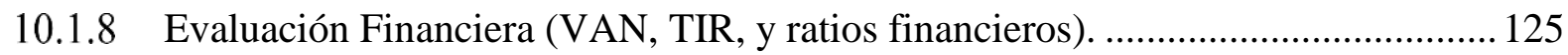

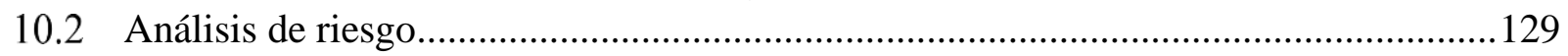

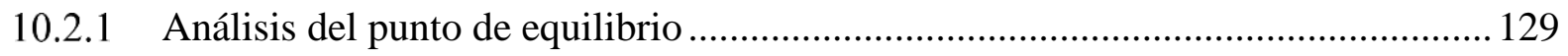

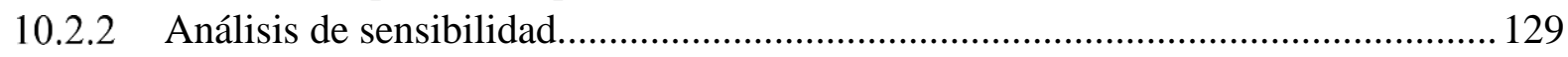

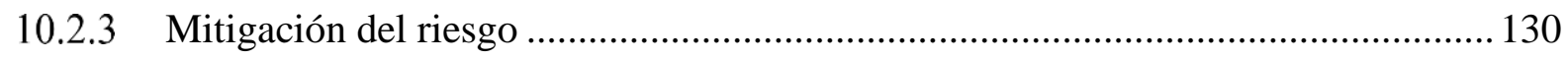

CONCLUSIONES Y RECOMENDACIONES 133

$\begin{array}{ll}\text { BIBLIOGRAFÍA } & 135\end{array}$

ANEXOS 137 


\section{ÍNDICE DE TABLAS}

Tabla 1 Gasto Público en educación por nivel educativo, países seleccionados de América

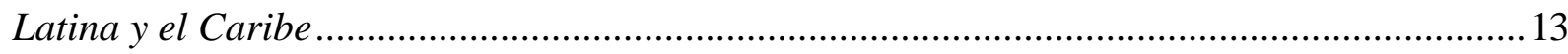

Tabla 2 Número de matrículas a Nivel Nacional de Educación Básica Regular - 2018 ..........14

Tabla 3 Número de matrículas registradas en el Perú de Educación Básica Regular período

2016 - $2018 .$.

Tabla 4 Número de matrículas de educación Básica Regular en la Región Cusco Nivel

Primaria $2016-2018$.

Tabla 5 Número de matrículas de Educación Básica Regular en la Región Cusco Nivel

Secundario 2016 - 2018..................................................................................................... 15

Tabla 6 Ingresos y Gastos según NSE 2018 - Perú (Urbano + Rural) .................................. 17

Tabla 7 Comparación de pensiones de la competencia directa según nivel escolar 2018 ........ 18

Tabla 8 Período por matricula según grado 2007-2018......................................................29

Tabla 9 Matrícula en colegios privados en el distrito de Santiago, según Nivel Educativo,

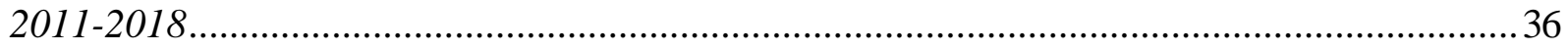

Tabla 10 Análisis de la visión actual de la institución educativa Santiago Apóstol .................37

Tabla 11 Matriz de la Visión propuesta para la institución educativa Santiago Apóstol..........38

Tabla 12 Análisis de la Misión actual de la institución educativa Santiago Apóstol................40

Tabla 13 Elementos de la Misión propuesta ............................................................................4 40

Tabla 14 Matriz axiológica de Valores ............................................................................. 42

Tabla 15 Matriz de la visión, misión y valores de la IEP Santiago Apóstol ............................43

Tabla 16 Matriz de relación entre la Visión y Valores de la IEP Santiago Apóstol .................43

Tabla 17 Matriz de relación entre la Misión y Valores de la IEP Santiago Apóstol .................43

Tabla 18 Distribución de hogares según NSE 2018(urbano)................................................48

Tabla 19 Gasto público en educación como porcentaje del PBI............................................48

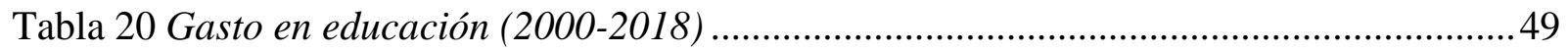

Tabla 21 Población en edad escolar estimada y proyectada, según edad y sexo 2005-2017 50

Tabla 22 Población en edad escolar, del distrito de Santiago 2015- 2017.............................50

Tabla 23 Impacto en clientes y proveedores (Análisis del Macroambiente)............................53

Tabla 24 Efecto en la IEP de cada una de las variables del entorno (Análisis del

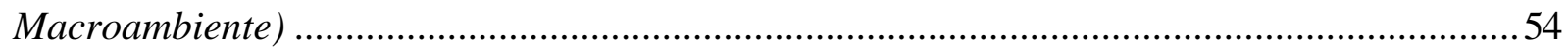

Tabla 25 Matriz de evaluación de los factores EFE.............................................................57 
Tabla 26 Instituciones educativas particulares en el distrito de Santiago 2018 - nivel primario

Tabla 27 Instituciones educativas en el distrito de Santiago - nivel secundario......................60

Tabla 28 Evolución de instituciones educativas ..................................................................65

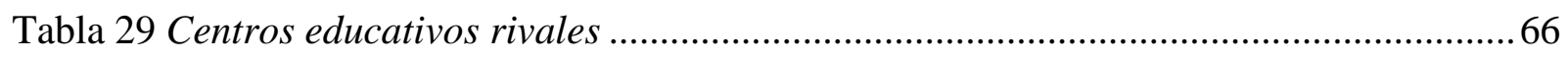

Tabla 30 Matriz de atractividad de las 5 fuerzas competidoras de Porter .............................68

Tabla 31 Matriz de perfil competitivo MP ........................................................................71

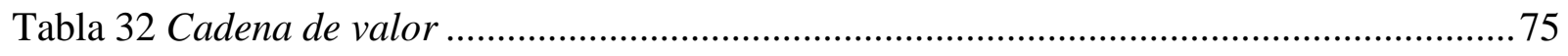

Tabla 33 Benchmarking y comparación con los líderes de la industria de cada una de las actividades de la cadena de valor ........................................................................................ 78

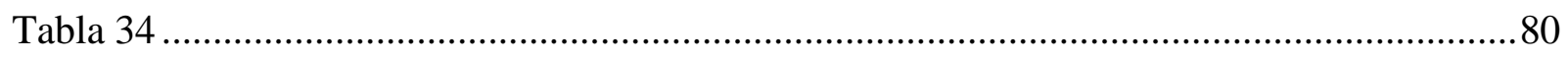

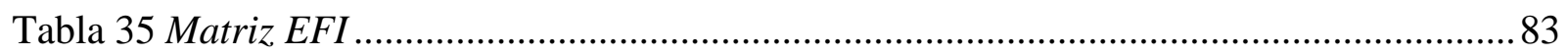

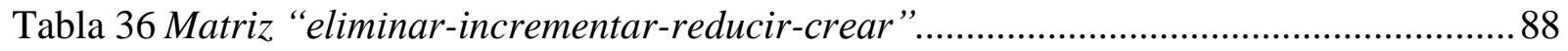

Tabla 37 Matriz FODA de la IEP Santiago Apóstol .............................................................90

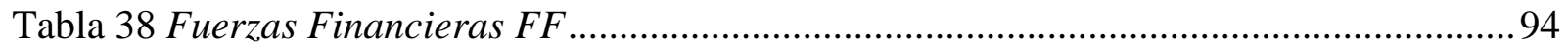

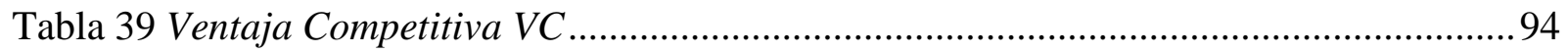

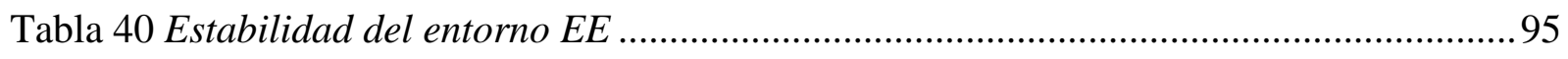

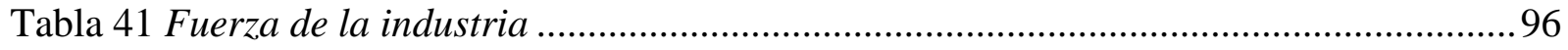

Tabla 42 Matriz de decisión de la Estrategia ....................................................................... 102

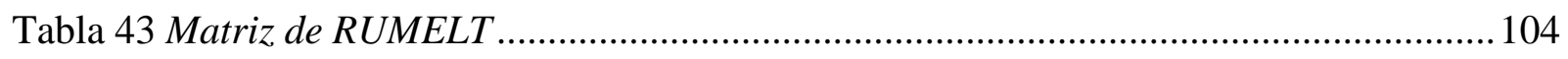

Tabla 44 Matriz cuantitativa del planeamiento estratégico ................................................. 105

Tabla 45 Impactos en las Estrategias.............................................................................. 108

Tabla 46 Objetivos del Balanced Scorecard .................................................................. 113

Tabla 47 Estado de Resultados histórico (en soles) ........................................................... 117

Tabla 48 Ingresos por ventas anuales sin estrategia (en soles) ........................................... 118

Tabla 49 Ingresos por ventas anuales con estrategia (en soles) ......................................... 118

Tabla 50 Flujo de efectivo (Primeros 6 meses del 2019) ................................................... 118

Tabla 51 Amortización del préstamo.............................................................................. 119

Tabla 52 Gastos de personal y administrativos................................................................ 120

Tabla 53 Costos de implementación de la estrategia (Años 1 al 5) ....................................... 121

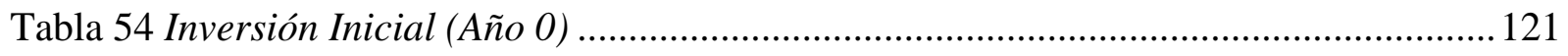


Tabla 55 Estado de Resultados sin Estrategia (en soles).................................................. 122

Tabla 56 Estado de Resultados con Estrategia (en soles)................................................... 123

Tabla 57 Estado de situación proyectado.......................................................................... 123

Tabla 58 Flujo de caja sin estrategia (en soles).............................................................. 124

Tabla 59 Flujo de caja con estrategia (en soles).............................................................. 124

Tabla 60 Cálculo del beta para el proyecto .................................................................... 125

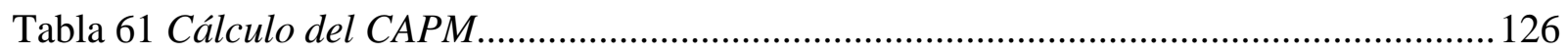

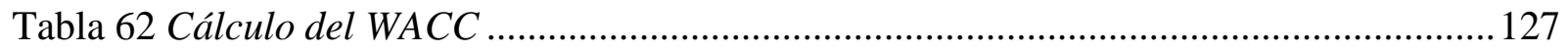

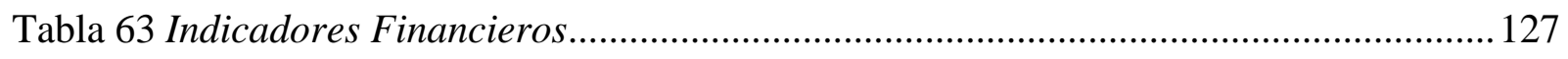

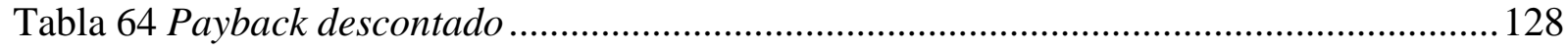

Tabla 65 Estimación de punto de equilibrio (soles y cantidades)........................................ 129

Tabla 66 Análisis de sensibilidad Unidimensional............................................................. 130

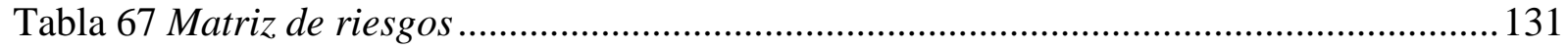

Tabla 68 Matriz de mitigaciones .................................................................................... 132 


\section{ÍNDICE DE FIGURAS}

Figura 1. Ciclo de Vida de la Industria Educativa. Elaboración propia.......................................25

Figura 2. Pronóstico de matriculados en el distrito de Santiago. Elaboración propia ...............26

Figura 3. Ciclo de Vida de la IEP Santiago Apóstol. Elaboración propia ...................................2

Figura 4. Pronóstico del número de matriculados al 2023 en la IEP Santiago Apóstol.

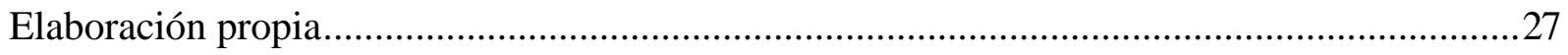

Figura 5. Ciclo de Vida del Servicio. Elaboración propia.....................................................28

Figura 6. Organigrama de la IEP Santiago Apóstol..................................................................31

Figura 7. Alumnos por computadoras Cusco 2017. ESCALE, MINEDU 2017........................51

Figura 8. Lienzo actual de la estrategia de la IEP Santiago Apóstol. Elaboración propia.........87

Figura 9. Lienzo de la estrategia actual de la industria. Elaboración propia .............................8 88

Figura 10. Matriz PEYEA de la IEP Santiago Apóstol. Elaboración propia...............................96

Figura 11. Matriz interna y externa de la IEP Santiago Apóstol. Elaboración propia................97

Figura 12. Población y matrícula en edad escolar de educación primaria en Cusco, 2010 -

2016. Proyecciones población INEI 2016 y Censo Escolar del Ministerio de Educación.........99

Figura 13. Población y matrícula en edad escolar de educación secundaria en Cusco, 20102016. Proyecciones población INEI, 2016 y Censo Escolar del Ministerio de Educación.

Elaboración propia

Figura 14. Posición de la IEP Santiago Apóstol. Elaboración propia .......................................100

Figura 15. Perspectivas de desarrollo. Elaboración Propia........................................................110

Figura 16. Mapa del Balanced Scorecard. Elaboración Propia ..............................................111 


\section{Generalidades}

\subsection{Antecedentes}

Según Luque, Barrientos, \& Pérez (2017, p. 44) “La educación es un derecho humano fundamental. La Constitución política la reconoce, dentro del marco de derecho reconocido en la Declaración Universal de los Derechos Humanos y en la Convención sobre los Derechos del Niño". Por otro lado, el estado brinda educación y está encargado de supervisar y monitorear el servicio educativo tanto en instituciones públicas como privadas a través del Ministerio de Educación y las instancias que dependen de él.

Del mismo modo, el Artículo 2 de la Ley General de Educación Nº 28044 (2003), indica que la educación contribuye a "la formación integral de las personas, al pleno desarrollo de sus potencialidades, a la creación de cultura, y al desarrollo de la familia y de la comunidad nacional, latinoamericana y mundial.” De acuerdo a esta Ley, la educación es una actividad que debe desarrollarse durante la vida de la persona. El Artículo 28 indica:

La Educación Básica regular se organiza en siete ciclos que se inicia en el nivel inicial, en el cual se configuran las bases fundamentales del desarrollo de la personalidad, que en las sucesivas fases de la vida se integrarán y consolidarán; pasando por la primaria y culminando con la secundaria (2003, p. 1).

De acuerdo con Jopen, Gomez, \& Olivera (2014, p. 8) “el Estado peruano, bajo su rol supervisor, debe asegurar que en el sistema educativo existan lineamientos generales que permitan compensar las desigualdades entre demandantes de educación que puedan originarse debido a diferencias económicas, geográficas, físicas, de género entre otras”. 
El Ministerio de Educación se encarga de la política educativa, así como de la reglamentación, cada región del Perú adecua y diversifica las propuestas del Ministerio. En consecuencia, se elabora el Diseño Curricular, documento normativo que sintetiza las intenciones educativas, le da unidad al sistema educativo peruano para su acreditación e identifica los aprendizajes que deben alcanzar los estudiantes al finalizar cada nivel. Este documento debe ser flexible, abierto y articulado, de modo tal que dirija un proceso continuo a través del desarrollo de capacidades, conocimientos, actitudes y valores. El criterio que maneja actualmente la educación en el Perú favorece directamente al desarrollo social y económico de cada región en la que se despliega, para que esto ocurra es básico el desarrollo de las capacidades personales y estructurar la identidad de todos los estudiantes para participar en la construcción de la sociedad.

Según el Informe del Banco Interamericano de Desarrollo (2017, p. 6), la región de América Latina y el Caribe invierte 3 puntos porcentuales del PBI, cifra que supera a lo invertido hace 25 años en el sector educación. La expansión y/o contracción de la economía limita la capacidad de gasto en educación en muchos países de América Latina, con el fin de evitar problemas cíclicos, se espera que los gobiernos optimicen el gasto corriente. El Perú es uno de los países de América Latina que menor porcentaje del PBI destina al sector educación, el valor utilizado para el año 2016 fue de 3.7\%, como se muestra en la Tabla 1. 
Tabla 1

Gasto Público en educación por nivel educativo, países seleccionados de América Latina y el Caribe

\begin{tabular}{cccccc}
\hline País & Total & Preprimaria & Primaria & Secundaria & $\begin{array}{c}\text { Terciaria } \\
\text { (Universidad) }\end{array}$ \\
\hline Argentina & $5.3 \%$ & $0.4 \%$ & $1.6 \%$ & $2.2 \%$ & $1.1 \%$ \\
Belice & $6.2 \%$ & $0.1 \%$ & $2.7 \%$ & $2.6 \%$ & $0.9 \%$ \\
Bolivia & $6.5 \%$ & $0.4 \%$ & $2.1 \%$ & $2.4 \%$ & $1.7 \%$ \\
Brasil & $6.1 \%$ & $0.4 \%$ & $1.8 \%$ & $2.6 \%$ & $1.2 \%$ \\
Chile & $4.6 \%$ & $0.7 \%$ & $1.4 \%$ & $1.5 \%$ & $1.0 \%$ \\
Colombia & $4.9 \%$ & $0.3 \%$ & $1.7 \%$ & $1.8 \%$ & $1.1 \%$ \\
Costa Rica & $7.6 \%$ & $0.5 \%$ & $2.9 \%$ & $1.9 \%$ & $2.3 \%$ \\
Ecuador & $4.8 \%$ & $0.7 \%$ & $2.1 \%$ & $0.8 \%$ & $1.2 \%$ \\
El Salvador & $3.8 \%$ & $0.4 \%$ & $1.8 \%$ & $1.2 \%$ & $0.5 \%$ \\
Guatemala & $2.8 \%$ & $0.3 \%$ & $1.7 \%$ & $0.5 \%$ & $0.3 \%$ \\
Honduras & $5.9 \%$ & $0.2 \%$ & $2.9 \%$ & $1.5 \%$ & $1.0 \%$ \\
Jamaica & $6.3 \%$ & $0.5 \%$ & $2.3 \%$ & $2.0 \%$ & $1.1 \%$ \\
México & $5.3 \%$ & $0.2 \%$ & $2.0 \%$ & $1.7 \%$ & $1.1 \%$ \\
Nicaragua & $4.5 \%$ & $0.5 \%$ & $1.9 \%$ & $0.6 \%$ & $1.3 \%$ \\
Panamá & $3.3 \%$ & $0.2 \%$ & $1.1 \%$ & $1.0 \%$ & $1.0 \%$ \\
Paraguay & $5.2 \%$ & $0.3 \%$ & $2.0 \%$ & $1.7 \%$ & $1.2 \%$ \\
Perú & $3.7 \%$ & $0.6 \%$ & $1.4 \%$ & $1.1 \%$ & $0.5 \%$ \\
República Dominicana & $2.6 \%$ & $0.2 \%$ & $1.3 \%$ & $0.9 \%$ & $0.2 \%$ \\
Uruguay & $4.5 \%$ & $0.5 \%$ & $1.0 \%$ & $1.6 \%$ & $1.4 \%$ \\
Venezuela & $7.5 \%$ & $1.0 \%$ & $2.9 \%$ & $1.6 \%$ & $2.0 \%$ \\
América Latina & $5.1 \%$ & $0.4 \%$ & $1.9 \%$ & $1.6 \%$ & $1.1 \%$ \\
Países de comparación & $3.8 \%$ & $0.4 \%$ & $1.3 \%$ & $1.5 \%$ & $0.8 \%$ \\
EE.UU. & $5.1 \%$ & $0.3 \%$ & $1.6 \%$ & $1.8 \%$ & $1.4 \%$ \\
ECDE & $4.9 \%$ & $0.5 \%$ & $1.3 \%$ & $1.9 \%$ & $1.2 \%$ \\
\hline Exo & $5 \%$ \% & & \\
\hline
\end{tabular}

Nota. Extraído del Cálculo de los autores utilizando la base de Estadísticas de Educación del Banco Mundial y Volman (2016).

Según ESCALE (2018), en el Perú la población en educación básica regular del sector privado fue de 7`821,050 alumnos; el $45 \%$ de la población estudiantil pertenece al nivel primaria y el 33\% al nivel secundaria. En la Tabla 2 muestra el número de alumnos del sector público y privado para el nivel inicial, primario y secundario. 
Tabla 2

Número de matrículas a Nivel Nacional de Educación Básica Regular - 2018

\begin{tabular}{cccccc}
\hline Nivel & Pública & \% de representación & Privada & \% de representación & Total por nivel \\
\hline Inicial & $1,254,332$ & $72 \%$ & 476,435 & $28 \%$ & $1,730,767$ \\
Primaria & $2,644,702$ & $75 \%$ & 902,021 & $25 \%$ & $3,546,723$ \\
Secundaria & $1,925,835$ & $76 \%$ & 617,725 & $24 \%$ & $2,543,560$ \\
\hline Total & $5,824,869$ & $74 \%$ & $1,996,181$ & $26 \%$ & $7,821,050$ \\
\hline
\end{tabular}

Nota. Elaboración Propia según información de ESCALE 2018, Ministerio de Educación

Respecto a la evolución del número de matrículas dentro de la educación básica

regular del sector privado en el Perú, para los años 2016; 2017 y 2018 se registra un

incremento promedio de $0.46 \%$ (ESCALE, 2018), de acuerdo a la Tabla 3.

Tabla 3

Número de matrículas registradas en el Perú de Educación Básica Regular período 2016 2018

\begin{tabular}{ccc}
\hline Año & Número de Matrículas & Porcentaje de Crecimiento \\
\hline 2016 & $1,983,838$ & $0.4 \%$ \\
2017 & $1,936,922$ & $-2 \%$ \\
2018 & $1,996,181$ & $3 \%$ \\
\hline
\end{tabular}

Nota. Elaboración Propia según información de ESCALE 2018, Ministerio de Educación

En el contexto regional del Cusco para los años 2016 - 2018 el número de las

matrículas dentro del nivel primario (sector privado) para una población de 6 - 11 años el

promedio de crecimiento fue de $2.3 \%$. Mientras que el número de matrículas dentro del nivel secundario (sector privado) para una población de 12 - 16 años mostró un descenso promedio de $-3.3 \%$ como se muestra en la Tabla 4. (ESCALE, 2018) 
Tabla 4

Número de matrículas de educación Básica Regular en la Región Cusco Nivel Primaria 2016 $-2018$

\begin{tabular}{ccccc}
\hline Año & $\begin{array}{c}\text { Matricula } \\
\text { primaria pública }\end{array}$ & $\begin{array}{c}\text { Porcentaje de crecimiento- } \\
\text { matricula primaria pública }\end{array}$ & $\begin{array}{c}\text { Matricula } \\
\text { primaria privada }\end{array}$ & $\begin{array}{c}\text { Porcentaje de crecimiento - } \\
\text { matricula primaria privada }\end{array}$ \\
\hline 2016 & 130,682 & $-2 \%$ & 23,490 & $5 \%$ \\
2017 & 127,066 & $-3 \%$ & 23,285 & $-1 \%$ \\
2018 & 124,399 & $-2 \%$ & 24,129 & $3 \%$ \\
\hline
\end{tabular}

Nota. Elaboración propia según datos del Informe ESCALE 2018

Tabla 5

Número de matrículas de Educación Básica Regular en la Región Cusco Nivel Secundario $2016-2018$

\begin{tabular}{ccccc}
\hline Año & $\begin{array}{c}\text { Matricula } \\
\text { secundaria } \\
\text { pública }\end{array}$ & $\begin{array}{c}\text { Porcentaje de crecimiento- } \\
\text { Matricula secundaria pública }\end{array}$ & $\begin{array}{c}\text { Matricula } \\
\text { secundaria } \\
\text { privada }\end{array}$ & $\begin{array}{c}\text { Porcentaje de crecimiento- } \\
\text { Matricula secundaria privada }\end{array}$ \\
\hline 2016 & 107,707 & $2 \%$ & 19,559 & $-2 \%$ \\
2017 & 106,724 & $-1 \%$ & 18,603 & $-5 \%$ \\
2018 & 103,020 & $-3 \%$ & 18,118 & $-3 \%$ \\
\hline
\end{tabular}

Nota. Elaboración propia según datos del Informe ESCALE 2018

La IEP Santiago Apóstol lleva 25 años al servicio de la educación básica regular.

Actualmente cuenta con 271 estudiantes para los niveles primaria y secundaria. La pensión establecida para ambos niveles es de S/ 280, monto que no ha tenido una variación significativa desde el 2014. La institución desarrolla sus actividades en un inmueble arrendado, cuya ubicación es en la plazoleta del distrito de Santiago N`517.

\subsection{Determinación del Problema}

Según ESCALE (2018) para el año 2018, están registradas 361 Instituciones Educativas Públicas y Privadas, de las cuales 208 son privadas. Sólo en el distrito de Santiago se registran 25 instituciones privadas que brindan servicios dirigidos a la educación básica regular nivel primario y secundario.

De acuerdo con la clasificación realizada por APEIM (2018), el Perú cuenta con los niveles socioeconómicos (NSE) A, B, C, D y E. La Tabla 6 muestra el promedio de ingreso en 
soles de cada nivel, y el promedio de gasto según las necesidades básicas. En el grupo 7, con respecto a los gastos para esparcimiento, diversión, servicios culturales y de enseñanza en los niveles socioeconómicos $\mathrm{C}$ y $\mathrm{D}$, se tiene un promedio de $\mathrm{S} / 317.50$ 
Tabla 6

Ingresos y Gastos según NSE 2018 - Perú (Urbano + Rural)

\begin{tabular}{|c|c|c|c|c|c|c|c|}
\hline Promedios & Total & $\mathrm{AB}$ & $\mathrm{C}$ & $\mathrm{C} 1$ & $\mathrm{C} 2$ & $\mathrm{D}$ & $E$ \\
\hline $\begin{array}{c}\text { Grupo } 1 \text { : Alimentos - gasto } \\
\text { promedio }\end{array}$ & S/. 922 & S/. 1,441 & S/. 1,193 & S/. 1,251 & S/. 1,102 & S/. 927 & S/. 551 \\
\hline $\begin{array}{c}\text { Grupo } 2: \text { Vestido y Calzado } \\
- \text { gasto promedio }\end{array}$ & S/. 154 & S/. 301 & S/. 188 & S/. 200 & S/. 169 & S/. 132 & S/. 97 \\
\hline $\begin{array}{c}\text { Grupo } 3 \text { : Alquiler de } \\
\text { vivienda, Combustible, } \\
\text { Electricidad y Conservación } \\
\text { de la Vivienda - gasto } \\
\text { promedio }\end{array}$ & S/. 266 & S/. 681 & S/. 356 & S/. 392 & S/. 301 & S/. 219 & S/. 97 \\
\hline $\begin{array}{l}\text { Grupo } 4 \text { : Muebles, Enseres } \\
\text { y Mantenimiento de la } \\
\text { vivienda - gasto promedio }\end{array}$ & S/. 148 & S/. 384 & S/. 158 & S/. 171 & S/. 137 & S/. 112 & S/. 88 \\
\hline $\begin{array}{c}\text { Grupo } 5 \text { : Cuidado, } \\
\text { Conservación de la Salud y } \\
\text { Servicios Médicos - gasto } \\
\text { promedio }\end{array}$ & S/. 168 & S/. 419 & S/. 227 & S/. 247 & S/. 197 & S/. 136 & S/. 65 \\
\hline $\begin{array}{c}\text { Grupo } 6 \text { : Transportes y } \\
\text { Comunicaciones - gasto } \\
\text { promedio }\end{array}$ & S/. 273 & S/. 818 & S/. 347 & S/. 401 & S/. 264 & S/. 182 & S/. 104 \\
\hline $\begin{array}{l}\text { Grupo } 7 \text { : Esparcimiento, } \\
\text { Diversión, Servicios } \\
\text { Culturales y de Enseñanza - } \\
\text { gasto promedio }\end{array}$ & S/. 276 & S/. 874 & S/. 376 & S/. 433 & S/. 285 & S/. 176 & S/. 77 \\
\hline $\begin{array}{l}\text { Grupo } 8: \text { Otros bienes y } \\
\text { servicios - gasto promedio }\end{array}$ & S/. 160 & S/. 337 & S/. 213 & S/. 230 & S/. 187 & S/. 141 & S/. 79 \\
\hline $\begin{array}{c}\text { PROMEDIO GENERAL DE } \\
\text { GASTO FAMILIAR } \\
\text { MENSUAL } \\
\end{array}$ & S/. 2,367 & S/. 5,255 & S/. 3,060 & S/. 3,325 & S/. 2,642 & S/. 2,025 & S/. 1,158 \\
\hline $\begin{array}{l}\text { Promedio general de ingreso } \\
\text { familiar mensual }\end{array}$ & S/. 3,125 & S/. 7,963 & S/. 4,051 & S/. 4,396 & S/. 3,509 & S/. 2,529 & S/. 1,286 \\
\hline
\end{tabular}

El distrito de Santiago es uno de los ocho distritos que forman parte de la provincia del

Cusco siendo uno de los más antiguos de la ciudad, forma parte del centro histórico y consta de 69.72 kilómetros cuadrados, tiene una población aproximada de 100,124 habitantes (INEI 2017). Dicho distrito está representado en su mayoría por los niveles socioeconómicos C y D con 15,062 habitantes en edad escolar, de este grupo 5,880 se encuentran matriculados en instituciones privadas cuyo porcentaje de la población estudiantil representan el $39.10 \%$ del total. (ESCALE, 2018) 
La IEP Santiago Apóstol no ha incrementado significativamente, el monto de las pensiones desde el año 2014 debido a las tarifas que maneja la competencia directa, como el colegio Didaskalio San José Obrero y el colegio Fleming (ver Tabla 7).

Tabla 7

Comparación de pensiones de la competencia directa según nivel escolar 2018

\begin{tabular}{cccc}
\hline Colegio & Nivel & Alumnos por aula & Importe de pensión \\
\hline Didaskalio San José Obrero & Primario & 41 & S/ 190.00 \\
Didaskalio San José Obrero & Secundario & 36 & S/ 185.00 \\
Fleming & Primario & 14 & S/ 250.00 \\
Fleming & Secundario & 29 & S/ 230.00 \\
Santiago Apóstol & Primario & 24 & S/ 280.00 \\
Santiago Apóstol & Secundario & 22 & S/ 280.00 \\
\hline
\end{tabular}

Nota. Elaboración propia adaptado de "http://Identicole.minedu.gob.pe/encuentracolegio/\#/

Por un lado, la Institución Educativa Privada Didaskalio San José Obrero lidera en el número de estudiantes con 1,013 alumnos para los niveles primario y secundario (17.2\% del total de estudiantes matriculados en el distrito). Cuenta con local propio ubicado en Av. Prolongación Grau, un inmueble con amplias instalaciones. La institución ofrece además al alumno la posibilidad de desarrollar carreras técnicas durante la secundaria. Por otro lado, la institución educativa Fleming cuenta 236 alumnos representando (4 \% del total de estudiantes matriculados en el distrito). Cuenta con local propio ubicado en Av. Mariscal Gamarra J.7. Ofrece adicionalmente el servicio de preparación preuniversitaria en el turno vespertino.

La institución educativa Santiago Apóstol cuenta con 271 alumnos (4.6\% del total de estudiantes matriculados en el distrito). No cuenta con local propio y paga mensualmente por el alquiler del inmueble. Debido a esta condición la institución no puede hacer modificaciones 
a la infraestructura como ampliaciones o adecuaciones de espacios, y en consecuencia no puede ofrecer más vacantes a nuevos postulantes.

Asimismo, se evidenció un crecimiento mínimo de la rentabilidad durante los 2 últimos años, como se aprecia en el indicador de rentabilidad sobre la inversión cuyos resultados fueron $14 \%$ y $16 \%$ para los años 2015 y 2016 respectivamente; y el indicador de rentabilidad sobre las ventas, cuyos resultados fueron para el año 2015 un total de $6 \%$ y para el año 2016 de 8\% (como se desarrolla en el Capítulo 8 - Selección de la Estrategia).

En resumen, la situación de la IEP Santiago Apóstol del Cusco es:

- El inmueble donde actualmente opera la IEP Santiago Apóstol es alquilado, ello ocasiona que la capacidad instalada no cubra la demanda de estudiantes.

- Las mensualidades no presentaron incremento significativo desde el año 2014, a pesar de estar en el nivel aceptable del gasto promedio en educación.

Ante ello cabe preguntarse ¿La falta de estrategias de negocios influye en la rentabilidad de la IEP Santiago Apóstol del Cusco? ¿La elaboración de un Plan Estratégico y la consecuente implementación de estrategias harán de la institución una empresa sostenible en el tiempo?

\subsection{Justificación del Proyecto}

La IEP Santiago Apóstol cuenta con un Plan de Trabajo vigente el cual es una guía que permite operativizar los objetivos propuestos en el Proyecto Educativo institucional; sin embargo, no tiene los beneficios que un Plan Estratégico le otorga a la dirección de la Institución. El Plan servirá como guía para la descripción de las estrategias de la institución y el análisis de las oportunidades de mejora que sean aplicables para hacer frente a su entorno. 
Debido al nivel socioeconómico del mercado objetivo y la competencia directa maneja precios más bajos, la IEP Santiago Apóstol no ha variado significativamente el monto de las pensiones durante los años 2014 - 2017. La propuesta servirá para elaborar estrategias con el fin de incrementar su rentabilidad en los próximos años y diferenciarse competitivamente en el mercado.

Los motivos por los cuales el presente proyecto merece su ejecución, son:

- En el aspecto institucional, con la implementación y aplicación del plan estratégico 2018 - 2023, permitirá optimizar los procesos administrativos y académicos de la IEP Santiago Apóstol.

- En el aspecto financiero, se busca incrementar la rentabilidad y mejorar los indicadores económicos para la administración de la institución en los próximos cinco años.

- En el aspecto operativo se pretende realizar una mejora en la cadena de valor para asegurar la calidad del servicio de educación.

- En el aspecto social buscará la formación de estudiantes con valores y brindar las condiciones adecuadas para su desempeño escolar y personal.

\subsection{Objetivos Generales y Específicos}

\subsubsection{Objetivo General.}

Diseñar un plan estratégico para la IEP Santiago Apóstol que logre incrementar la rentabilidad en el período 2018-2023.

\subsubsection{Objetivos Específicos.}


1) Analizar los factores externos en materia educativa, para determinar las oportunidades y amenazas clave que influyen la educación en la población del distrito de Santiago de Cusco.

2) Analizar los factores internos en materia educativa, para identificar sus fortalezas y debilidades de la IEP Santiago Apóstol.

3) Formular las estrategias necesarias que conducirán a la IEP Santiago Apóstol a la dirección futura deseada.

\subsection{Alcances y Limitaciones de la investigación}

\subsubsection{Alcances de la IEP Santiago Apóstol.}

- El plan estratégico busca determinar los objetivos y estrategias necesarias para la mejora de la rentabilidad de la IEP Santiago Apóstol del Cusco.

El presente plan estratégico se basa en el modelo integral de administración estratégica de David (2013) que comprende tres etapas importantes: formulación de estrategias, implementación de estrategias y evaluación de estrategias. De acuerdo al siguiente procedimiento:

- Desarrollar la declaración de la misión, visión y valores de la empresa.

- Ejecutar una auditoría externa e interna.

- Establecer los objetivos a largo plazo.

- Generar, evaluar y seleccionar las estrategias.

- Proponer y evaluar estrategias de administración.

- Proponer y evaluar: temas de marketing, finanzas y contabilidad.

- Medir y evaluar el desempeño. 
- Para el desarrollo del plan estratégico se considera un diseño de investigación mixto, debido a que el planteamiento del problema requiere enfoques cuantitativos y cualitativos, para ello se requiere fuentes primarias recabadas a través de focus group a clientes de la IEP Santiago Apóstol y aplicación de encuestas a clientes actuales y clientes potenciales. Asimismo, se considera analizar su posicionamiento en el distrito de Santiago y realizar una comparación frente a sus competidores de la industria educativa.

\subsubsection{Limitaciones.}

Limitación de la información financiera de otras instituciones educativas privadas debido a que estas no son de carácter público. 


\section{Capítulo I. La Empresa}

\subsection{Antecedentes de la Empresa}

La IEP Santiago Apóstol se encuentra ubicada en la provincia de Cusco, distrito de Santiago, en la Plaza de Santiago 517, tiene 25 años de creación. La visión y la misión de la institución se enmarcan en una educación productivo-ambientalista que fomenta la práctica de valores en sus estudiantes mediante el desarrollo de diversas actividades que pretenden sensibilizar a la comunidad en el cuidado y respeto del patrimonio natural y cultural.

La IEP Santiago Apóstol inició su funcionamiento en el año 1994. La inquietud de su promotora, la señora Leonor Villagarcía Aquize, fue invertir en un proyecto que contribuyera al desarrollo del distrito de Santiago, que por ese entonces carecía de colegios particulares orientados a la calidad educativa. El colegio abre sus puertas con el nivel primario con 107 alumnos en el turno diurno, con Autorización de Apertura y Funcionamiento R.D. N 0198 del 03 de marzo del año 1994.

La Administración de la IEP Santiago Apóstol decidió ampliar el nivel secundario y se inició con la apertura del $1^{\circ}$ Grado de Secundaria el 17 de Setiembre del 2001 con R.D. N ${ }^{\circ}$ 2888, para los alumnos que habían iniciado sus estudios en la institución desde el primer grado de primaria. La IEP para ese entonces, contaba con 126 alumnos entre el nivel primario y el primer año de secundaria.

Se tenía la idea de realizar la apertura de cada grado del nivel secundario, a medida que los alumnos desarrollaban su avance académico; sin embargo, los trámites en el Ministerio de Educación resultaron bastante complejos. Por este motivo se ampliaron todos los niveles de $2^{\circ}, 3^{\circ}, 4^{\circ}$ y $5^{\circ}$ de secundaria con la R.D. $N^{\circ} 249$ del 12 de junio del 2002. 
La institución fue constituida como Persona Natural con Negocio. Adicionalmente, la IEP Santiago Apóstol, ha considerado como un propósito complementario la formación moral de los alumnos.

\subsection{Descripción del negocio}

El negocio de la IEP Santiago Apóstol es la educación primaria y secundaria de menores. La institución ofrece sus servicios a niños y adolescentes de los NSE C y D, entre 6 y 17 años. Actualmente, la institución educativa cuenta con 271 alumnos. Se rige bajo La Ley 28044 - Ley General de Educación y la Ley 26549 - Ley de los Centros Educativos Privados y el Decreto Legislativo 882 - Ley de Promoción de la Inversión en Educación.

La Unidad de Gestión Educativa Local (UGEL), para regularizar el funcionamiento de las Instituciones Educativas establece rutas académicas que obligan a la entidad a cumplir un avance específico, además del desarrollo de algunas materias para los estudiantes. Aunque la institución ha optado por seguir parte de estos lineamientos sin perder el esquema de la educación tradicional y, de esta manera, fomentar un análisis de los alumnos respecto a sus logros académicos.

\subsection{Ciclo de vida de la Industria}

Los cambios de una industria en el tiempo son un importante determinante a considerar cuando se analizan sus fuerzas competitivas. , una herramienta útil para analizar los efectos que la evolución de la industria tiene en las fuerzas competitivas es el modelo del ciclo de vida de la industria, este modelo identifica cinco etapas secuenciales en su evolución: embrionario, crecimiento, reestructuración, madurez y declinación Hill, Jones \& Schilling (2014). 
En la figura 1 se observa el ciclo de vida de la Industria Educativa en la ciudad del Cusco, la que se encuentra en una Etapa de Crecimiento. Como señala (ESCALE, 2018), 10 instituciones educativas obtuvieron resolución durante el año 2017.

En el distrito de Santiago para años 2018; 2017; 2016; 2015 y 2014 se demuestra el crecimiento de la industria educativa en promedio de $1 \%$ para los tres niveles educativos: inicial, primaria y secundaria. (Anexo 9)

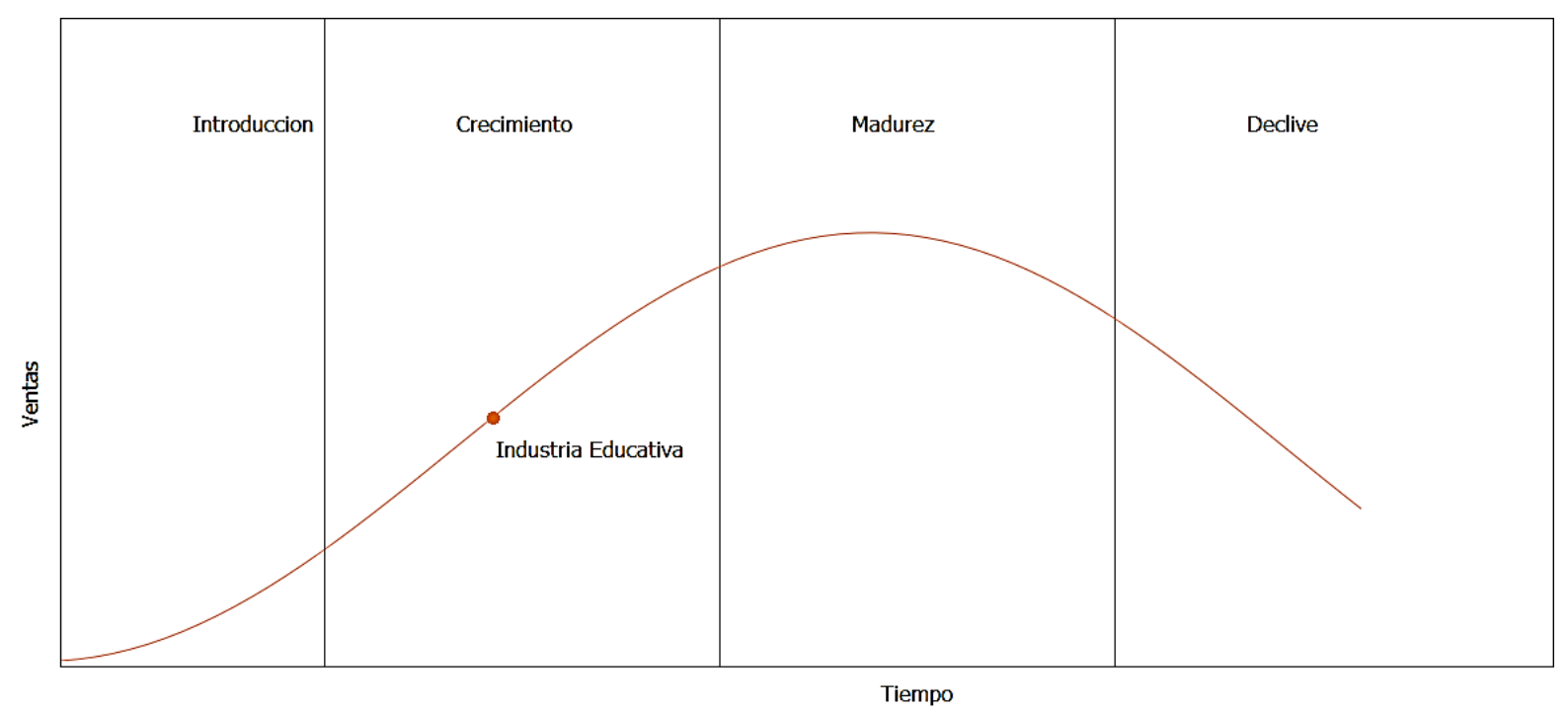

Figura 1. Ciclo de Vida de la Industria Educativa. Elaboración propia.

Se espera un incremento de 164 alumnos durante el período 2017-2023, como se puede observar en el pronóstico de la figura 2, que grafica la matrícula en colegios privados en el distrito de Santiago para los niveles Primaria y Secundaria 


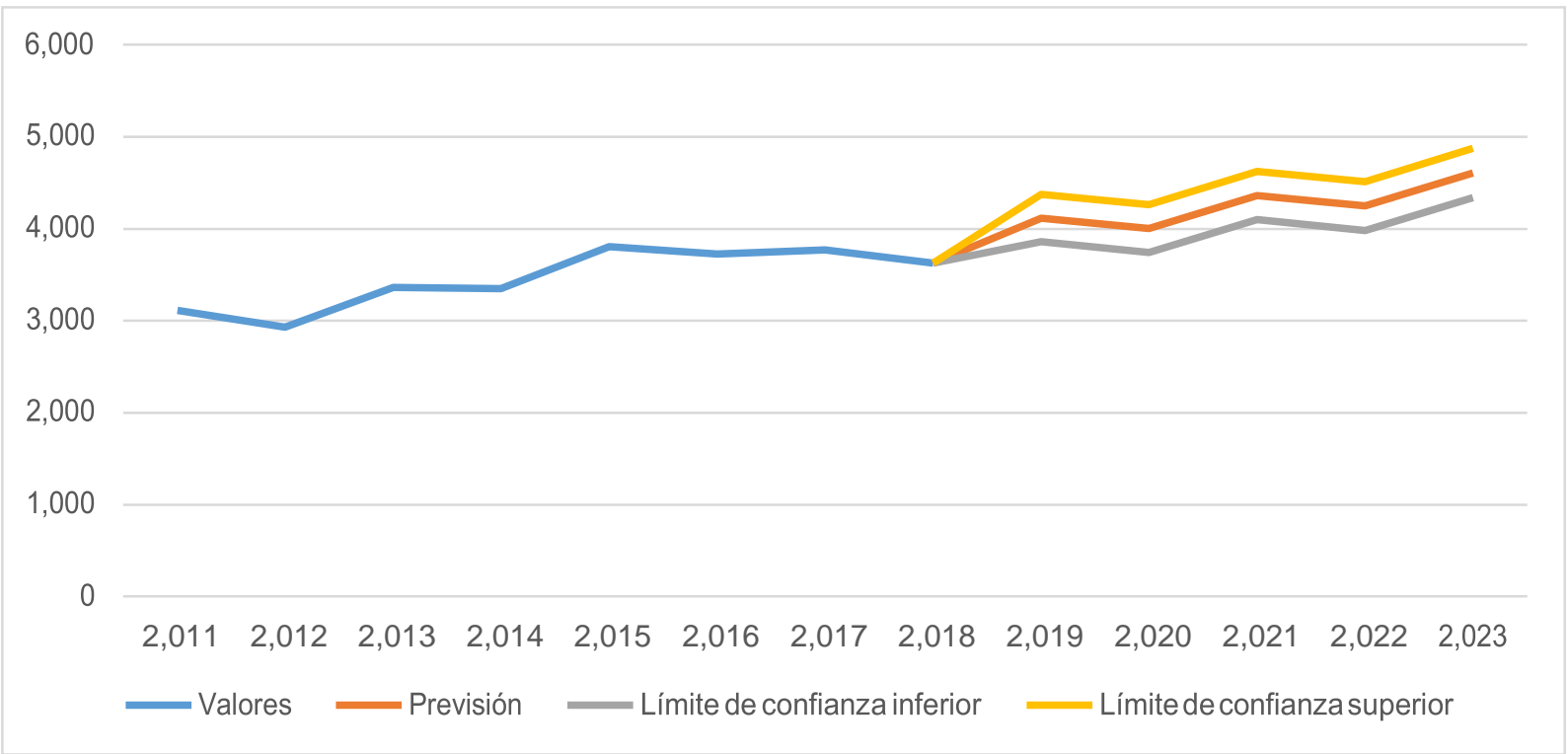

Figura 2. Pronóstico de matriculados en el distrito de Santiago. Elaboración propia.

En la figura 3, se observa el ciclo de vida de la empresa, la IEP Santiago Apóstol se encuentra en una Etapa de Evolución o Madurez ya que la demanda del alumnado se ha mantenido estable durante tres años consecutivos, para el 2015 contó con 268 alumnos, el 2016 con 278 alumnos, el 2017 con 274 alumnos y el 2018 con 271 alumnos. Por otro lado, las mensualidades no mostraron un incremento significativo, la Institución tiene una participación estable en el mercado. De acuerdo con el pronóstico al año 2023 utilizando los datos de la tabla 8 , se prevé un incremento de $18.95 \%$ en las matrículas de la IEP Santiago Apóstol (ver figura 4). 


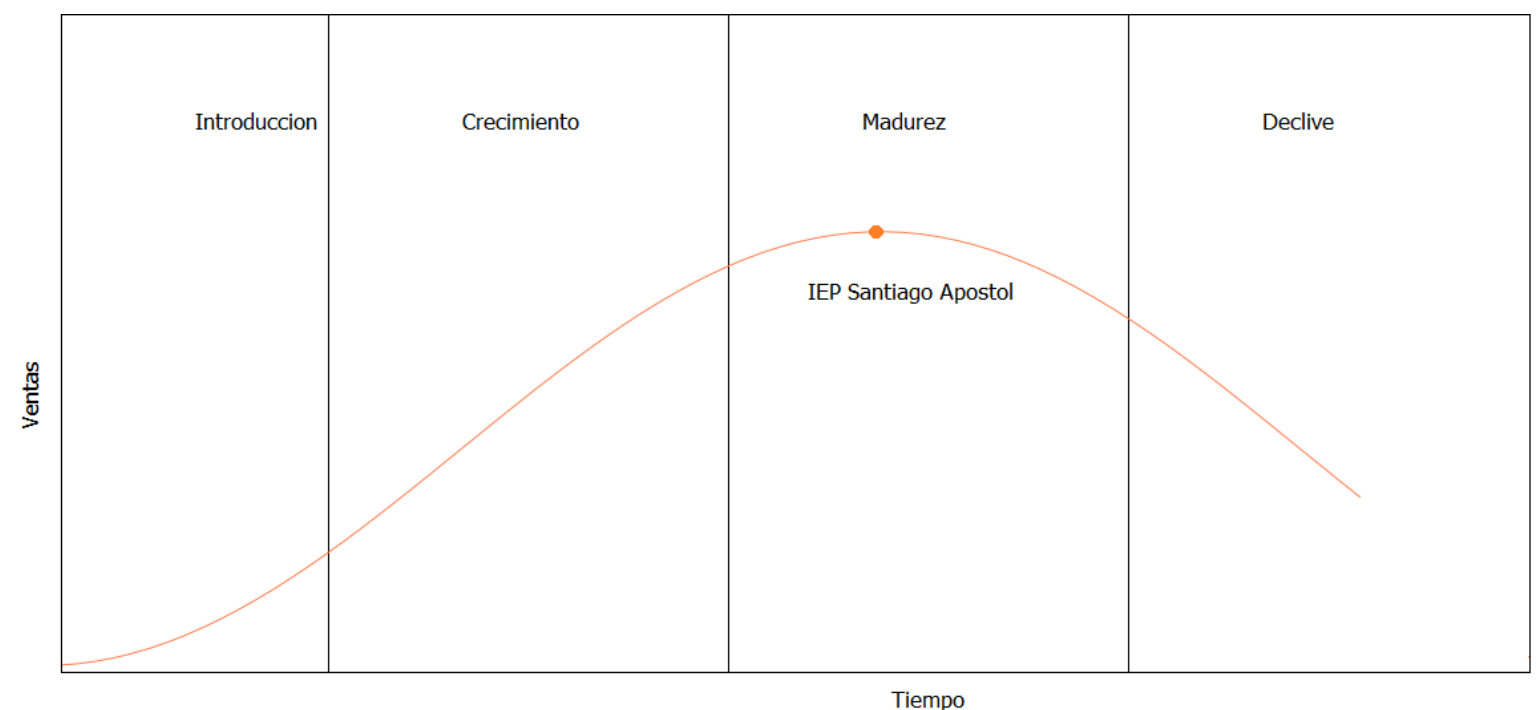

Figura 3. Ciclo de Vida de la IEP Santiago Apóstol. Elaboración propia.

La figura 4 muestra el pronóstico del número de matriculados en la IEP Santiago Apóstol para el período 2018-2023, se espera un incremento promedio de 13 matriculados por año, tomando como referencia al límite de confianza superior del pronóstico

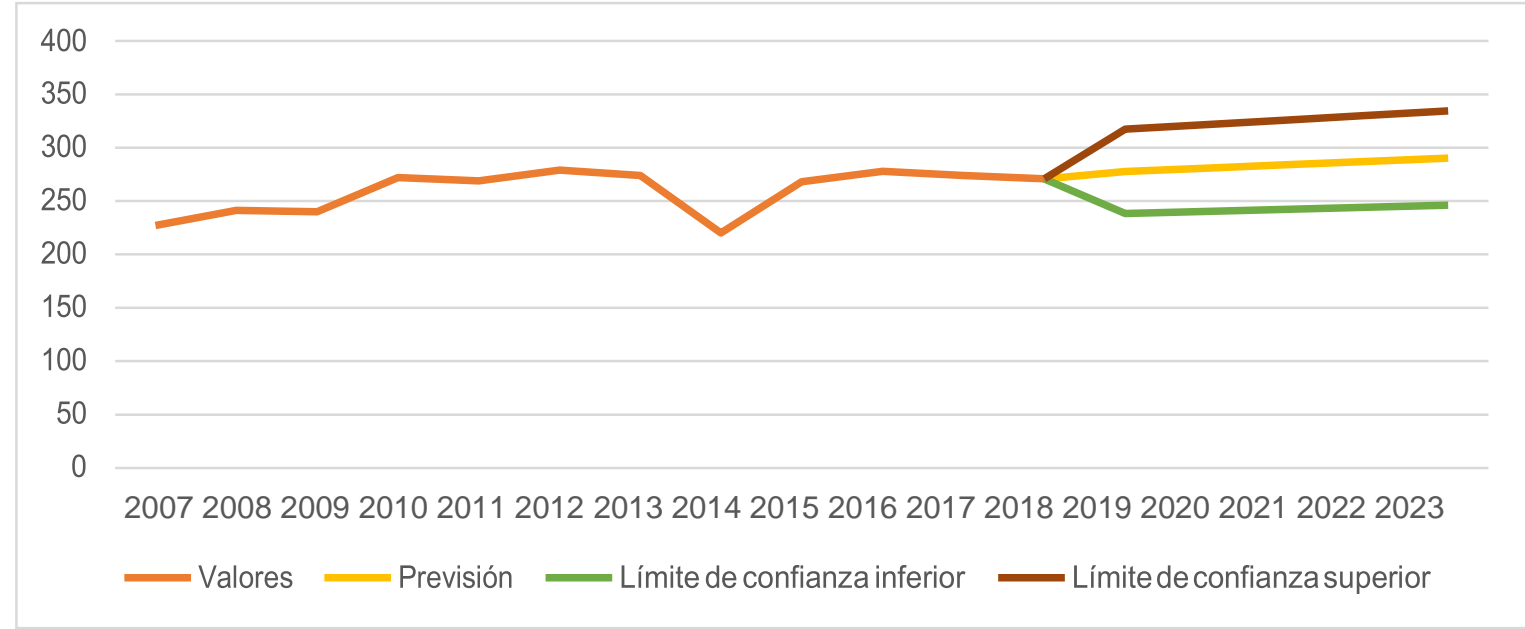

Figura 4. Pronóstico del número de matriculados al 2023 en la IEP Santiago Apóstol. Elaboración propia. 
El ciclo de vida del servicio educativo que ofrece la IEP Santiago Apóstol se encuentra en una Etapa de Crecimiento, como se aprecia en la figura 5, porque tiene aceptación en el mercado y responde a las necesidades de sus consumidores dando a conocer las bondades del servicio que ofrece.

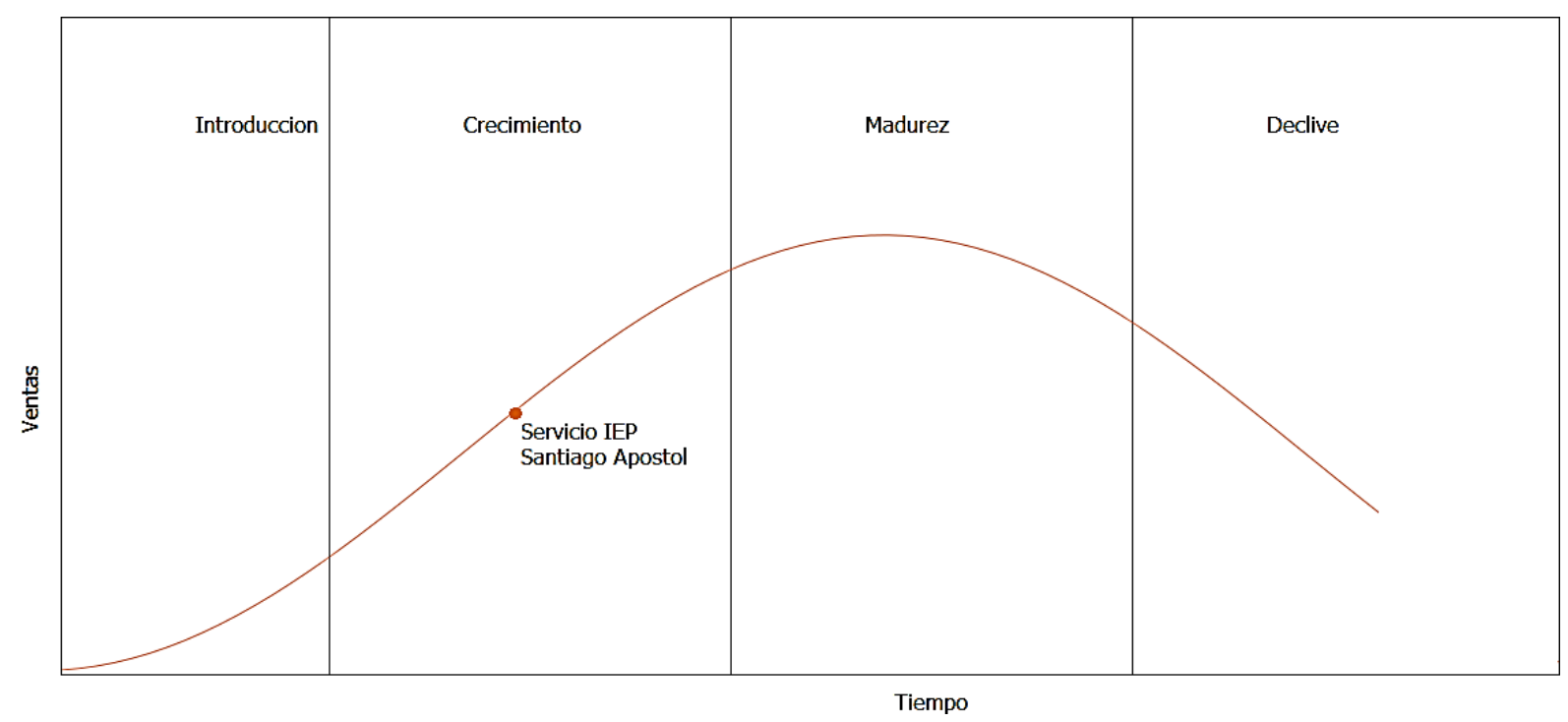

Figura 5. Ciclo de Vida del Servicio. Elaboración propia.

En la Tabla 8 se observa el comportamiento de matrículas en los últimos diez años para los diferentes grados que la IEP Santiago Apóstol ofrece al mercado, cuyo crecimiento estable se mantiene para los niveles primarios y secundarios, ello demuestra la aceptación del servicio de la IEP en el mercado. 
Tabla 8

Período por matricula según grado 2007-2018

\begin{tabular}{|c|c|c|c|c|c|c|c|c|c|c|c|c|}
\hline Año & 2007 & 2008 & 2009 & 2010 & 2011 & 2012 & 2013 & 2014 & 2015 & 2016 & 2017 & 2018 \\
\hline $1^{\circ}$ Grado & 30 & 31 & 20 & 30 & 28 & 27 & 23 & 12 & 49 & 30 & 26 & 26 \\
\hline $2^{\circ}$ Grado & 30 & 31 & 29 & 32 & 28 & 30 & 23 & 22 & 16 & 53 & 30 & 24 \\
\hline $3^{\circ}$ Grado & 24 & 29 & 31 & 31 & 29 & 30 & 32 & 19 & 25 & 20 & 56 & 30 \\
\hline $4^{\circ}$ Grado & 36 & 23 & 29 & 33 & 27 & 29 & 28 & 23 & 24 & 23 & 19 & 48 \\
\hline $5^{\circ}$ Grado & 26 & 36 & 19 & 30 & 33 & 27 & 31 & 23 & 22 & 19 & 24 & 18 \\
\hline $6^{\circ}$ Grado & 20 & 21 & 34 & 23 & 27 & 33 & 26 & 25 & 26 & 19 & 15 & 21 \\
\hline Total Primaria & 166 & 171 & 162 & 179 & 172 & 176 & 163 & 124 & 162 & 164 & 170 & 167 \\
\hline $1^{\circ}$ Grado & 14 & 13 & 18 & 26 & 20 & 25 & 25 & 25 & 24 & 28 & 21 & 21 \\
\hline $2^{\circ}$ Grado & 15 & 17 & 15 & 18 & 27 & 19 & 23 & 17 & 26 & 24 & 26 & 26 \\
\hline $3^{\circ}$ Grado & 12 & 13 & 19 & 17 & 20 & 27 & 18 & 18 & 16 & 24 & 21 & 21 \\
\hline $4^{\circ}$ Grado & 12 & 16 & 14 & 19 & 15 & 18 & 28 & 13 & 24 & 18 & 19 & 19 \\
\hline $5^{\circ}$ Grado & 8 & 11 & 12 & 13 & 15 & 14 & 17 & 23 & 16 & 20 & 17 & 17 \\
\hline Total Secundaria & 61 & 70 & 78 & 93 & 97 & 103 & 111 & 96 & 106 & 114 & 104 & 104 \\
\hline Total & 227 & 241 & 240 & 272 & 269 & 279 & 274 & 220 & 268 & 278 & 274 & 271 \\
\hline
\end{tabular}

Nota. Elaboración propia según datos ESCALE 2018

\subsection{Estructura organizacional actual de la empresa}

Según el Manual de Organización y Funciones de la IEP Santiago Apóstol se presenta el organigrama (figura 6), cuyo diseño estructural es funcional., según Daft (2011) "En una estructura funcional se consolidan los conocimientos y habilidades humanas con respecto a las actividades específicas, ofreciendo conocimientos profundos de valor para la organización"; asimismo menciona que "según el tamaño y metas de una organización se considera un tipo denominado burocracia profesional, cuya característica principal al interior de la organización es la conformación de profesionales capacitados y especializados y su personal de apoyo técnico es reducido; por otro lado tienen como principal función la oferta de servicios”.

La estructura organizacional de la IEP Santiago Apóstol ha permitido el desarrollo de habilidades y conocimientos por cada departamento, sin embargo, se tiene limitaciones relacionadas a la capacidad de respuesta frente a cambios del entorno, principalmente por la falta de un departamento que se encargue de realizar una adecuada investigación y desarrollo de mercado y posteriormente diseñar un plan estratégico. 
Tomando en cuenta las Dimensiones estructurales de Daft (2011), la IEP Santiago Apóstol tiene un bajo nivel de formalización por no contar con manuales que definan con claridad las actividades que se desempeñan, toda la plana docente posee un nivel académico profesional, la supervisión se centraliza en la Entidad Promotora así como la toma de decisiones importantes y cada departamento realiza tareas específicas.

Tomando en cuenta las Dimensiones contextuales, la IEP Santiago Apóstol cuenta con un total de 27 trabajadores al 2018. Gestiona el sistema de información denominado SIAGIE (Sistema de Información de Apoyo a la Gestión); dicho sistema es utilizado por todas las instituciones educativas a nivel nacional. Adicionalmente cuenta con un laboratorio de cómputo para sus estudiantes. No cuenta con planes de acción claros para enfrentar su entorno y distribución de recursos., Se practican valores transversales e identidad institucional entre los trabajadores. 


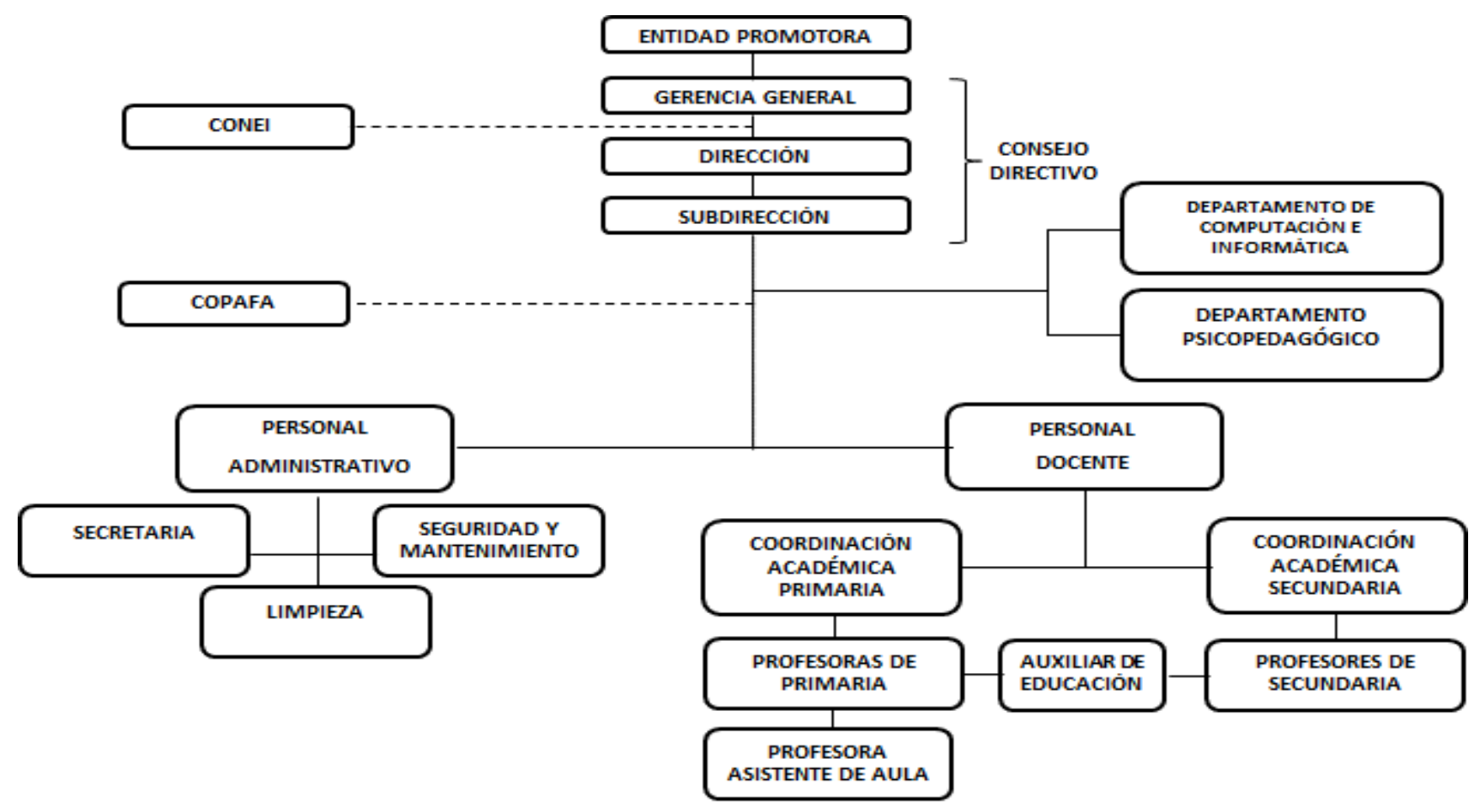

E S T U D I A N T E S D E P R I M A R I A $Y$ S E C U N D A R I A

Figura 6. Organigrama de la IEP Santiago Apóstol 
La organización estructural de la institución tiene los órganos siguientes:

\subsubsection{Entidad promotora.}

Es la autoridad máxima de la institución y órgano de decisión y ejecución cuyo objetivo central es conducir la buena marcha y desarrollo de la institución educativa de acuerdo con la línea axiológica determinada por ésta.

\subsection{2 Órganos de dirección.}

- Consejo Directivo: es designado por la entidad promotora, tiene la responsabilidad de planificar y coordinar las actividades administrativas con el Consejo Directivo.

- Dirección: Es la autoridad académica, designada por la gerencia general y reconocida por Resolución Directoral de la Dirección Regional de Educación con informe elevado por la UGEL Cusco, tiene la responsabilidad de planificar, formular, coordinar, ejecutar, dirigir, supervisar y evaluar el proyecto educativo, el plan anual de trabajo y todas las actividades educativas de la institución.

- Subdirección: Es designado por la gerencia general y la dirección. Se encarga de planificar, organizar, programar, coordinar, ejecutar, dirigir, supervisar y evaluar todas las actividades técnico pedagógicas de la Institución así como de velar por el cumplimiento de los objetivos educacionales e institucionales a fin de brindar un servicio educativo eficiente y de calidad así como apoyar y asesorar a la dirección y a los demás organismos de la Institución en los aspectos ontológicos, axiológicos, normativos, pedagógicos y conductuales, ejecutando para tales fines actividades y proyectos.

\subsection{3 Órganos de asesoramiento.}

- CONEI: Órgano de participación, concertación y vigilancia ciudadana de la institución educativa que colabora con la promoción y ejercicio de una gestión eficaz, 
transparente, ética y democrática que promueve el respeto a los principios de equidad, inclusión e interculturalidad en las Instituciones. Formado por la dirección sub dirección, representantes del personal docente, del personal administrativo, de los estudiantes, de los ex alumnos y los padres de familia.

- COPAFA: Comité de padres de familia.

\subsection{4 Órganos de línea.}

- Coordinación Académica: responsable de debe velar por el desarrollo eficaz, eficiente y de calidad en el proceso de enseñanza aprendizaje del nivel que le corresponde, ofreciendo a los docentes a su cargo, el apoyo, orientación, asesoramiento técnico pedagógico y consejo, actuando en coordinación con el subdirector.

- Coordinación de tutoría y OBE: Orienta el servicio de Tutoría de la institución actuando en estrecha coordinación con la Administración, la Dirección, la Subdirección, la Coordinación Académica y el personal docente.

\subsection{5 Órganos de apoyo.}

- Departamento Psicopedagógico: planifica, organiza, capacita, supervisa y evalúa las actividades relacionadas a los servicios de atención psicológica y de orientación a alumnos, padres de familia y comunidad educativa en general.

- Departamento de Psicología: coordina las actividades que le son propias y delimita funciones con los otros miembros del departamento.

- Departamento de Computación e Informática: prepara, planifica, coordina, apoya y ejecuta la parte teórico - práctica de la asignatura de Computación e Informática con los demás docentes del área, así como administra el Sistema de Información de Apoyo a la Gestión de la Institución educativa (SIAGIE). 


\subsection{6 Órganos de ejecución.}

- Profesores: son los educadores de la institución que, por su especialización en un determinado nivel educativo y materia, se encargan de la conducción y dirección del aprendizaje y del fomento y práctica de las virtudes cívicas y humanas. Deben estar plenamente identificados e integrados a los principios y axiología de la institución para transmitir los valores que la identifican.

- Tutores: son las personas que comparten la tarea común de formar personas de calidad, sensibles ante los cambios que nos plantea la sociedad actual.

- Auxiliar de Educación: es la persona con estudios pedagógicos que colabora con el personal docente en el desarrollo de las acciones educativas, tanto dentro o fuera de la institución y en el mantenimiento del orden y cumplimiento del Reglamento Interno por parte de los estudiantes.

- Profesores Asistentas de Aula: son los docentes que acompañan en todas las actividades técnico pedagógico a los estudiantes de una determinada sección, principalmente de los primeros grados y están a disposición de la profesora de aula y de los profesores de talleres para colaborar en el desarrollo de las actividades propias del acto educacional. Dicho profesor debe estar plenamente identificado e integrado a los principios y axiología de la institución para transmitir los valores que la identifican.

\subsection{7 Órganos de apoyo administrativo.}

- Secretaría: bajo la coordinación y supervisión del director, es responsable inmediato de la gestión documentaria, archivos de estudios y de los libros oficiales de los mismos. Se encarga de recibir y contestar toda la correspondencia de la Institución. 
- Personal de Seguridad y Mantenimiento: es el personal que cuida, controla y brinda seguridad a las personas que laboran en la Institución, así como a los bienes y edificio escolar, vigilando la parte interior y exterior impidiendo que se realicen u ocurran actos irregulares. Atiende a los padres de familia, visitantes y público en general informándoles y orientándoles sobre el asunto de su trámite.

- Personal Limpieza: se responsabilizará de organizar, preparar, desarrollar y controlar todas las acciones de limpieza, mantenimiento y conservación de la infraestructura, mobiliario de la institución, a fin de garantizar un servicio educativo con higiene y orden, creando un ambiente de estudio agradable y de buena salud.

\subsection{Situación de Mercado y Financiera actual de la Industria}

Según el Ministerio de Educacion (2018) la provincia de Cusco cuenta con 361 instituciones educativas públicas de gestión directa, públicas de gestión privada y privadas dedicadas a la enseñanza de primaria y secundaria de menores. De los cuales solo 137 son instituciones educativas públicas de gestión directa, 16 son instituciones públicas de gestión privada y las restantes 208 son instituciones educativas privadas de las cuales 25 se encuentran ubicadas en el distrito de Santiago en el año 2017.

La IEP Santiago Apóstol cuenta en la actualidad con 271 alumnos que pagan una pensión de 280 soles. 
Tabla 9

Matrícula en colegios privados en el distrito de Santiago, según Nivel Educativo, 2011-2018

\begin{tabular}{ccccccccc}
\hline Año & 2011 & 2012 & 2013 & 2014 & 2015 & 2016 & 2017 & 2018 \\
\hline Primaria & 1,827 & 1,903 & 1,906 & 1,903 & 2,163 & 2,152 & 2251 & 2292 \\
Secundaria & 1,288 & 1,027 & 1,459 & 1,447 & 1,645 & 1,573 & 1519 & 1336 \\
\hline Total & 3,115 & 2,930 & 3,365 & 3,350 & 3,808 & 3,725 & 3,770 & 3628 \\
\hline
\end{tabular}

Nota. MINISTERIO DE EDUCACIÓN - Censo Escolar

En la Tabla 9 se observa la cantidad de alumnado matriculado en las instituciones

educativas en el distrito de Santiago. Para el año 2018, el universo total de alumnos en

educación básica regular de instituciones privadas para los niveles primaria y secundaria fue de 3,628 . 


\section{Capítulo II. Formulación de Visión, Misión y Valores de la empresa}

\subsection{Visión}

\subsubsection{Visión actual de la institución.}

Según el Plan de Monitoreo y supervisión de la IEP Santiago Apóstol la visión con la que actualmente trabajan es:

“La Institución Educativa Santiago Apóstol es líder en la región por su trayectoria y posicionamiento en el campo educativo, utiliza tecnología moderna en el proceso educativo, forma personas de calidad con ética, valores cristianos y tolerancia, capaces de generar proyectos innovadores para el desarrollo sostenible y sustentable de la Región y el País."

\subsubsection{Análisis de la visión actual.}

La visión, a pesar de ser simple, clara y comprensible no se perfila convincentemente hacia el futuro, es decir, no define un horizonte de tiempo y su espacio geográfico al que se proyecta no tiene límite; además no es de dominio de todo el personal que labora en la institución. Así se observa en la tabla 10

Tabla 10

Análisis de la visión actual de la institución educativa Santiago Apóstol

\begin{tabular}{|c|c|c|c|}
\hline Elementos & $\mathrm{Si}$ & No & ¿Por qué? \\
\hline Simple, claro y compresible & $\mathrm{X}$ & & Utiliza términos sencillos y comprensibles. \\
\hline Ambiciosa, convincente y realista & & $\mathrm{X}$ & No hace referencia al futuro. \\
\hline Definida con un horizonte de tiempo & & $\mathrm{X}$ & No especifica un rango de tiempo. \\
\hline Proyectada a un alcance geográfico & & $\mathrm{X}$ & No especifica su ámbito de desarrollo. \\
\hline Conocida por todos & & $\mathrm{X}$ & No todo el personal la conoce. \\
\hline Expresada con sentido de urgencia & & $\mathrm{X}$ & No \\
\hline $\begin{array}{c}\text { Idea clara de adónde desea ir la } \\
\text { institución }\end{array}$ & & $\mathrm{X}$ & $\begin{array}{c}\text { Detalla su interés de generar proyectos } \\
\text { innovadores para el desarrollo sostenible y } \\
\text { sustentable sin especificar un alcance } \\
\text { específico. }\end{array}$ \\
\hline
\end{tabular}

Nota. Adaptado de El Proceso Estratégico. Un enfoque de gerencia, F. D’Alessio 2008 pag.61

De acuerdo a D'Alessio (2006), la visión de una organización es la definición deseada de su futuro, responde a la pregunta ¿Qué queremos llegar a ser? Para ello es necesario realizar un diagnóstico actual de la empresa, para luego realizar la proyección a futuro en su industria. La 
formulación de la visión debe ser un proceso desarrollado al interior de la organización y su elaboración debe ser integradora y motivadora con todos los integrantes de la organización.

La IEP Santiago Apóstol tiene como principal actividad la educación básica regular (nivel primario y secundario); por ello, el giro principal del negocio, es formar a personas de calidad con ética mediante los valores cristianos.

Respecto a sus clientes, no hace referencia a cuáles son sus principales necesidades o conductas actuales, tampoco se describe sobre sus futuras expectativas.

En lo concerniente a sus grupos de interés, no se menciona acerca de cómo la institución educativa se relaciona con los mismos. Sobre la aplicación de las tecnologías de información., únicamente refiere la importancia de aplicar herramientas, sin describir su impacto, ni alcance.

\subsubsection{Matriz de la visión propuesta para la institución.}

\section{Tabla 11}

Matriz de la Visión propuesta para la institución educativa Santiago Apóstol

\begin{tabular}{cc}
\hline Elementos & \\
\hline Ambiciosa, convincente y realista & $\begin{array}{c}\text { Ser la institución educativa escolar reconocida } \\
\text { Distrito de Santiago, en la provincia y departamento de } \\
\text { Cusco. }\end{array}$ \\
Expresada con sentido de urgencia & $\begin{array}{c}\text { aplicando una propuesta de educación personalizada } \\
\text { con calidad }\end{array}$ \\
Idea clara de adónde desea ir la institución & $\begin{array}{c}\text { Contribuir al desarrollo personal y realización } \\
\text { profesional futura de nuestros alumnos }\end{array}$ \\
\hline
\end{tabular}

Nota. Adaptada de El Proceso Estratégico Un enfoque de gerencia, F.D’Alessio

\subsubsection{Visión propuesta.}

"Ser una institución educativa escolar reconocida en la ciudad del Cusco, aplicando una propuesta de educación personalizada con calidad, para contribuir al desarrollo personal y social de nuestros alumnos". 


\subsection{Misión}

\subsubsection{Misión actual de la institución.}

Según el Plan de Monitoreo y supervisión de la IEP Santiago Apóstol la misión con la que actualmente trabajan es:

"Somos una Institución Educativa Privada que educa con el ejemplo, en libertad, respeto y disciplina, para ello contamos con una selecta Plana Docente dedicada a formar personas de calidad, dotándoles de herramientas académicas y tecnológicas para que sean capaces de enfrentar los nuevos retos de un mundo en permanente cambio y generando así conciencia ambiental."

\subsubsection{Análisis de la misión actual.}

Según Thompson, Gamble, Peteraf, \& Strickland III (2012), una declaración de misión comunica el propósito de una compañía con un lenguaje lo bastante específico, de este modo dar a la compañía su propia identidad.

Según Pearce (1982), la misión debe incluir nueve componentes:

- Clientes - Consumidores.

- Productos: bienes o servicios.

- Mercados.

- Tecnologías.

- Objetivos de la organización: supervivencia, crecimiento, y rentabilidad.

- Filosofía de la organización.

- Auto concepto de la organización.

- Preocupación por la imagen pública.

- Preocupación por los empleados. 
La Misión actual define qué tipo de organización es, a quienes está orientada y cuáles son sus aspiraciones, además es amplia, clara y especifica porque promueve el crecimiento

institucional, y aunque brinda credibilidad en sus servicios, no identifica claramente el público al cual orienta su labor. Así se observa en la tabla 12.

\section{Tabla 12}

\section{Análisis de la Misión actual de la institución educativa Santiago Apóstol}

\begin{tabular}{|c|c|c|c|}
\hline Elementos para declarar la misión & Sí & No & ¿Por qué? \\
\hline $\begin{array}{l}\text { Define qué es la organización y qué } \\
\text { aspira. }\end{array}$ & $\mathrm{X}$ & & $\begin{array}{c}\text { Describe cuáles son los recursos y capital humano que } \\
\text { utiliza para formar a sus estudiantes. }\end{array}$ \\
\hline Es amplia y promueve el crecimiento & $\mathrm{X}$ & & $\begin{array}{l}\text { Indica cómo enfrentará los nuevos cambios y su conciencia } \\
\qquad \text { ambiental }\end{array}$ \\
\hline Es clara y específica para todos. & $\mathrm{X}$ & & $\begin{array}{c}\text { Los miembros de la institución educativa sí reconocen la } \\
\text { misión actual. }\end{array}$ \\
\hline Brinda credibilidad. & $\mathrm{X}$ & & $\begin{array}{c}\text { Considera a los valores como la libertad, respeto y } \\
\text { disciplina. }\end{array}$ \\
\hline $\begin{array}{l}\text { ¿Quiénes son los clientes y/o } \\
\text { consumidores de la organización? }\end{array}$ & & $\mathrm{X}$ & $\begin{array}{c}\text { Falta mayor precisión en describir el perfil de sus } \\
\text { consumidores. }\end{array}$ \\
\hline $\begin{array}{l}\text { ¿Cuáles son los principales } \\
\text { productos: bienes o servicios que la } \\
\text { organización produce? }\end{array}$ & & $\mathrm{X}$ & $\begin{array}{c}\text { Describe sobre la formación de personas con herramientas } \\
\text { académicas y tecnológicas, pero no detalla el servicio } \\
\text { principal que ofrece. }\end{array}$ \\
\hline
\end{tabular}

Nota. Adaptada de “El Proceso Estratégico. Un enfoque de gerencia, "por F.D’Alessio

\subsubsection{Elementos de la misión propuesta para la institución.}

\section{Tabla 13}

Elementos de la Misión propuesta

Elementos para declarar la misión

Define qué es la organización y qué aspira.

Es amplia y promueve el crecimiento

Es clara y específica para todos.

Brinda credibilidad.

¿Quiénes son los clientes y/o consumidores de la organización?

¿Cuáles son los principales productos: bienes o servicios que la organización produce?
Educar a niños y jóvenes escolares

Promueve la integración y adaptación de sus estudiantes a la sociedad.

Sí.

Imparte formación académica y moral

Niños y jóvenes escolares

Coadyuva al desarrollo de capacidades, conocimientos y habilidades de sus estudiantes.

Nota. Adaptada de “El Proceso Estratégico. Un enfoque de gerencia, "por F.D’Alessio 


\subsubsection{Misión propuesta.}

“Contribuimos con la formación académica y moral de niños y jóvenes escolares potenciando sus capacidades conocimientos y habilidades con el fin de que se puedan integrar y adaptar a nuestra sociedad con valores."

\subsection{Valores}

\subsubsection{Valores de la institución.}

Los docentes y estudiantes de la institución educativa Santiago Apóstol, se conducen de acuerdo a los siguientes valores:

- Laboriosidad.

- Responsabilidad.

- Respeto

- Solidaridad.

- Identidad.

\subsubsection{Análisis de los valores actuales.}

Los valores de la IEP Santiago Apóstol, se caracterizan por ser las directrices que encausan el desempeño de todo su personal para lograr los objetivos y alinear las principales estrategias de negocio de una empresa.

\subsubsection{Elementos de los valores propuestos para la institución.}

Según Serna (2008) los valores corporativos serán definidos considerando a los grupos de interés con los que la IEP Santiago Apóstol interactúa, por ello los comportamientos y calidad de esta interacción deben estar regidos por principios corporativos.

Dentro de la gama de valores que existen y que son imprescindibles para la marcha organizada de una institución educativa, la IEP Santiago Apóstol ha priorizado los valores de: 
laboriosidad, responsabilidad, respeto, solidaridad e identidad como parte de su propuesta axiológica centrando su trabajo en la práctica de estos valores tanto los trabajadores como los estudiantes y padres de familia (clientes) de la Institución. Así se observa en la tabla 14.

Tabla 14

Matriz axiológica de Valores

\begin{tabular}{cccccc}
\hline Valores & Accionistas & Proveedor & Cliente & Colaborador & Sociedad \\
\hline Laboriosidad. & & & $\mathrm{X}$ & $\mathrm{X}$ & $\mathrm{X}$ \\
Responsabilidad. & & $\mathrm{X}$ & $\mathrm{X}$ & $\mathrm{X}$ & $\mathrm{X}$ \\
Respeto & $\mathrm{X}$ & $\mathrm{X}$ & $\mathrm{X}$ & $\mathrm{X}$ & $\mathrm{X}$ \\
Solidaridad. & & $\mathrm{X}$ & $\mathrm{X}$ & $\mathrm{X}$ & $\mathrm{X}$ \\
Identidad. & $\mathrm{X}$ & $\mathrm{X}$ & $\mathrm{X}$ & $\mathrm{X}$ & $\mathrm{X}$ \\
\hline
\end{tabular}

Nota. Adaptada de "Gerencia estratégica" H. Serna

\subsubsection{Valores propuestos.}

Los valores actuales de la IEP Santiago Apóstol, tienen un enfoque hacia la responsabilidad social, sin embargo, es posible añadir un enfoque orientado a los resultados. Para ello se unen los valores laboriosidad y responsabilidad y declarar el valor: Vocación de servicio.

La solidaridad, será un valor que mantendremos, el cual se reformulará como integridad, ya que esta nueva directriz inferirá a los integrantes de la institución educativa para que actúen con mayor probidad, según el diccionario de la Real Academia Española (RAE), la integridad se define como una cualidad de íntegro, dicho de una personar recta, proba, intachable.

El respeto y la identidad tienen un alcance a todos los grupos de interés del colegio, por esta razón seguirán manteniéndose.

\subsection{Alineamiento estratégico de la visión, misión y valores de la institución}

Para determinar la alineación de propósitos entre la visión, misión y valores de la organización se describen los enunciados propuestos en la tabla 15. 
Tabla 15

Matriz de la visión, misión y valores de la IEP Santiago Apóstol

\begin{tabular}{ccc}
\hline Visión & Valores & Misión \\
\hline Ser la institución educativa escolar & Vocación de & servicio. \\
reconocida en el distrito de Santiago, & Contribuir con la formación académica y moral \\
aplicando una propuesta de educación & Integridad. & Respeto. \\
personalizada con calidad, para contribuir & capacidades conocimientos y habilidades con el \\
al desarrollo personal y realización & Identidad. & fin de que se puedan integrar y adaptar a nuestra \\
profesional futura de nuestros alumnos & & sociedad con valores
\end{tabular}

Nota. Elaboración Propia

En las tablas 16 y 17, se observa la correlación entre la visión, misión y los valores.

Tabla 16

Matriz de relación entre la Visión y Valores de la IEP Santiago Apóstol

\begin{tabular}{cc}
\hline Visión & Valor Requerido \\
\hline Institución educativa escolar reconocida & Identidad \\
Propuesta de educación personalizada con calidad & Vocación de servicio e \\
integridad & Respeto e identidad \\
\hline
\end{tabular}

Nota. Elaboración Propia

Tabla 17

Matriz de relación entre la Misión y Valores de la IEP Santiago Apóstol

\begin{tabular}{cc}
\hline Misión & Valor Requerido \\
\hline Formación académica y moral & Vocación de servicio \\
Contribuir a la Sociedad mediante la educación & Integridad y vocación de servicio \\
Impulsar valores en niños y jóvenes & Respeto e identidad \\
\hline
\end{tabular}

Nota. Elaboración Propia 


\section{Capítulo III. Análisis Externo}

El análisis externo es de suma importancia para evaluar aquellas oportunidades y amenazas que afectan la industria educativa escolar, en el presente capitulo se analizarán los factores más importantes.

\subsection{Tendencias de las variables del entorno}

\subsubsection{Análisis político-gubernamental y legal.}

En el Perú la educación se rige bajo la Ley General de Educación que según el Artículo $1^{\circ}$ Objeto y Ámbito de Aplicación, que tiene:

Por objeto establecer los lineamientos generales del sistema educativo peruano, las atribuciones y obligaciones del Estado y los derechos responsabilidades de las personas y la sociedad en su función educadora. Rige todas las actividades educativas realizadas dentro del territorio nacional, desarrolladas por personas naturales o jurídicas, públicas o privadas, nacionales o extranjeras (2003, p. 1)

Los fines de la educación peruana según el artículo 9 de la Ley General de Educación son:

Formar personas capaces de lograr su realización ética, intelectual, artística, cultural afectiva, física espiritual y religiosa, promoviendo la formación y consolidación de su identidad y autoestima y su integración adecuada y critica a la sociedad para el ejercicio de su ciudadanía en armonía con su entorno, así como el desarrollo de sus capacidades y habilidades para vincular su vida con el mundo del trabajo y para afrontar los incesantes cambios en la sociedad y el conocimiento. (2003, p. 3) 
Contribuir a formar una sociedad democrática, solidaria, justa, inclusiva, prospera, tolerante y forjadora de una cultura de paz que afirme la identidad nacional sustentada en la diversidad cultural, étnica y lingüística, supere la pobreza e impulse el desarrollo sostenible del país y fomente la integración latinoamericana teniendo en cuenta los retos del mundo globalizado. (2003, p. 3)

Según esta ley, las instituciones educativas privadas son personas jurídicas de derecho privado, creadas por iniciativa de personas naturales o jurídicas, autorizadas por las instancias descentralizadas del sector educación. El Estado, en concordancia con la libertad de enseñanza y la promoción de la pluralidad de la oferta educativa, reconoce, valora y supervisa la educación privada.

En lo que les corresponda, son funciones de la institución educativa las establecidas en el artículo $68^{\circ}$. Sin perjuicio de ello se constituyen y definen su régimen legal de acuerdo a las normas vigentes. Se organizan y conducen su gestión administrativa y económico-financiera, estableciendo sus regímenes: económico, de pensiones y de personal docente y administrativo. Participan en la medición de la calidad de la educación de acuerdo a los criterios establecidos por el Instituto de Evaluación, Acreditación y Certificación de la calidad educativa. Garantizan la participación de los padres de los alumnos a través de la Asociación de Padres de Familia, e individualmente, en el proceso educativo de sus hijos.

Adicionalmente se analizan otras normas:

- La Aprobación del Currículo Nacional de la Educación Básica: que rige desde el año 2017 hasta el 2021 ha generado en la industria de la educación uniformizar el avance académico y adaptarlo de acuerdo a la realidad de cada región en las instituciones de educación básica regular tanto públicas como privadas. Permitiendo de esta manera la 
formación integral de los alumnos enfatizando el desarrollo de sus propias competencias.

Para verificar el funcionamiento de esta el gobierno efectúa una Medición de la calidad de la educación en la región del Cusco mediante una Evaluación censal donde se indica que los alumnos del cuarto grado del nivel primario en la Evaluación Censal de Estudiantes ECE (2018) obtuvieron un resultado satisfactorio de $35.3 \%$ y $37.3 \%$ en matemática y lectura respectivamente y para los alumnos del segundo grado de secundaria se obtuvo un resultado satisfactorio de $12.4 \%$ en lectura, $11.3 \%$ en matemática y $10.2 \%$ en ciencias sociales. (ESCALE, 2018).

Actualmente en las universidades del Cusco tanto la Universidad Nacional San Antonio Abad del Cusco, como la Universidad Particular Andina del Cusco tienen autonomía para determinar las materias de los exámenes de admisión, pero estos difieren de los aplicados en el Currículo Nacional de la Educación Básica Regular.

- El procedimiento para autorización de apertura y funcionamiento de Instituciones Educativas Privadas: Se requiere de trámites diversos en muchas entidades Públicas como son SUNAT, SUNARP, colegios de Ingenieros o Arquitectos, Ministerio de Trabajo y Municipios, representando en la industria educativa un obstáculo para apertura de nuevas instituciones educativas básicas regulares (Anexo 1).

- La Ley de Promoción de la Inversión en Educación: aprobada por Decreto Legislativo N882, establece las condiciones y garantías destinadas a promover la inversión de servicios educativos con la finalidad de modernizar el sistema educativo y ampliar la oferta y cobertura de la educación del país. Sus normas son aplicables a todas las instituciones educativas particulares en el territorio nacional, tales como centros y programas educativos particulares, cualquiera que sea su nivel o modalidad. Mediante 
esta norma se regularon una serie de beneficios, que se traducen en una serie de exoneraciones y créditos contra el impuesto a la renta, para aquellas personas naturales o jurídicas que en forma particular se dediquen a promover, conducir y constituir entidades educativas con o sin finalidad lucrativa, y que se encuentren debidamente reconocidas por el ministerio de educación.

- Asociación con el estado para Obras por Impuesto: Según MINEDU es un mecanismo adicional de participación privada que contribuye a cerrar la brecha de infraestructura educativa del sector público en beneficio de los estudiantes, teniendo obras en un corto plazo, y generando una mejor gestión de gasto para las instituciones públicas. Permite a una empresa privada o a un conjunto de ellas, celebrar un convenio con gobiernos regionales, gobiernos locales y universidades públicas para financiar y ejecutar proyectos de inversión pública considerando hasta el 50\% de su impuesto a la renta. A su vez, permite a los gobiernos regionales y locales pagar dichas obras, sin intereses, a cuenta de sus recursos de canon, sobre canon, regalías mineras, rentas de aduana y participaciones, hasta en diez años.

- La Ley de Reforma Magisterial: da una nueva revaloración al trabajo docente considerando aspectos como el incremento remunerativo, beneficios sociales, plazas docentes para la Carrera Pública Magisterial y las evaluaciones de desempeño aplicada a los docentes, todo ello genera una expectativa importante para los docentes que buscan una oportunidad dentro de la industria educativa.

\subsubsection{Análisis Económico.}


De acuerdo con la UNESCO (2017, pág. 12) “el Perú pertenece a una región que refleja altos niveles de desigualdad y esta característica se traduce en el sistema educativo a través de brechas en la población representadas en el aprendizaje, matrícula, finalización de los estudios"

En la tabla 18 se puede verificar que los niveles Socioeconómicos C y D representan el 43.6 \% de hogares de la Región Cusco según datos de APEIM (2018). El gasto promedio para esparcimiento, diversión, servicios culturales y de enseñanza en los NSE C y D, es de S/ 317.50 (capitulo 1,Tabla 6) ello representa una oportunidad para que la IEP Santiago Apóstol siga orientado a este mercado meta.

Tabla 18 Distribución de hogares según NSE 2018(urbano)

\begin{tabular}{cc}
\hline Nivel Socioeconómico & Cusco (en porcentaje) \\
\hline $\mathrm{AB}$ & $7.5 \%$ \\
$\mathrm{C}$ & $18.2 \%$ \\
$\mathrm{D}$ & $25.4 \%$ \\
$\mathrm{E}$ & $48.9 \%$ \\
\hline Total & $100 \%$ \\
\hline
\end{tabular}

Nota. Elaboración propia con Datos de la Asociación Peruana de Empresas de Investigación de mercado

En la Tabla 19 se puede evidenciar que el gasto público en educación como porcentaje del Producto Bruto Interno (PBI) tiene un ligero incremento para el año 2013, porcentaje que al año 2018 se mantiene invariable. Tendencia que se mantiene también en la región Cusco.

Tabla 19

Gasto público en educación como porcentaje del PBI

\begin{tabular}{ccccccccccccc}
\hline Año & 2007 & 2008 & 2009 & 2010 & 2011 & 2012 & 2013 & 2014 & 2015 & 2016 & 2017 & 2018 \\
\hline $\begin{array}{c}\text { Perú } \\
\text { Región }\end{array}$ & 2.5 & 2.7 & 2.9 & 2.9 & 3 & 2.9 & 3.3 & 3.3 & 3.6 & 3.5 & 3.5 & 3.5 \\
Cusco & 3.7 & 4.8 & 4.7 & 4.8 & 4.9 & 4.6 & 5.2 & 5.0 & 4.2 & 3.9 & 3.9 & 4.4 \\
\hline
\end{tabular}

Nota. Adaptado con datos de "Indicadores 2018 y tendencias: Gasto público en educación como porcentaje del PBI," por Estadística de la Calidad Educativa (ESCALE 2018). Recuperado de http://escale.minedu.gob.pe/tendencias

El gasto privado en educación corresponde al Valor bruto de la producción de la actividad de la Educación Privada (ver tabla 20), en el que se observa que la inversión en educación en el sector público el año 2000 fue de S/ 4,663,781 y para el año 2018 se incrementó 
en S/ 19,701,000 .En el sector privado en el año 2000 se tuvo una inversión de S/ 9,191,971y para el año 2018 S/ 29,221,000 mostrándose un incremento de hasta 3 veces más que en la inversión del año 2000.

Tabla 20

Gasto en educación (2000-2018)

\begin{tabular}{cccc}
\hline Año & Total & Sector Publico & Sector Privado \\
\hline 2000 & 13855752 & 4663781 & 9191971 \\
2001 & 14487828 & 4667018 & 9820810 \\
2002 & 15447737 & 5174792 & 10272945 \\
2003 & 16554304 & 5566921 & 10987383 \\
2004 & 18016748 & 6212893 & 11803855 \\
2005 & 19148605 & 6671259 & 12477346 \\
2006 & 20594313 & 7155354 & 13438959 \\
2007 & 18908000 & 7446000 & 11462000 \\
2008 & 20493000 & 8042000 & 12451000 \\
2009 & 21585000 & 8191000 & 13394000 \\
2010 & 22700000 & 8182000 & 14518000 \\
2011 & 24829000 & 9199000 & 15630000 \\
2012 & 27169000 & 10021000 & 17148000 \\
2013 & 30179000 & 11124000 & 19055000 \\
2014 & 33637000 & 12674000 & 20963000 \\
2015 & 37777000 & 14665000 & 23112000 \\
2016 & 41788000 & 16333000 & 25455000 \\
2017 & 46107000 & 18530000 & 27577000 \\
2018 & 48922000 & 19701000 & 29221000 \\
\hline
\end{tabular}

Nota. Adaptado con datos de "Gasto destinado al Sector Educación 1994-2018," por INEI 2018 . Recuperado de http: www.inei.gob.pe/estadisticas/indice-tematico/sociales/

Debido a esta razón, grandes corporaciones educativas están incursionando en educación, así como ampliando sus mercados objetivos.

\subsubsection{Análisis Demográfico.}

La tabla 21 muestra proyecciones de la población en edad escolar a nivel nacional, esta información evidencia que la cantidad de estudiantes en edad escolar se mantuvo relativamente estable en su nivel de crecimiento. 
Tabla 21

Población en edad escolar estimada y proyectada, según edad y sexo 2005-2017

\begin{tabular}{ccccccc}
\hline Sexo y Edad & \multicolumn{7}{c}{ Población en edad escolar } \\
\cline { 2 - 7 } simple & 2005 & 2010 & 2012 & 2013 & 2015 & 2017 \\
\hline $6-11$ & $3,553,824$ & $3,521,603$ & $3,518,093$ & $3,517,481$ & $3,508,432$ & $3,362,253$ \\
$12-16$ & $2,920,065$ & $2,922,537$ & $2,916,065$ & $2,911,633$ & $2,905,049$ & $2,674,987$ \\
Hombres & $6,352,682$ & $6,438,011$ & $6,454,561$ & $6,458,963$ & $6,458,694$ & $5,904,569$ \\
Mujeres & $6,169,195$ & $6,241,136$ & $6,251,673$ & $6,252,971$ & $6,246,932$ & $6,101,469$ \\
\hline Total & $12,521,877$ & $12,679,147$ & $12,706,234$ & $12,711,934$ & $12,705,626$ & $12,006,038$ \\
\hline
\end{tabular}

Nota. Instituto Nacional de Estadística e Informática - Perú: Estimaciones y Proyecciones de Población, 1950 - 2050

- Boletín de Análisis Demográfico Nº 36

Respecto al distrito Santiago de la provincia de Cusco según INEI (2018), el crecimiento de la población de 5 a 19 años de edad para los años 2015- 2017 incremento en promedio de 8\%, según la tabla $\mathrm{N}^{\circ} 22$

Tabla 22

Población en edad escolar, del distrito de Santiago 2015- 2017

\begin{tabular}{|c|c|c|}
\hline Rango de edades & \multicolumn{2}{|c|}{2015 Población de 5 a 19 años 2017} \\
\hline $5-9$ & 7712 & 8609 \\
\hline $10-14$ & 7432 & 8212 \\
\hline $15-19$ & 8762 & 9198 \\
\hline Total & 23906 & 26019 \\
\hline
\end{tabular}

Nota. Instituto Nacional de Estadística e Informática - http://censos2017.inei.gob.pe/redatam/

\subsubsection{Análisis Tecnológico.}

En el censo efectuado por ESCALE (2018) como parte de los resultados del censo escolar se observó un aspecto relacionado al acceso de equipos de cómputo de alumnos en el departamento de Cusco, tanto de entidades públicas como privadas. En la figura 7 se muestra la cantidad de alumnos por computadora: en el nivel primario por 6 alumnos se dispone de una computadora y en el nivel secundario por 5 alumnos, una computadora. Asimismo, informa la 
disponibilidad que tienen las instituciones educativas a internet, el porcentaje en las escuelas del nivel primario es de $34.4 \%$; y en el nivel secundario es de $73.4 \%$.

En el año 2008 existió un proyecto mediante el cual se hizo entrega de laptop a los estudiantes de diversos centros educativos del sector público uno por cada uno con la finalidad de facilitar el aprendizaje, pero se verificó que no hubo mayor mejora y por la falta de capacitación de los docentes en el uso de estos equipos quedaron rápidamente en desuso, así como deterioro de los equipos por falta de mantenimiento constante.

\section{Ratio de alumnos por computadora 2017}

\begin{tabular}{l|l|}
\hline UUSCO \\
\hline UGEL \\
\hline UGEL CUSCO \\
UGEL ACOMAYO \\
\hline UGEL ANTA \\
\hline UGEL CALCA \\
\hline UGEL CANAS \\
\hline UGEL CANCHIS \\
\hline UGEL CHUMBIVILCAS \\
UGEL ESPINAR \\
\hline UGEL LA CONVENCION \\
\hline UGEL PARURO \\
\hline UGEL PAUCARTAMBO \\
\hline UGEL QUISPICANCHI \\
UGEL URUBAMBA \\
\hline UGEL PIChari-Kimbiri
\end{tabular}

\section{PRIMARIA}

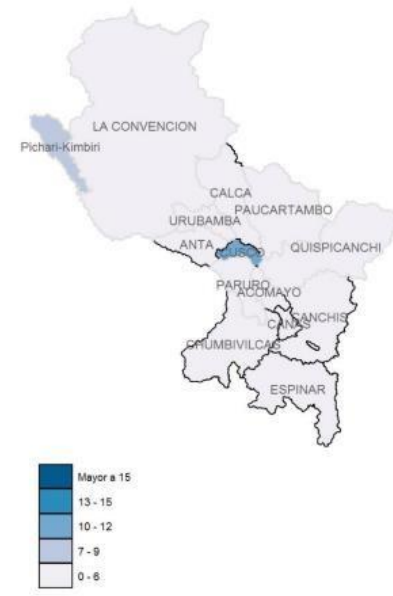

\section{SECUNDARIA}

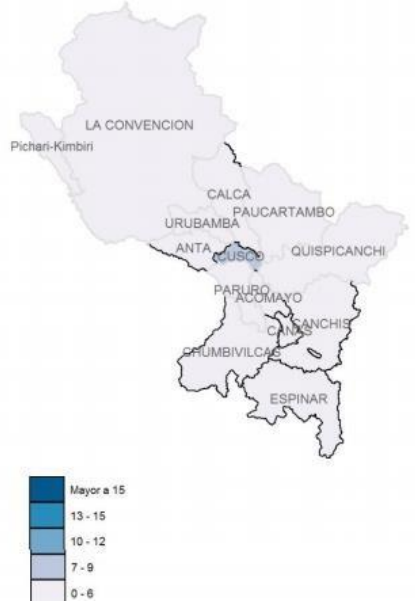

\begin{tabular}{|l|l|}
\hline CUSCO & $\mathbf{5}$ \\
\hline UGEL & $\mathbf{8}$ \\
\hline UGEL CUSCO & 4 \\
\hline UGEL ACOMAYO & 3 \\
\hline UGEL ANTA & 4 \\
UGEL CALCA & $\mathbf{3}$ \\
\hline UGEL CANAS & 5 \\
\hline UGEL CANCHIS & 4 \\
\hline UGEL CHUMBIVILCAS & 4 \\
\hline UGEL ESPINAR & \\
\hline UGEL LA CONVENCION & 4 \\
\hline UGEL PARURO & $\mathbf{2}$ \\
\hline UGEL PAUCARTAMBO & $\mathbf{5}$ \\
\hline UGEL QUISPICANCHI & 4 \\
\hline UGEL URUBAMBA & 4 \\
\hline UGEL PiChari-Kimbiri & 5 \\
\hline
\end{tabular}

Figura 7. Alumnos por computadoras Cusco 2017. ESCALE, MINEDU 2017

\subsubsection{Análisis Ecológico.}

El Ministerio de Educación (2016) propone ejecutar el Plan Nacional de Ecología (2017- 2022), para fortalecer la cultura en educación ambiental con desarrollo sostenible mediante la implementación de acciones específicas. Plan que a la fecha se encuentra vigente.

De esta manera, la industria educativa formará instituciones educativas ecoeficientes porque utilizarán de manera racional los recursos existentes, reducirán el impacto ambiental de 
sus actividades y agregarán un nuevo valor al servicio educativo: sostenibilidad, innovación y emprendimiento socio-ambiental.

\subsection{Impacto en clientes / proveedores de cada una de las variables del entorno}

A continuación, en la tabla 20 se exponen las variables del entorno y el análisis del

impacto sobre los clientes y los proveedores. Asimismo, se identifica si el impacto es positivo o negativo. 
Tabla 23

Impacto en clientes y proveedores (Análisis del Macroambiente)

\begin{tabular}{|c|c|c|c|c|}
\hline $\mathrm{N}^{\circ}$ & & Variables & Impacto en clientes & Impacto en proveedores \\
\hline \multirow[t]{6}{*}{1} & \multicolumn{4}{|c|}{ Político - Gubernamental y Legal } \\
\hline & 1.1. & $\begin{array}{c}\text { Aprobación del } \\
\text { Currículo Nacional de } \\
\text { la Educación Básica } \\
\text { que rige desde el } 2017 \\
\text { al } 2021 . \\
\end{array}$ & $\begin{array}{l}\text { Avance curricular programado } \\
\text { ejecutado en el período } \\
\text { establecido generando } \\
\text { conformidad en los padres de } \\
\text { familia. (POSITIVO) } \\
\end{array}$ & $\begin{array}{l}\text { Docentes más capacitados para que } \\
\text { puedan cumplir con los objetivos } \\
\text { propuestos en la programación } \\
\text { curricular. (POSITIVO) }\end{array}$ \\
\hline & 1.2 & $\begin{array}{l}\text { Procedimiento para } \\
\text { autorización de } \\
\text { apertura y } \\
\text { funcionamiento de } \\
\text { instituciones } \\
\text { Educativas Privadas } \\
\end{array}$ & SIN EFECTO E IMPACTO & $\begin{array}{c}\text { Disminución de la demanda de } \\
\text { profesionales especializados en } \\
\text { asesorías para constitución de } \\
\text { empresas del sector educativo. } \\
\text { (NEGATIVO) }\end{array}$ \\
\hline & 1.3 & $\begin{array}{l}\text { Ley de Promoción de } \\
\text { la Inversión Educativa }\end{array}$ & SIN EFECTO E IMPACTO & $\begin{array}{c}\text { Demanda de proveedores (contadores). } \\
\text { (POSITIVO) }\end{array}$ \\
\hline & 1.4 & $\begin{array}{l}\text { Asociación con el } \\
\text { estado para obras por } \\
\text { Impuesto }\end{array}$ & $\begin{array}{l}\text { Los padres de familia podrían } \\
\text { acceder a ofertas académicas del } \\
\text { sector público. (POSITIVO) }\end{array}$ & SIN EFECTO E IMPACTO \\
\hline & 1.5 & $\begin{array}{l}\text { Reforma Magisterial } \\
\text { Peruana }\end{array}$ & $\begin{array}{c}\text { Baja disponibilidad de docentes } \\
\text { especializados por la oferta } \\
\text { laboral con la reforma magisterial } \\
\text { (NEGATIVO) }\end{array}$ & $\begin{array}{l}\text { Mayor competencia de docentes } \\
\text { altamente especializados. (POSITIVO) }\end{array}$ \\
\hline 2 & \multicolumn{4}{|c|}{ Económico } \\
\hline & 2.1 & $\begin{array}{c}\text { Niveles } \\
\text { Socioeconómicos C y } \\
\text { D representan el } 43 \% \\
\text { de la población en } \\
\text { Cusco } \\
\end{array}$ & SIN EFECTO E IMPACTO & SIN EFECTO E IMPACTO \\
\hline & 2.2 & $\begin{array}{c}\text { El gasto promedio } \\
\text { para esparcimiento, } \\
\text { diversión, servicios } \\
\text { culturales y de } \\
\text { enseñanza en los NSE } \\
\text { C y D, es de S/ 317.50. }\end{array}$ & $\begin{array}{l}\text { Acceso favorable al servicio de } \\
\text { educación básica regular } \\
\text { disponible en el Mercado. }\end{array}$ & $\begin{array}{c}\text { El gasto promedio para esparcimiento, } \\
\text { diversión, servicios culturales y de } \\
\text { enseñanza en los NSE C y D, es de S/ } \\
317.50\end{array}$ \\
\hline & 2.3 & $\begin{array}{l}\text { Incremento del Gasto } \\
\text { en educación del } \\
\text { Sector Privado }\end{array}$ & $\begin{array}{c}\text { Los padres de familia tienen más } \\
\text { opciones en el sector Privado } \\
\text { educativo para } \\
\text { decidir.(POSITIVO) } \\
\end{array}$ & $\begin{array}{c}\text { Más opciones laborales para docentes y } \\
\text { más proveedores con la aparición de } \\
\text { nuevos centros } \\
\text { educativos.(POSITIVO) }\end{array}$ \\
\hline 3 & \multicolumn{4}{|c|}{ Demográfico } \\
\hline & 3.1. & $\begin{array}{c}\text { Proyecciones de } \\
\text { crecimiento de la } \\
\text { población en edad se } \\
\text { mantienen en el } \\
\text { mismo rango desde el } \\
2012 \text { a nivel Nacional } \\
\text {,pero existe un } \\
\text { incremento de } \\
\text { población estudiantil }\end{array}$ & SIN EFECTO E IMPACTO & SIN EFECTO E IMPACTO \\
\hline
\end{tabular}




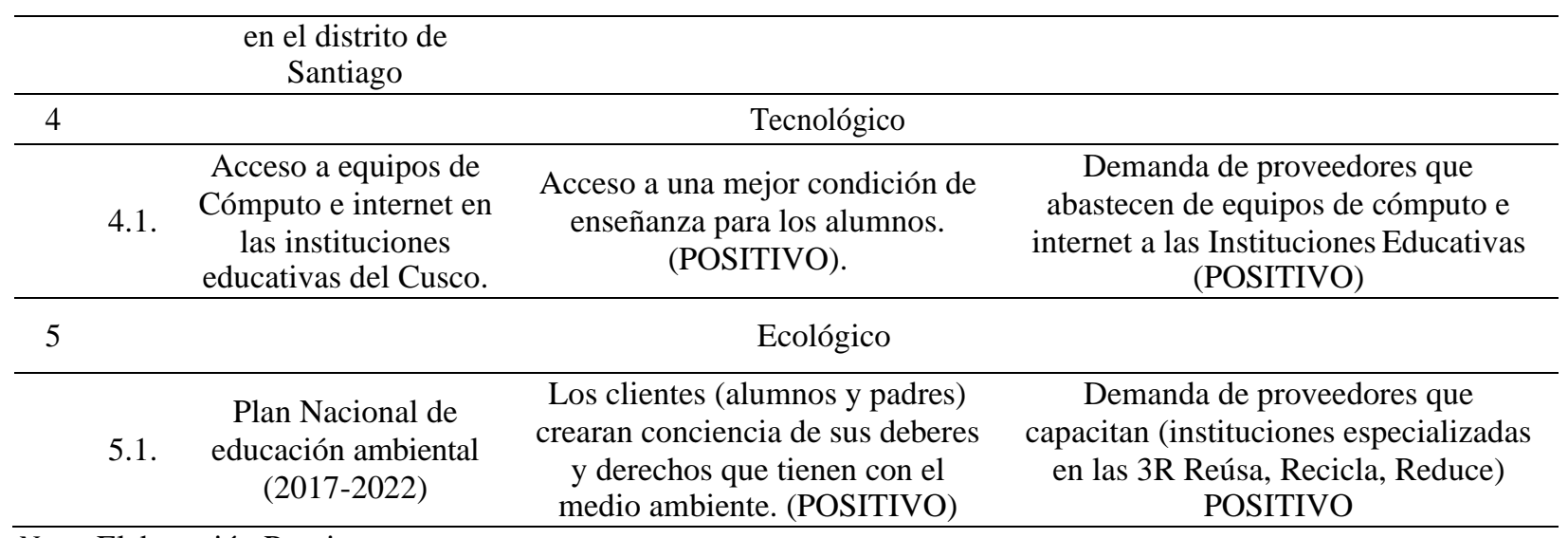

Nota. Elaboración Propia

\subsection{Efecto en la IEP de cada una de las variables del entorno}

La tabla 24 explica variables del entorno y el análisis del efecto sobre la IEP, en términos de oportunidades o amenazas.

Tabla 24

Efecto en la IEP de cada una de las variables del entorno (Análisis del Macroambiente)

\begin{tabular}{ccc}
\hline $\mathrm{N}^{\circ}$ & Variables & Efecto en la IEP Santiago Apóstol \\
\hline 1 & \multicolumn{2}{c}{ Político - Gubernamental-Legal } \\
\hline & Aprobación del Currículo & La plana docente de la IEP cuenta con la formación \\
& Nacional de la Educación & profional adecuada para gestionar los objetivos \\
& Básica que rige desde el & propuestos en relación a las capacidades, conocimientos \\
& 2017 al 2021. & y competencias que el alumnado debe desarrollar.
\end{tabular}

\begin{tabular}{|c|c|c|c|}
\hline & 1.2 . & $\begin{array}{l}\text { Procedimiento para } \\
\text { autorización de apertura y } \\
\text { funcionamiento de } \\
\text { instituciones educativas } \\
\text { privadas }\end{array}$ & $\begin{array}{l}\text { Las facilidades de este procedimiento permiten la } \\
\text { aparición de corporaciones educativas con experiencia } \\
\text { en el rubro. (AMENAZA). }\end{array}$ \\
\hline & 1.3 & $\begin{array}{l}\text { Ley de Promoción de la } \\
\text { Inversión Educativa }\end{array}$ & $\begin{array}{l}\text { La IEP accede a beneficios tributarios y exoneraciones } \\
\text { de obligaciones cumpliendo ciertos requisitos de la } \\
\text { normatividad vigente (anexo 7) (OPORTUNIDAD) }\end{array}$ \\
\hline & 1.4. & $\begin{array}{l}\text { Asociación con el Estado } \\
\text { para obras por impuesto }\end{array}$ & $\begin{array}{l}\text { Tiene un efecto positivo para las instituciones } \\
\text { educativas Privadas puesto que el } 50 \% \text { de su impuesto a } \\
\text { la renta podrá ser usado en proyectos de construcción } \\
\text { inmobiliaria de instituciones educativas públicas } \\
\text { haciéndolos parte de una asociación Pública Privada } \\
\text { mediante convenios con los gobiernos regionales } \\
\text { obteniendo diversos beneficios. (OPORTUNIDAD) }\end{array}$ \\
\hline & 1.5 . & $\begin{array}{l}\text { Reforma Magisterial } \\
\text { Peruana }\end{array}$ & $\begin{array}{l}\text { Es un efecto negativo porque hace que los principales } \\
\text { proveedores de la IEP (docentes) postulen a las plazas } \\
\text { con mejor propuesta económica ofrecidas por el estado. } \\
\text { (AMENAZA) }\end{array}$ \\
\hline 2 & \multicolumn{3}{|c|}{ Económico } \\
\hline & 2.1 . & $\begin{array}{l}\text { Niveles Socioeconómicos } \\
\text { C y D representan el }\end{array}$ & $\begin{array}{c}\text { Siendo el mercado objetivo de la IEP los sectores } \\
\text { socioeconómicos C y D al representar casi la mitad de la }\end{array}$ \\
\hline
\end{tabular}




\begin{tabular}{|c|c|c|c|}
\hline & & $\begin{array}{l}\text { 43.6\% de la población en } \\
\text { Cusco }\end{array}$ & $\begin{array}{l}\text { población de la ciudad, permite ofrecer sus servicios. } \\
\text { (OPORTUNIDAD) }\end{array}$ \\
\hline & 2.2 & $\begin{array}{l}\text { El gasto promedio para } \\
\text { esparcimiento, diversión, } \\
\text { servicios culturales y de } \\
\text { enseñanza en los NSE C y } \\
\text { D, es de S/ } 317.50 \text {. }\end{array}$ & $\begin{array}{l}\text { El precio ofertado por el servicio educativo que presta } \\
\text { la IEP se encuentra dentro del gasto promedio } \\
\text { (OPORTUNIDAD) }\end{array}$ \\
\hline & 2.3 & $\begin{array}{l}\text { Incremento del Gasto en } \\
\text { educación del Sector } \\
\text { Privado }\end{array}$ & $\begin{array}{l}\text { La IEP se ve amenazada por la aparición de nuevas } \\
\text { corporaciones que invierten en el Sector educativo. } \\
\text { (AMENAZA) }\end{array}$ \\
\hline 3 & \multicolumn{3}{|c|}{ Demográfico } \\
\hline & 3.1. & $\begin{array}{c}\text { Proyecciones de } \\
\text { crecimiento de la } \\
\text { población en edad se } \\
\text { mantienen en el mismo } \\
\text { rango desde el } 2012 \text { a } \\
\text { nivel Nacional ,pero existe } \\
\text { un incremento de } \\
\text { población estudiantil en el } \\
\text { distrito de Santiago }\end{array}$ & $\begin{array}{c}\text { El número de clientes potenciales no está creciendo, ello } \\
\text { afecta el nivel de su participación de mercado. } \\
\text { (AMENAZA) }\end{array}$ \\
\hline \multirow[t]{2}{*}{4} & \multicolumn{3}{|c|}{ Tecnológico } \\
\hline & 4.1. & $\begin{array}{l}\text { Acceso a equipos de } \\
\text { Cómputo e internet en las } \\
\text { instituciones educativas } \\
\text { del Cusco }\end{array}$ & $\begin{array}{c}\text { La IEP cuenta con equipos de cómputo suficientes para } \\
\text { una adecuada disponibilidad por parte de los } \\
\text { estudiantes. Así como servicio de internet. } \\
\text { (OPORTUNIDAD) }\end{array}$ \\
\hline 5 & \multicolumn{3}{|c|}{ Ecológico } \\
\hline & 5.1. & $\begin{array}{l}\text { Plan Nacional de } \\
\text { educación ambiental } \\
\quad(2017-2022)\end{array}$ & $\begin{array}{l}\text { La IEP pone en práctica la concientización y cultura } \\
\text { ambiental mediante la educación en ecoeficiencia desde } \\
\text { su creación, cumpliendo con el plan nacional en } \\
\text { educación ambiental (OPORTUNIDAD) }\end{array}$ \\
\hline
\end{tabular}

Nota. Elaboración Propia

\subsection{Oportunidades y Amenazas}

\subsubsection{Oportunidades.}

1) Inadecuada aplicación del Currículo Nacional de Educación Básica en las instituciones educativas.

2) Incremento de la capacidad de Gasto de los NSE C y D

3) Beneficios tributarios y exoneraciones a empresas del Sector Educación.

4) Deficiencia en la implementación tecnológica en el Sector Público.

5) Implementación del enfoque ambiental para el Sector Educación.

\subsubsection{Amenazas.}


1) Aparición de nuevas instituciones educativas y corporaciones educativas con más experiencia y capacidad de inversión.

2) Competencia en función a la oferta de precios.

3) Proyecciones de crecimiento de la población en edad escolar se mantiene en el mismo rango desde el 2012, aunque en el distrito de Santiago se incrementa.

4) Ofertas laborales para el sector Público por la Reforma Magisterial Peruana

\subsection{Matriz de Evaluación de los Factores Externos EFE}

La evaluación de los factores externos está orientado a un análisis de los acontecimientos ajenos a la institución, o sobre los cuales no puede ejercer influencia y control. Este análisis permite identificar y aprovechar las oportunidades, así como minimizar amenazas que pueden influir en la IEP Santiago Apóstol.

"La matriz de Evaluación de Factores Externos (EFE) permite a los estrategas resumir y evaluar la información económica, social, cultural, demográfica, ambiental, política, gubernamental, legal, tecnológica y competitiva" (David, 2013, p. 110).

La matriz EFE fue desarrollada con apoyo de los especialistas en educación

- Choqueneira Villa, Edwin (Especialista UGEL Cusco)

- Oviedo Moreno, Juan (Especialista SIAGIE UGEL Cusco)

- Ccoscco Alfaro Martiana (Especialista UGEL Cusco) 
Tabla 25

Matriz de evaluación de los factores EFE

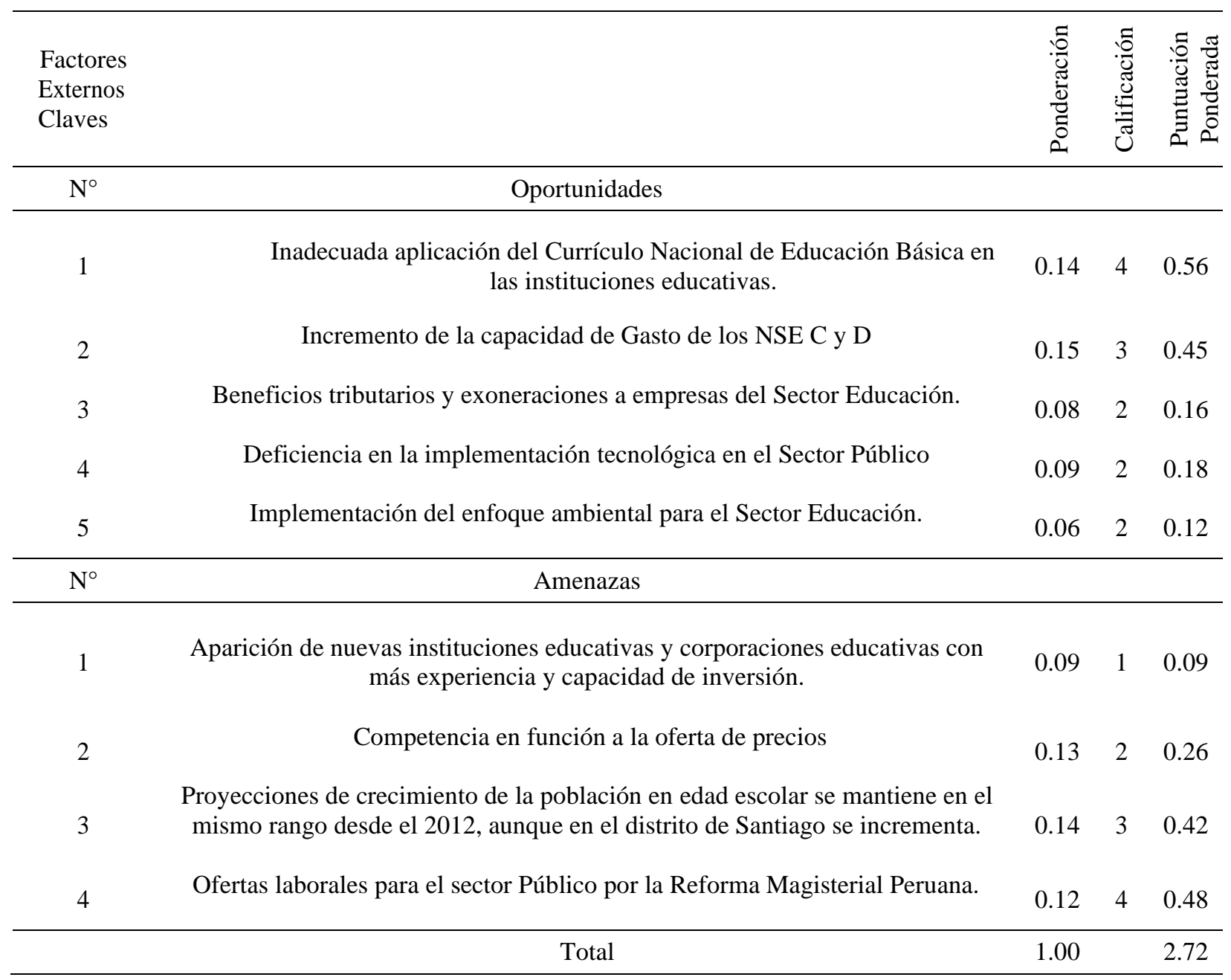

Nota. Elaboración Propia

Considerando la cantidad de oportunidades y amenazas incluidas en la matriz EFE, la condición más óptima es obtener un total ponderado de 4.0 y el resultado total ponderado más bajo posible, 1.0.

En observación a la matriz EFE de la IEP Santiago Apóstol, el total ponderado es 2.72, puntaje superior al nivel promedio ponderado de 2.5. Lo que indica que la IEP Santiago Apóstol responde de manera regular a las oportunidades y amenazas existentes, no se está aprovechando con eficacia las oportunidades existentes y minimizando los posibles efectos negativos de las amenazas externas. 
La matriz EFE de la IEP Santiago Apóstol considera la inadecuada aplicación del Currículo Nacional de Educación Básica en las instituciones educativas. y el incremento de la capacidad de gasto de los NSE C y D como oportunidades de alto impacto.

Y en lo que respecta a las amenazas con mayor impacto, se considera a las ofertas laborales para el sector público por la reforma Magisterial Peruana, así como las proyecciones y resultados de crecimiento de la población en edad escolar. 


\section{Capítulo IV. Análisis de la Industria}

\subsection{Descripción del Mercado (demanda) e Industria (oferta)}

Según (ESCALE, 2018) se registraron 361 instituciones educativas, entre públicas, públicas de gestión privada (convenio) y privadas, con funcionamiento vigente en la Región del Cusco. Actualmente en el distrito de Santiago existen 53 instituciones educativas, que representan el 15\% del total de instituciones educativas dentro de la Provincia de Cusco.

Para evaluar la tendencia de la oferta se tomará en cuenta el número de instituciones educativas privadas dentro del distrito de Santiago como figura en las tablas 26 y 27. Para el nivel primario se consideran 14 instituciones educativas; para el nivel secundario se consideran 11 instituciones educativas.

Tabla 26

Instituciones educativas particulares en el distrito de Santiago 2018 - nivel primario

\begin{tabular}{cccccc}
\hline $\mathrm{N}^{\circ}$ & Nombre de la IE & Nivel & Alumnos & Docentes & Secciones \\
\hline 1 & SAN JOSE & Primaria & 415 & 19 & 15 \\
2 & INNOVA SCHOOLS - HUANCARO & Primaria & 225 & 19 & 8 \\
3 & SANTIAGO APOSTOL & Primaria & 185 & 14 & 7 \\
4 & LICEO ITALIANO & Primaria & 180 & 6 & 6 \\
5 & ABRAHAM LINCOLN & Primaria & 138 & 2 & 6 \\
6 & PABLO APOSTOL & Primaria & 123 & 8 & 6 \\
7 & FLEMING & Primaria & 105 & 9 & 6 \\
8 & DIVINO AMOR & Primaria & 104 & 5 & 4 \\
9 & MARIA ANGOLA & Primaria & 95 & 6 & 6 \\
10 & INMACULADA CONCEPCION & Primaria & 84 & 6 & 6 \\
11 & LIDERES & Primaria & 46 & 6 & 6 \\
12 & PIO ROSARIO NUÑEZ DEL PRADO & Primaria & 17 & 6 & 4 \\
13 & PURIRISUN & Primaria & 6 & 1 & 1 \\
14 & DIDASKALIO SAN JOSE OBRERO & Primaria & 684 & 25 & 18 \\
\hline
\end{tabular}

Nota. ESCALE 2018 (Estadística de la Calidad Educativa). 
Tabla 27

Instituciones educativas en el distrito de Santiago - nivel secundario

\begin{tabular}{cccccc}
\hline $\mathrm{N}^{\circ}$ & Nombre de la IE & Nivel & Alumnos & Docentes & Aulas \\
\hline 1 & SAN JOSE & Secundaria & 246 & 18 & 10 \\
2 & FLEMING & Secundaria & 131 & 8 & 5 \\
3 & SANTIAGO APOSTOL & Secundaria & 100 & 12 & 5 \\
4 & PABLO APOSTOL & Secundaria & 95 & 9 & 5 \\
5 & LICEO ITALIANO & Secundaria & 80 & 5 & 5 \\
6 & LIDERES & Secundaria & 80 & 5 & 5 \\
7 & ABRAHAM LINCOLN & Secundaria & 78 & 2 & 5 \\
8 & MARIA ANGOLA & Secundaria & 57 & 8 & 5 \\
9 & INNOVA SCHOOLS - HUANCARO & Secundaria & 56 & 11 & 2 \\
10 & INMACULADA CONCEPCION & Secundaria & 51 & 8 & 5 \\
11 & DIDASKALIO SAN JOSE OBRERO & Secundaria & 329 & 22 & 10 \\
\hline
\end{tabular}

Nota. ESCALE 2018 (Estadística de la Calidad Educativa).

Considerando exclusivamente a todas las instituciones educativas privadas dentro del distrito de Santiago, se puede observar, por un lado, que la IE Didaskalio San José Obrero cuenta con mayor número de alumnos para el nivel primario y secundario representado el $26.5 \%$ del total de alumnos de gestión privada en el distrito de Santiago. Por otro lado, la IEP Santiago Apóstol representa el $4.6 \%$ del total de alumnos de gestión privada.

\subsection{Descripción de las cinco fuerzas competitivas de la industria}

En el modelo de las cinco fuerzas de Porter (1979), el análisis competitivo se utiliza para desarrollar estrategias orientadas lograr una rentabilidad por encima del promedio en la IEP Santiago Apóstol en comparación con la competencia en la industria.

\subsubsection{Sustitutos.}

Se describe a la amenaza de los sustitutos como las empresas que son capaces de reemplazar los productos y servicios de la industria o presentar una alternativa para satisfacer la demanda. C. Hax \& Majluf (2004). Las presiones competitivas que surgen por los servicios sustitutos aumentan a medida que el precio relativo de éstos disminuye, y conforme el costo en que incurren los consumidores por cambiar a ellos también se reduce. Los sustitutos están 
disponibles e identificados claramente, en este caso se pueden considerar como sustitutos los colegios no escolarizados. Los costos en que incurren los compradores al cambiar a sustitutos son medios, asociados al cambio desalientan la compra de servicios sustitutos de la educación básica regular. Estos costos están relacionados a los cambios que implican tiempo, inconveniencias y costos de probar la calidad y confiabilidad del servicio de un colegio de educación básica alternativa.

Amenaza de nuevos participantes en el mercado: Debido a la importancia de contar con un nivel alto de inversión para ingresar a la industria de educación, es necesario cumplir con una serie de requisitos para instaurar un centro que brinde servicios no escolarizados, en la actualidad no se tiene registros de institutos no escolarizados activos en el distrito de Santiago.

Propensión de los compradores a sustituir por costos: Para este factor se considera los colegios no escolarizados que podrían ser convenientes cuando se considera costos como tiempo y rapidez para que un alumno concluya con su educación básica; ello no representa una amenaza debido a que en el año 2018, la cantidad de matrículas en la modalidad de educación básica alternativa del sector privado en la provincia de Cusco representó el $2.4 \%$ y $0.5 \%$ en el distrito de Santiago ESCALE (2018),

Precio y valor del sustituto: De acuerdo a ESCALE (2018), en los distritos de Santiago y Cusco, los servicios no escolarizados no se encontraron activos.

Los alumnos tienen la opción de elegir entre un centro educativo público o privado. Sin embargo, un porcentaje opta por un colegio no escolarizado, que brinda otros beneficios. El factor de decisión responde al costo - precio y a la calidad del servicio. En algunos casos también influyen factores adicionales como la ubicación. 


\subsubsection{Potenciales nuevos competidores.}

Los competidores potenciales son instituciones educativas que aún no rivalizan en la industria, pero tienen la capacidad de hacerlo ocasionando así un incremento en la intensidad de la competitividad y disminuyendo la participación en el mercado de las instituciones educativas ya existentes. Sin embargo, existen barreras contra el ingreso como falta de experiencia, políticas de regulación gubernamental, ubicaciones deseables, etc.

Según Porter (1979), se debe considerar los siguientes aspectos para analizar la industria de los competidores:

Barreras de entrada:

- Experiencia y curva de aprendizaje: La IEP Santiago Apóstol tiene amplio conocimiento de las necesidades de educación para los niños y jóvenes del distrito de Santiago que pertenecen a los niveles socioeconómicos $\mathrm{C}$ y $\mathrm{D}$, por sus años de experiencia en la industria.

- Altos requisitos de capital: La creación e implementación de un centro educativo requiere un alto nivel de inversión.

- Políticas gubernamentales: Actualmente todas las instituciones educativas deben cumplir con el Currículo Nacional de la Educación Básica que rige desde el 2017 al 2021, así como normas técnicas para el adecuado desarrollo de la gestión educativa, ello requiere tener amplio conocimiento y el capital humano idóneo.

- Marca y lealtad del cliente: Actualmente la IEP Santiago Apóstol cuenta con una participación de mercado de $4.6 \%$ del total alumnos matriculados en primaria y secundaria, tomando en cuenta a los centros educativos privados que operan en el distrito de Santiago. Por otro lado, de acuerdo a lo expuesto en el ciclo de vida del 
servicio, el comportamiento de matrículas en la IEP Santiago Apóstol se mantuvo estable.

- Riesgo de empresas con mayor experiencia en el mercado: Una de las inversiones más importantes en la ciudad del Cusco en el sector educación, es el ingreso de Innova Schools desde el 2018, sin embargo, su público objetivo (nivel socio económico A y B), al que se dirige demanda otras necesidades como calidad superior, asimismo el gasto promedio disponible de los padres de familia es superior, según APEIM, su gasto promedio destinado a enseñanza es de S/. 874 nuevos soles, monto que está acorde al precio de la pensión del mencionado colegio.

De acuerdo al análisis, se puede mencionar que el factor clave de éxito frente a los nuevos competidores es, posicionamiento de la marca en el mercado meta de la IEP Santiago Apóstol.

\subsubsection{Poder de negociación de los clientes.}

Cuando los clientes tienen un nivel de concentración alto, su poder de negociación representa una importante fuerza que afecta la intensidad de la competencia en la industria. El poder de negociación, en este caso de los padres de familia, es mayor cuando los costos por cambiar a un alumno de colegio son relativamente bajos.

El poder del comprador se incrementa cuando los bienes o servicios de la industria están estandarizados, para este caso se debe considerar que las tarifas y derechos de ingreso para un alumno nuevo varían de acuerdo a la oferta de cada institución educativa.

Los clientes negocian su decisión final según los siguientes factores claves de éxito como: la competitividad de precios, la infraestructura, la ubicación, identidad y docentes calificados. 
En el distrito de Santiago existen instituciones educativas privadas que reúnen a 1, 705 alumnos (nivel primario) y 11 instituciones educativas para un total de 978 alumnos (nivel secundario).

La sensibilidad al precio del comprador se incrementa cuando tiene bajos ingresos familiares. Según APEIM, los padres de familia de los niveles C y D cuentan con un promedio de 317.5 soles mensuales para la educación de sus hijos, frente a la tarifa mensual de 280 soles que la IEP Santiago Apóstol ofrece, evidenciando con ello la disponibilidad del gasto con respecto a su tarifa actual.

\subsubsection{Poder de negociación de Proveedores.}

El poder de negociación con los proveedores también afecta la intensidad de la competencia en una industria.

- Cantidad de proveedores disponibles: Los docentes serán considerados como el capital intangible indispensable para la IEP Santiago Apóstol ya que ellos brindan el servicio directo con los alumnos, por lo tanto, la calidad de su servicio permitirá obtener una fuerza competitiva en el mercado. Según ESCALE (2018), la demanda del mercado laboral estuvo constituido por 9,408 docentes para el nivel primario y 9 594 para el nivel secundario. Sin embargo, tomando en cuenta que los docentes que deben conformar la plana docente de la IEP Santiago Apóstol, deben tener un perfil profesional con experiencia y con complementación pedagógica, por ello se considera que su nivel de negociación es medio.

- Arrendador del inmueble donde opera la IEP Santiago Apóstol: Durante los 25 años de su funcionamiento, ha operado en el mismo local. Este hecho posiciona al proveedor con un alto poder de negociación, ya que el contrato de arrendamiento establece condiciones que limitan efectuar cambios o mejoras en la infraestructura. 
- Disponibilidad de materias primas sustitutas: Los proveedores de recursos materiales son principalmente; editoriales de libros, empresas de servicios (luz, agua, internet, etc.), empresas de fabricación de bienes muebles (escritorios, pizarras, carpetas, entre otros), los cuales pueden ser seleccionados entre la variedad de oferta en el mercado, por lo tanto, el poder de negociación frente a ellos es alto.

\subsubsection{Rivalidad entre los competidores.}

Este tipo de rivalidad suele ser la más poderosa de las cinco fuerzas competitivas según David (2013), ya que las estrategias de una empresa únicamente pueden tener éxito en la medida en que le proporcionan la ventaja competitiva sobre las estrategias de las empresas rivales.

Según los datos de ESCALE (2018) en el departamento de Cusco hubo un incremento significativo de instituciones educativas desde el 2014 (ver Tabla 28).

Tabla 28

Evolución de instituciones educativas

\begin{tabular}{cccccc}
\hline Año & 2014 & 2015 & 2016 & 2017 & 2018 \\
\hline \multirow{2}{*}{ Número de Instituciones } & 5,536 & 5,667 & 5,807 & 5,880 & 5,920 \\
\hline
\end{tabular}

Nota. Adecuado de ESCALE 2018.MINEDU

La rivalidad se intensifica cuando se incrementa el número de competidores conforme se asemejan en tamaño y fuerza competitiva. Considerando la rivalidad entre instituciones educativas privadas, la IEP Santiago Apóstol compite directamente con 13 instituciones para el nivel primario y 10 instituciones para el nivel secundario. De acuerdo a lo mencionado anteriormente, las instituciones educativas Didaskalio San José Obrero y Fleming son los rivales más fuertes. La diferenciación del servicio subyace en la competencia directa y el valor adicional que ofrecen ambas instituciones.

Existen barreras para que un centro educativo se instaure en la industria: La base legal que se requiere para su apertura y funcionamiento es riguroso, a fin de asegurar los estándares 
exigidos por el Estado, así como lo referido a la normatividad de cómo establecer el servicio para los educandos.

○ Ley 28044, Ley General de Educación.

- Aprobación del Currículo Nacional de la Educación Básica que rige desde el 2017 al 2021.

○ Aprobación de la Norma Técnica denominada: "Normas y orientaciones para el desarrollo del año escolar 2017”.

En la tabla 29 se observa que la IEP Santiago Apóstol tiene los precios más elevados a diferencia de la competencia directa, instituciones educativas Didaskalio San José Obrero y Fleming.

Tabla 29

Centros educativos rivales

\begin{tabular}{cccc}
\hline & Santiago Apóstol & $\begin{array}{c}\text { Didaskalio San José } \\
\text { Obrero }\end{array}$ & Fleming \\
\hline Sector Dirigido & C y D & C y D & C y D \\
Costo de la Pensión (Primaria) & S/ 280.00 & S/ 190.00 & S/ 250.00 \\
Costo de la Pensión (Secundaria) & S/ 280.00 & S/ 185.00 & S/ 230.00 \\
\hline
\end{tabular}

Nota. Elaboración Propia datos 2016

Es importante recordar que la IEP Didaskalio San José Obrero ofrece un valor adicional a su servicio de educación básica regular, la alternativa de una certificación técnica a sus estudiantes. Adicionalmente ofrece becas en institutos para los mejores alumnos en lugares que pertenezcan a la congregación Lumen Dai. La institución también posee la mayor cantidad de alumnos del distrito y cobra la mensualidad más baja.

El centro Educativo Fleming ubicado en el límite del distrito de Santiago con el distrito Cusco se enfoca en la preparación preuniversitaria avanzada en los últimos grados del nivel secundario. De acuerdo a lo mencionado, cada institución del sector educación tiene una 
propuesta de valor diferenciada para sus alumnos, por ello el factor clave de éxito frente a los competidores es la propuesta educativa.

\subsection{Matriz de Atractividad de cada una de las cinco fuerzas.}

Según Porter (1979) diseñó un modelo de las cinco fuerzas con la finalidad de entender mejor un "negocio atractivo" en la industria a la hora de tomar decisiones y de las estrategias que puedan ser implementadas.

El análisis de la amenaza de entrada de nuevos competidores afectaría directamente los ingresos de la IEP Santiago Apóstol, al disminuir el número de alumnos ingresantes desde el nivel primario y alumnos nuevos. La amenaza dependerá básicamente del nivel de barreras de entradas existentes, como los trámites y documentación para obtener la Licencia de Apertura y Licencia de Funcionamiento. En segundo lugar, la amenaza de los productos sustitutos como los institutos de educación básica no escolarizados, constituyen otra de las fuerzas a analizar.

Con respecto al poder de negociación con los proveedores, dependerá del nivel de la cantidad de proveedores y del grado de dependencia de los competidores.

En relación a lo expuesto, se consideran como fuerzas la amenaza de sustitutos, las amenazas de entradas de nuevos centros educativos, el poder negociador de los proveedores y la rivalidad entre los competidores directos.

\subsection{Análisis del Grado de Atractividad de la Industria.}

La tabla 30 muestra la Matriz de atractividad de las 5 fuerzas competidoras de Porter, se observa que la industria del sector de educación básica para instituciones educativas dentro del distrito de Santiago posee un grado de Atractividad de 1.3 (de un puntaje máximo de 4), el cual ubica al servicio de educación en un estado de vigilia constante a sus competidores, debido a la mejora continua que estas instituciones realizan para sus servicios educativos. 
Tabla 30

Matriz de atractividad de las 5 fuerzas competidoras de Porter

\begin{tabular}{cccc}
\hline Atractividad & Relevancia & Atractivo & Resultado \\
\hline Amenaza de Sustitutos & 0.15 & 1 & 0.15 \\
Amenaza de entrada de nuevas & 0.20 & 2 & 0.40 \\
Instituciones Educativas & 0.35 & 4 & 1.40 \\
Poder Negociador con los Proveedores & 0.30 & 3 & 0.90 \\
Rivalidad entre competidores & & & 2.85 \\
\hline Total & &
\end{tabular}

Nota. Elaboración Propia

Leyenda de calificación

$\begin{array}{cc}\text { Muy Baja } & 1 \\ \text { Baja } & 2 \\ \text { Alta } & 3 \\ \text { Muy Alta } & 4\end{array}$

Nota. Elaboración Propia

\subsection{Matriz de Perfil Competitivo MPC.}

La Matriz de Perfil Competitivo (MPC) identifica los principales competidores de la compañía, así como sus fortalezas y debilidades particulares en relación con la posición estratégica, empero los factores críticos de éxito en una MPC incluyen tanto cuestiones internas como externas; por consiguiente, las calificaciones se refieren a las fortalezas y debilidades.

Las puntuaciones ponderadas totales para las compañías rivales pueden ser comparadas contra la compañía muestra. (David, 2013)

La Matriz de Perfil Competitivo (MPC) identificará los principales competidores de la Institución educativa Santiago Apóstol, así como sus fortalezas y debilidades particulares en relación con la posición estratégica. Las calificaciones se refieren a las fortalezas y debilidades, donde 4 = fortaleza principal, $3=$ fortaleza menor, $2=$ debilidad menor y $1=$ debilidad principal . A diferencia de lo que ocurre en la matriz EFE, en la MPC los factores críticos de éxito no están agrupados en oportunidades y amenazas. 
En la MPC las calificaciones y las puntuaciones ponderadas totales para las otras instituciones educativas competidoras pueden ser comparadas contra IEP Santiago Apóstol. Este análisis comparativo arroja importante información estratégica interna. Consideramos como principales competidores a:

- IEP Didaskalio San José Obrero

- IEP Fleming

Según la matriz, la IEP Didaskalio San José Obrero tiene un mejor perfil competitivo en comparación a la institución educativa Santiago Apóstol en los siguientes factores:

- Presupuesto, Ya que al poseer un gran número de alumnos obtiene un ingreso mayor que formará parte del presupuesto asignar en el próximo año.

- Participación en el mercado también por la cantidad de alumnado que es mayor ofrece una certificación técnica adicionalmente a la formación académica estándar de sus alumnos.

- Prestigio, el IE Didaskalio San José Obrero posee una imagen institucional reconocida en el distrito.

- Ubicación geográfica: Este factor tiene la puntuación más baja, debido a que el establecimiento se encuentra en una zona rural con accesibilidad moderada.

La IEP Fleming tiene como único factor de éxito mayor con respecto a la IEP Santiago Apóstol la ubicación geográfica, por tener alta accesibilidad y cercanía al Distrito de Cusco.

La matriz de perfil competitivo fue desarrollada con apoyo de los especialistas en educación:

- Choqueneira Villa, Edwin (Especialista UGEL Cusco)

- Oviedo Moreno, Juan (Especialista SIAGIE UGEL Cusco) 
- Ccoscco Alfaro Martiana (Especialista UGEL Cusco) 
Tabla 31

Matriz de perfil competitivo MP

\begin{tabular}{|c|c|c|c|c|c|c|c|c|}
\hline \multirow{2}{*}{$\mathrm{N}^{\circ}$} & \multirow{2}{*}{ Factores Críticos para el Éxito } & \multicolumn{3}{|c|}{ IEP “Santiago Apóstol” } & \multicolumn{2}{|c|}{ Didaskalio San José Obrero } & \multicolumn{2}{|c|}{ Fleming } \\
\hline & & Peso & Calificación & Ponderado & Calificación & Ponderado & Calificación & Ponderado \\
\hline 1 & Presupuesto & 0.05 & 2 & 0.10 & 4 & 0.20 & 1 & 0.05 \\
\hline 2 & Competitividad de Precios & 0.10 & 2 & 0.20 & 3 & 0.30 & 2 & 0.2 \\
\hline 3 & Propuesta educativa diferenciada & 0.07 & 2 & 0.14 & 4 & 0.28 & 2 & 0.14 \\
\hline 4 & Ubicación del CE & 0.12 & 2 & 0.24 & 1 & 0.12 & 3 & 0.36 \\
\hline 5 & Docentes calificados & 0.30 & 3 & 0.90 & 3 & 0.90 & 2 & 0.6 \\
\hline 6 & Lealtad de los Clientes & 0.10 & 3 & 0.30 & 3 & 0.30 & 2 & 0.2 \\
\hline 7 & Prestigio & 0.15 & 3 & 0.45 & 4 & 0.60 & 2 & 0.3 \\
\hline \multirow[t]{2}{*}{8} & Posicionamiento de marca & 0.11 & 2 & 0.22 & 1 & 0.11 & 3 & 0.33 \\
\hline & Total & 1 & & 2.55 & & 2.81 & & 2.18 \\
\hline
\end{tabular}

Nota. Elaboración Propia 


\section{Capítulo V. Análisis Interno}

\subsection{Descripción de las actividades de la Cadena de Valor}

De acuerdo con Porter (1979), la mejor forma de describir el negocio de una empresa es con una cadena de valor, en la cual los ingresos totales menos los costos totales de todas las actividades emprendidas para desarrollar y comercializar un producto o servicio producen valor.

De acuerdo a los procesos actuales, se realizó el análisis de la cadena de valor, a continuación, se presenta los procesos que la componen:

\subsubsection{Procesos Estratégicos.}

- Planeación Institucional: La entidad promotora y el Consejo Directivo son los encargados de diseñar los lineamientos, políticas y planes de acción para las diversas funciones que se desarrollan dentro de la institución educativa.

- Política Interna: Reglamentos internos, manuales de procesos y procedimientos de la IEP Santiago Apóstol, elaborados por el Consejo Directivo.

\subsubsection{Procesos Operativos.}

- Marketing y Ventas: La institución educativa define un plan de las ventas de forma anual para ofrecer su servicio al mercado.

- Logística: La gestión de logística y almacén no ha variado desde la apertura de la institución educativa. Las instalaciones y el mobiliario cuentan con mantenimiento permanente, que permite tener un ambiente óptimo para el desarrollo de sus actividades. 


\subsubsection{Procesos del Ciclo Operacional.}

- Programación Académica, la dirección se encarga de este proceso para administrar la programación de horarios y la asignación de los docentes de primaria y secundaria según cursos.

- Oferta Académica, la gerencia general y la dirección se encargan de planear y organizar los lineamientos de promoción y publicidad.

- Diseño Curricular: La dirección se responsabiliza de planear y organizar el avance curricular académico.

- Matrícula: en este proceso los padres de familia manifiestan su interés por conseguir una vacante, para los alumnos nuevos se requiere de una donación que asciende a S/ 400.00 y posteriormente el pago de la matrícula como alumnos regulares.

- Evaluaciones: este proceso involucra la entrega de los registros por parte de los docentes al departamento de informática para su centralización efectuándose de forma mensual para luego ser reportado a los padres de familia.

- Asistencia: Proceso a cargo del auxiliar de educación para controlar el registro de la asistencia de los docentes y alumnos al colegio.

- Capacitación Docente: proceso a cargo del Consejo Directivo, cuyo fin es formar a los docentes de la IEP Santiago Apóstol, considerando las políticas, conocimientos, actitudes y habilidades, a fin de prepararlos para cumplir sus labores eficazmente en el salón de clases.

- Evaluación Docente: proceso a cargo de la Dirección, cuyo propósito es realizar una evaluación de desempeño de los docentes en la IEP Santiago Apóstol.

\subsubsection{Procesos de Soporte.}


- Administración y Finanzas: Proceso administrativo a cargo de entidad promotora y la dirección de la Institución, responsables de la toma de decisiones y su ejecución, basado en una gestión orientada a la coordinación y la retroalimentación de información a todas las áreas de la organización.

La entidad promotora y el consejo directivo son los encargados de gestionar el Capital Humano de la institución.

Las finanzas, tesorería y facturación están a cargo de la entidad promotora. La contabilidad es llevada por un tercero.

- Infraestructura, la IEP Santiago Apóstol posee una cultura organizacional sólida debido al alto nivel de identidad institucional por parte de sus trabajadores. (Anexo 5 y 6). Por otro lado, la práctica de valores transversales como la laboriosidad, responsabilidad. respeto y solidaridad, delinean la diferencia en la formación de los estudiantes de la IEP.

- Atención a los padres de familia, gestionada directamente por la subdirección respecto a los procesos académicos y reclamos que se presenten.

\subsubsection{Procesos de medición, análisis y mejora.}

- Auditoría Interna: es el control de calidad interna de la IEP Santiago Apóstol efectuada por la dirección de forma mensual a los docentes en el desarrollo de sus clases.

- Auditoría Externa: es el control de calidad minucioso que efectúa anualmente la UGEL Cusco a los docentes mediante encuestas y evaluaciones. 
Tabla 32

Cadena de valor

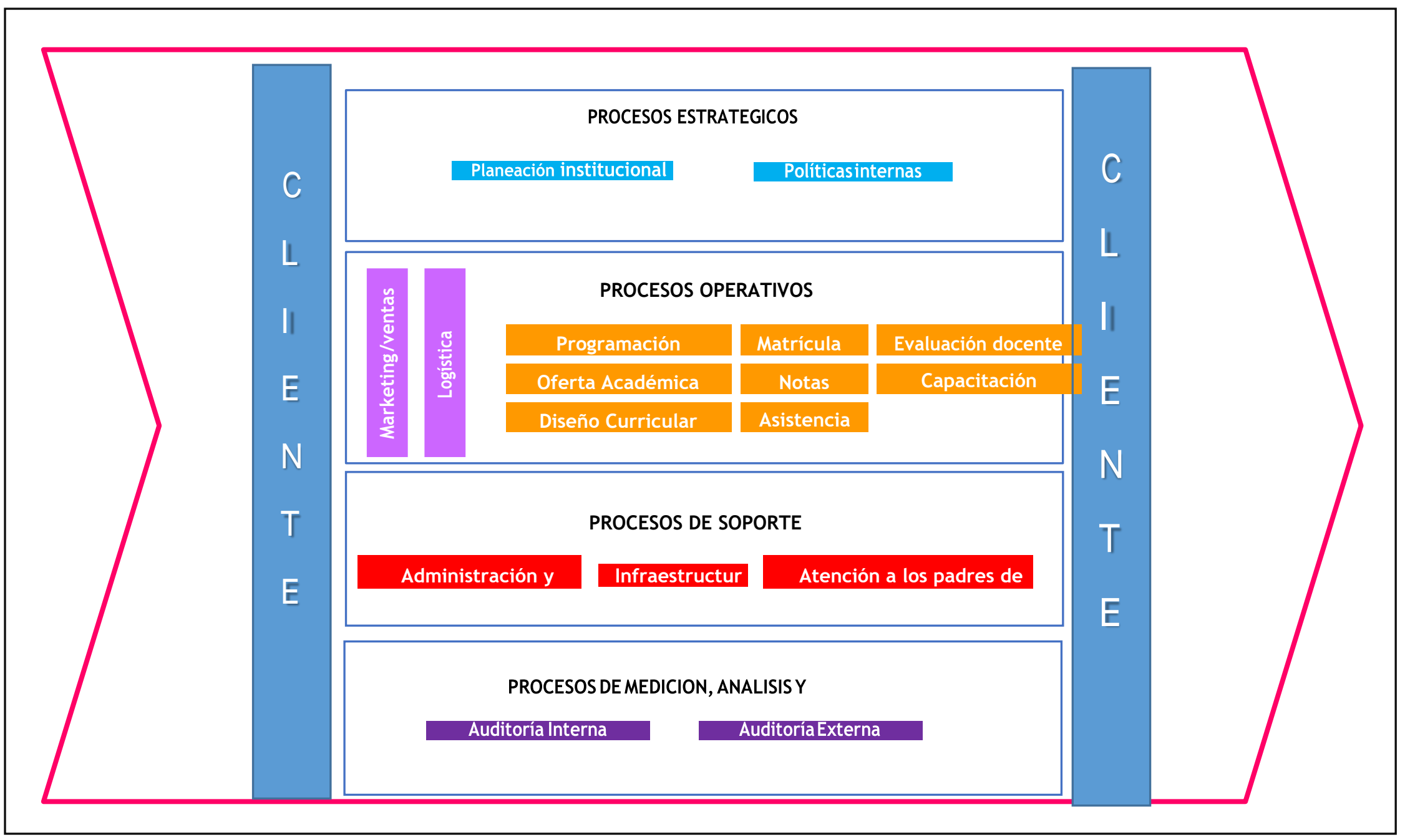

Nota. Elaboración propia 


\subsection{Indicadores de cada una de las Actividades de la Cadena de Valor}

Los indicadores de gestión de administración y finanzas son:

- Cartera Atrasada:

En el año 2016 la IEP Santiago Apóstol tuvo una cartera atrasada de 7\%. En el año 217 presenta una cartera atrasada del $6 \%$ del total de alumnos, con una variación de $1 \%$. Este indicador se calcula mensualmente.

- Rentabilidad Patrimonial ROE

Este indicador se obtiene de forma anual y podemos observar que en el año 2016 se ha obtenido un $40 \%$ de productividad de los capitales propios de la empresa y para el 2017 se ve reducido a un $26 \%$.

- Margen EBITBA

Este indicador se obtiene con una periodicidad anual y en el año 2016 tiene un resultado positivo de S/ 65,193.74, que significa que la gestión realizada en la institución es positiva, al igual que en el año 2017 con un resultado de S/ 59,219.

\section{- Margen Neto}

Este indicador se obtiene con una periodicidad anual y representa la razón de las ventas con respecto de la utilidad neta de la empresa, la cual fue favorable en el año 2016 con un $8 \%$ y en el año 2017 con un $6 \%$.

- Rentabilidad del Activo ROA

Este indicador es determinado en forma anual, y se tiene una rentabilidad del activo frente a la utilidad neta de $19 \%$ en el año 2016 y de $15 \%$ en el 2017.

Los indicadores de gestión educativa son:

- Ingreso a la Universidad 
Este indicador es determinado en forma anual y representa el porcentaje de alumnos egresados que ingresaron a las universidades que en el 2016 fue de $55 \%$ y en el 2017 de $35 \%$.

Los indicadores de gestión y desarrollo humano son:

- Clima Laboral

El porcentaje de satisfacción, se determina de forma anual aplicando una encuesta de satisfacción a los trabajadores en el año 2017 con un resultado de 88\% de satisfacción laboral. (Anexos 5 y 6).

- Capacitación:

Este indicador se obtiene con periodicidad anual. En el año 2016 se obtuvo un $64 \%$ de cumplimiento y en el año 2017 un 70\% de cumplimiento de las actividades de capacitación programadas.

\subsection{Benchmarking y comparación con los líderes de la industria de cada una de las actividades de la Cadena de Valor}

Según Kotler \& Keller (2012, p. 349) “el benchmarking es la comparación de productos y procesos en relación a los líderes con el fin de implementar buena gestión”. Los gerentes pueden identificar las mejores prácticas de las empresas líderes en el mundo al consultar con clientes, proveedores, distribuidores, analistas financieros, asociaciones comerciales y medios de comunicación para ver quien parece estar haciendo mejor el trabajo.

La tabla 33 muestra una comparación de los principales competidores en relación a la calidad del servicio (número de ingresos a la universidad, tipo de constitución e infraestructura) así como los procesos utilizados por cada institución. 
Tabla 33

Benchmarking y comparación con los líderes de la industria de cada una de las actividades de la cadena de valor

\begin{tabular}{|c|c|c|c|}
\hline Variables & IEP Santiago Apóstol & $\begin{array}{c}\text { Didaskalio San José } \\
\text { Obrero }\end{array}$ & Alexander Fleming \\
\hline Costo de matricula & 500 soles & 185 soles & 100 soles \\
\hline Costo mensualidad & $\begin{array}{l}280 \text { soles primaria y } \\
\text { secundaria }\end{array}$ & $\begin{array}{l}190 \text { soles primaria y } \\
185 \text { secundaria }\end{array}$ & $\begin{array}{l}250 \text { soles primaria y } \\
230 \text { soles secundaria }\end{array}$ \\
\hline Número de estudiantes por aula & $\begin{array}{l}24 \text { primaria y } 17 \\
\text { secundaria }\end{array}$ & $\begin{array}{l}36 \text { primaria y } 41 \\
\text { secundaria }\end{array}$ & $\begin{array}{l}18 \text { primaria y } 28 \\
\text { secundaria }\end{array}$ \\
\hline Horas de clase laboradas por día & $\begin{array}{l}7 \text { horas primaria y } 8 \\
\text { horas secundaria }\end{array}$ & $\begin{array}{c}7 \text { horas primaria y } \\
\text { horas secundaria }\end{array}$ & $\begin{array}{c}7 \text { horas primaria y } \\
\text { horas secundaria }\end{array}$ \\
\hline Número de docentes & $\begin{array}{l}7 \text { primaria y } 11 \\
\text { secundaria }\end{array}$ & $\begin{array}{l}16 \text { primaria y } 19 \\
\text { secundaria }\end{array}$ & $\begin{array}{l}10 \text { primaria y } \\
\text { secundaria }\end{array}$ \\
\hline Cantidad de aulas & $\begin{array}{l}7 \text { primaria y } \\
\text { secundaria }\end{array}$ & $\begin{array}{l}14 \text { primaria y } 10 \\
\text { secundaria }\end{array}$ & $\begin{array}{l}6 \text { primaria y } 6 \\
\text { secundaria }\end{array}$ \\
\hline $\begin{array}{c}\text { Años de servicio docente en la } \\
\text { institución }\end{array}$ & 10 años & 5 años & 4 años \\
\hline Programas académicos & $\begin{array}{c}\text { Ferias de ciencia } \\
\text { (FENCyT), Olimpiada } \\
\text { Matemáticas, Juegos } \\
\text { florales. }\end{array}$ & $\begin{array}{c}\text { Ferias de ciencia } \\
\text { (FENCyT), Olimpiada } \\
\text { Matemáticas. }\end{array}$ & No participa. \\
\hline $\begin{array}{c}\text { Eventos culturales, recreativos y } \\
\text { deportivos }\end{array}$ & $\begin{array}{c}\text { Festidanza, olimpiadas } \\
\text { deportivas, ecología } \\
\text { vivencial }\end{array}$ & Olimpiadas deportivas & No participa. \\
\hline $\begin{array}{c}\text { Numero de Ingresantes a las } \\
\text { Universidades }\end{array}$ & $35 \%$ de egresados & $35 \%$ de egresados & $40 \%$ de egresados \\
\hline
\end{tabular}

Nota. Elaboración propia

\subsection{Determinar las Competencias de la Institución}

Según Prahalad y Hamel (1990, p. 25) "Las competencias centrales son definidas por un conjunto de habilidades o experiencia que le permite a una organización proveer un beneficio específico o valor agregado a los consumidores”. En términos más simples, son los factores que hacen que un cliente elija un producto sobre otro en el mercado como el padre de familia selecciona una institución educativa frente a otra para la educación de su hijo.

- Las competencias en la IEP Santiago Apóstol son las cualidades definidas por la cultura existente en esta y es aplicable para todo el personal como una forma de entender el negocio, ello los diferencia en relación a las demás Instituciones Educativas Privadas. Tomando en consideración los procesos de la cadena de valor y 
la opinión de los clientes mediante una encuesta aplicada a padres de familia y focus group (anexo 6) para alumnos y padres de familia, las competencias son:

- Servicio de enseñanza adecuado, la institución educativa ofrece un servicio adecuado para los alumnos, considerando como parte fundamental la experiencia de los docentes y la gestión administrativa y financiera de su Consejo Directivo.

- Infraestructura y ubicación: La infraestructura es adecuada, sin embargo, las instalaciones de la IEP podrían ser mejoradas realizando mejoras o ampliación de las aulas y espacios en común para los alumnos. Asimismo, su ubicación geográfica es ventajosa para los alumnos y padres de familia.

- Docentes calificados: La importancia de contar con una plana docente calificada logra que la IEP logre cumplir con sus principales objetivos institucionales.

\subsubsection{Propuesta de Valor.}

Considerando la competencia directa, la IEP Santiago Apóstol desarrolló su propuesta educativa para formar alumnos de calidad con tolerancia, ética y valores,

Producto (servicio): Su servicio está enfocado a los principales factores claves de éxito percibidos por los padres de familia: material de enseñanza y docentes calificados. De esta manera logra una ventaja diferencial en el distrito de Santiago.

- Precio: En la actualidad, la IEP maneja una política de precios acorde a la capacidad de gasto disponible para enseñanza de los NSE C y D. La política actual de precios requiere un diseño en base a los costos reales y la propuesta diferenciada del servicio con criterios adecuados para la determinación del precio. 
Respecto a la política del pago de mensualidades, al inicio del año escolar los padres de familia firman una carta de compromiso con la IEP, a fin de establecer los plazos de pagos y mora. Los pagos se efectúan a través de la Caja Municipal de Ahorro y Crédito Cusco.

- Plaza: La IEP dispone de un local alquilado para prestar su servicio educativo, desde el inicio de su funcionamiento en el sector.

- Promoción: La organización necesita aplicar estudios de mercado mediante una metodología objetiva para determinar las necesidades, oportunidades y amenazas en su industria. Asimismo, la promoción y publicidad de sus servicios se desarrolla a través de medios de comunicación (radio y volanteo), captación de nuevos clientes (familiares de los alumnos actuales) ofreciendo descuentos especiales.

\subsection{Identificación y determinación de las Ventajas Competitivas de la Institución}

De acuerdo con Hill, Jones y Schilling (2014, p. 6), "la ventaja competitiva se basa en competencias distintivas, que son las fortalezas específicas de la empresa que le permiten diferenciar sus productos y lograr costos sustancialmente más bajos que sus rivales”.

La ventaja competitiva que tiene la IEP Santiago apóstol es el tener docentes especializados y sus programas académicos, culturales y deportivas.

De acuerdo a Peng, M. (2014), la ventaja competitiva responde al análisis de valor, acceso reducido, imitabilidad y uso de recursos.

\section{Tabla 34}

Matriz VRIO - Identificación de la Ventaja Competitiva 
Nota. Adaptado de Global Strategy (p. 72), por M. Peng, 2014, 3ra edición, Cengage Learning

\begin{tabular}{|c|c|c|c|c|c|}
\hline Competencias & Valioso & Raro & $\begin{array}{c}\text { Costoso } \\
\text { de } \\
\text { imitar }\end{array}$ & $\begin{array}{l}\text { Uso del } \\
\text { recurso }\end{array}$ & Implicancia \\
\hline Ubicación geográfica estratégica. & $\mathrm{Si}$ & No & No & $\mathrm{Si}$ & $\begin{array}{l}\text { Paridad } \\
\text { competitiva }\end{array}$ \\
\hline Lealtad de clientes. & $\mathrm{Si}$ & No & No & $\mathrm{Si}$ & $\begin{array}{l}\text { Paridad } \\
\text { competitiva }\end{array}$ \\
\hline Docentes calificados. & $\mathrm{Si}$ & No & No & $\mathrm{Si}$ & $\begin{array}{l}\text { Paridad } \\
\text { competitiva }\end{array}$ \\
\hline Clima laboral favorable. & $\mathrm{Si}$ & No & No & $\mathrm{Si}$ & $\begin{array}{l}\text { Paridad } \\
\text { competitiva }\end{array}$ \\
\hline $\begin{array}{l}\text { Desarrollo de actividades académicas, } \\
\text { culturales y deportivas para los alumnos }\end{array}$ & $\mathrm{Si}$ & No & No & $\mathrm{Si}$ & $\begin{array}{l}\text { Paridad } \\
\text { competitiva }\end{array}$ \\
\hline
\end{tabular}

6.6 Lista de Fortalezas y Debilidades

\subsubsection{Fortalezas.}

- Ubicación geográfica estratégica.

- Lealtad de clientes.

- Docentes calificados.

- Clima laboral favorable.

- Desarrollo de actividades académicas, culturales y deportivas.

\subsubsection{Debilidades.}

- Infraestructura alquilada.

- Capacidad instalada insuficiente para la demanda de estudiantes.

- Falta de medios para la investigación de mercado.

- Demora en cobro de mensualidad (Cartera atrasada).

\subsection{Matriz de Evaluación de los Factores Internos EFI}


Como David (2013) dice, la Matriz de evaluación de Factores Internos (EFI) es una síntesis dentro del proceso de auditoría interna de la administración estratégica. Esta herramienta para la formulación de estrategias sintetiza y evalúa las fortalezas y debilidades más importantes encontradas en las áreas funcionales de una empresa y también constituye la base para identificar y evaluar las relaciones entre estas áreas.

La matriz EFI fue desarrollada con apoyo de los especialistas en educación:

- Castro Vilca Marco Antonio (Director de la IEP Santiago Apóstol)

- Gutiérrez Gamarra Nelly Eusebia (Coordinadora de la IEP Santiago Apóstol)

- Porras Huamán Karina (Docente de la IEP Santiago Apóstol). 
Tabla 35

Matriz EFI

\begin{tabular}{|c|c|c|c|c|}
\hline $\begin{array}{c}\text { Factores } \\
\text { Internos Claves }\end{array}$ & & 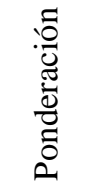 & 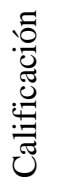 & 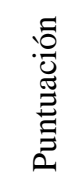 \\
\hline $\mathrm{N}^{\circ}$ & Fortalezas & & & \\
\hline 1 & Ubicación geográfica estratégica. & 0.13 & 3 & 0.39 \\
\hline 2 & Lealtad de clientes. & 0.10 & 3 & 0.30 \\
\hline 3 & Docentes calificados. & 0.12 & 4 & 0.48 \\
\hline 4 & Clima laboral favorable. & 0.14 & 3 & 0.42 \\
\hline 5 & Desarrollo de actividades académicas, culturales y deportivas & 0.09 & 3 & 0.27 \\
\hline $\mathrm{N}^{\circ}$ & Debilidades & & & \\
\hline 1 & Infraestructura alquilada. & 0.14 & 1 & 0.14 \\
\hline 2 & Capacidad instalada insuficiente para la demanda de estudiantes. & 0.12 & 1 & 0.12 \\
\hline 3 & Falta de medios para la investigación de mercado. & 0.09 & 2 & 0.18 \\
\hline 4 & Demora en cobro de mensualidad (Cartera atrasada). & 0.07 & 2 & 0.14 \\
\hline Total & & 1.00 & & 2.44 \\
\hline
\end{tabular}

Nota. Elaboración Propia

Sea cual fuere la cantidad de factores que se incluyen en una matriz EFI, el total

ponderado puede ir de un mínimo de 1.0 a un máximo de 4.0, siendo la calificación promedio de

2.5. Los totales ponderados muy por debajo de 2.5 caracterizan a las organizaciones que son

débiles, mientras que las calificaciones muy por arriba de 2.5 indican una posición interna fuerte.

La matriz EFI, al igual que la matriz EFE, debe incluir entre 10 y 20 factores clave. La cantidad

de factores no influye en la escala de los totales ponderados porque los pesos siempre suman 1.0.

La matriz EFI de la IEP Santiago Apóstol obtiene un total ponderado de 2.44, cuyo valor

se encuentra por debajo de 2.5 , con ello se concluye la posición interna débil que posee en la actualidad. 


\section{Capítulo VI. Formulación de los Objetivos y Diseño de las Estrategias}

En este capítulo se desarrolla los objetivos de largo plazo y el diseño de las estrategias en base a la información de los capítulos anteriores. Respecto a los objetivos, según D'Alessio (2006, p. 219) "Los objetivos representan los resultados que la organización espera alcanzar luego de implementar las estrategias externas especificas escogidas, las cuales conducen hacia la visión establecida". Para el diseño de la estrategia se presenta diferentes modelos de matrices, con la finalidad de determinar el modelo de estrategia idóneo para la IEP Santiago Apóstol

\subsection{Alcance y planteamiento de los objetivos}

\subsubsection{Objetivos Estratégicos.}
A. Alcanzar un crecimiento anual de la rentabilidad de $2 \%$ hasta el año 2023.
B. Incrementar la participación del mercado en $0.7 \%$ anual hasta el año 2023.
C. Contar con el $80 \%$ de docentes especializados para el 2023.

\subsubsection{Análisis de los objetivos estratégicos.}

A. Alcanzar un crecimiento anual de la rentabilidad de 2\% hasta el año 2023: El incremento de la rentabilidad en un 10\% para el 2023 implica un incremento en el número de matriculados en un $4 \%$ anual promedio.

B. Incrementar la participación del mercado en $0.7 \%$ anual hasta el año 2023: De acuerdo al análisis realizado en los capítulos anteriores se observa que la población atendida en las instituciones educativas privadas del distrito de Santiago, representan el $38 \%$ de la población estudiantil matriculada en primaria y secundaria dentro de la ciudad del Cusco. La IEP Santiago Apóstol puede incrementar su participación de mercado, considerando su participación del año 2018 (4.2\%) a un crecimiento anual de $0.7 \%$. Esto se puede llevar a cabo atrayendo a los clientes de la competencia o clientes potenciales (estudiantes matriculados en instituciones educativas públicas). 
El cumplimiento de este objetivo se dará con servicios adicionales que satisfagan las necesidades no cubiertas en el mercado educativo, implementando actividades extra curriculares (música y danza) para un mejor desarrollo de competencias y capacidades de los estudiantes.

C. Contar con el $80 \%$ de docentes especializados para el 2023.

Este objetivo considera tener plana docente con especialidad en pedagogía y especialidad en las materias que desempeñan para el año 2023. Se llevará a cabo mediante un plan de capacitación para desarrollar sus conocimientos y habilidades con el fin de mejorar la eficiencia y, por ende, dar continuidad a una de las competencias más importantes de la IEP que sus clientes consideran, tener docentes calificados.

\subsubsection{Modelo de Océano Azul.}

Según Kim y Mauborgne (2005, p. 4). “La industria representada por océano rojo es un lugar donde el mercado y los competidores se encuentran definidos y el negocio de conducido de una manera particular." La industria educativa en el distrito de Santiago tiene características de un océano rojo, ya que existen un promedio de 11 instituciones educativas de nivel secundario y 14 de nivel primario en los últimos tres años; es decir, ya se tienen competidores definidos. Por otro lado, también se tiene un mercado definido, correspondiente a los alumnos que se matriculan en los grados de primaria y secundaria del distrito (ver tabla 8). Por otro lado, una estrategia de océano azul propone considerar la importancia de la innovación cuando se abren nuevos mercados y la competencia se torna irrelevante. 


\subsubsection{Lienzo de la estrategia actual de la empresa.}

El lienzo de la estrategia actual del IEP Santiago Apóstol muestra las siguientes variables que han sido identificadas y determinadas desde el punto de vista de los padres de familia quienes son los clientes. Las variables que se utilizaron como base en las encuestas a los clientes de IEP Santiago Apóstol a una muestra de 100 padres de familia (ver Anexos 2 y 3).

Los clientes han calificado a cada una de las variables con un puntaje del 1 al 5, donde 1 hace referencia a una calificación baja, mientras que el puntaje de 5, hace referencia a una calificación alta, con la escala 5- Excelente 4- Muy Bueno 3-Bueno 2- Regular 1-Deficiente. Material de enseñanza y docentes obtuvieron las calificaciones más altas, mientras que costes, aulas de estudiantes y vacantes obtuvieron la calificación más baja. Esto se debe a que el principal foco de la IEP Santiago Apóstol es tener docentes competentes la cual refleja una aceptabilidad por parte de los clientes y el material de enseñanza es bueno que a la fecha tiene resultados favorables en la formación de sus estudiantes. 


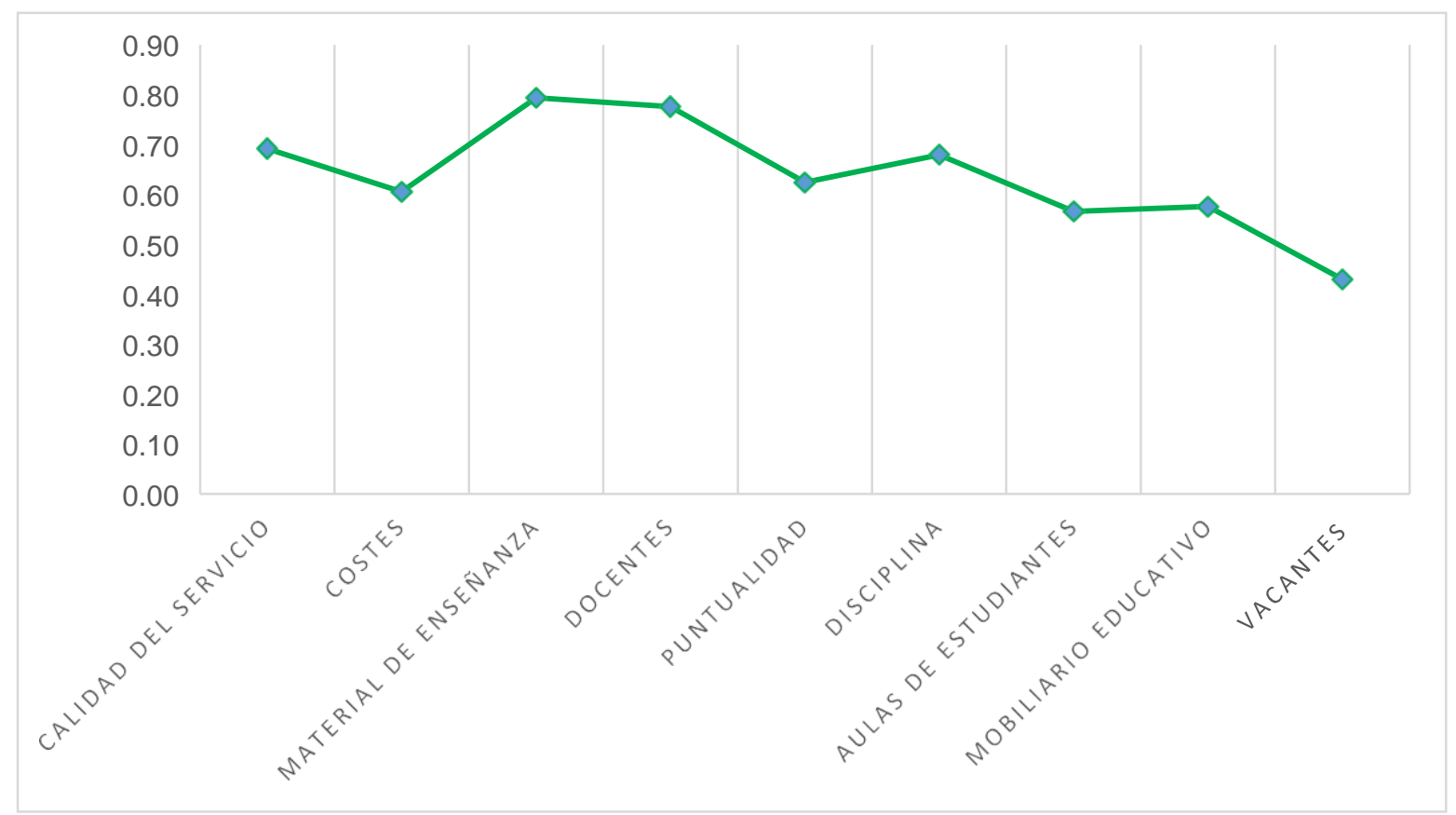

Figura 8. Lienzo actual de la estrategia de la IEP Santiago Apóstol. Elaboración propia.

\subsubsection{Lienzo de la estrategia de la industria.}

Para elaborar el lienzo de la estrategia de la industria, se ha tomado como base las encuestas realizadas a los clientes del IEP Santiago Apóstol (ver Anexos 2 y 3). En dichas encuestas se ha considerado a los principales competidores, tales como IEP Didaskalio San José Obrero, Fleming. que están ubicadas en el Distrito de Santiago de la Ciudad del Cusco llegando a los siguientes resultados:

En la figura líneas abajo muestra que los niveles de las variables, material de enseñanza, docentes y mobiliario educativo son iguales a la oferta actual de la IEP Santiago Apóstol. Sin embargo, la diversidad de clases sociales de donde proceden los estudiantes, hace que los padres de familia según recursos económicos elijan el tipo de institución educativa va a preferir para sus hijos. 


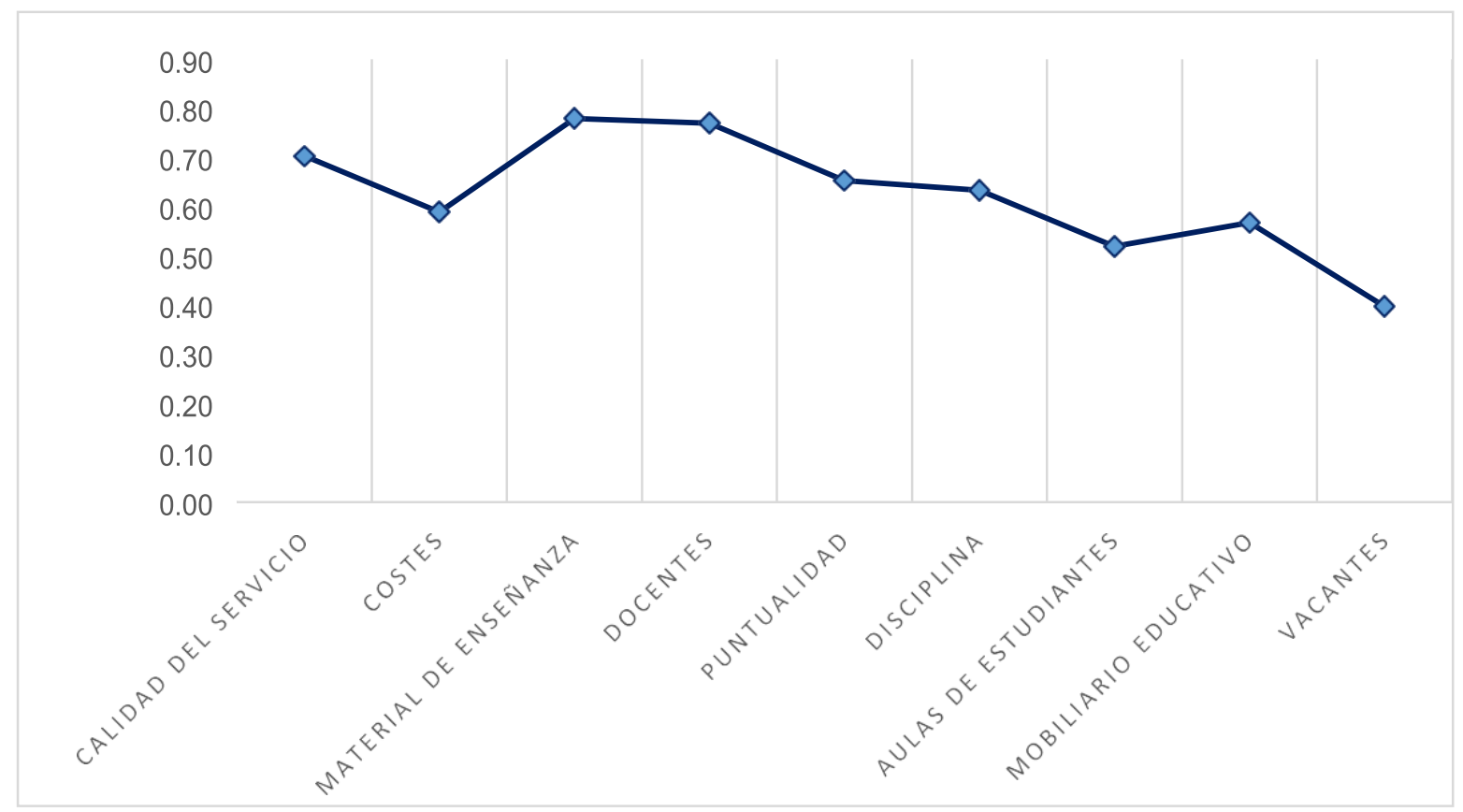

Figura 9. Lienzo de la estrategia actual de la industria. Elaboración propia.

\subsubsection{Matriz (Eliminar, Reducir, Incrementar, Crear).}

Según Kim y Mauborgne (2005). La matriz “eliminar-incrementar-reducir-crear” promueve a la empresa a hacerse las siguientes preguntas:

- ¿Cuáles variables que la industria da por sentadas se deben eliminar?

- ¿Cuáles variables se deben reducir muy por debajo de la norma de la industria?

- ¿Cuáles variables se deben incrementar muy por encima de la norma de la industria?

- ¿Cuáles variables se deben de crear porque la industria nunca las ha ofrecido?

Tabla 36

Matriz "eliminar-incrementar-reducir-crear"

\begin{tabular}{cc}
\hline ELIMINAR & $\begin{array}{c}\text { REDUCIR } \\
\text { - Costos }\end{array}$ \\
\hline INCREMENTAR & CREAR \\
- Docentes & - Vacantes \\
- Aulas para los estudiantes & \\
- Mobiliario educativo & \\
\hline
\end{tabular}


Nota. Elaboración propia

La matriz "eliminar-incrementar-reducir-crear" sugiere las siguientes estrategias;

- Se debe reducir los costos de consumo para potenciar la inversión en el local para los estudiantes.

- Se debe crear vacantes para estudiantes en vista que son escasos en la IEP Santiago Apóstol para los niños y adolescentes del distrito de Santiago aplicando publicidad, promoción y ofertas de estudios.

- Se debe incrementar el número aulas debidamente implementadas para poder albergar mayor cantidad de estudiantes que precisarán más docentes.

\subsubsection{Matrices de Formulación de Estrategias.}

\subsubsection{Matriz FODA.}




\section{FORTALEZAS - F}

1. Ubicación geográfica estratégica.

2. Lealtad de clientes.

3. Docentes calificados.

\section{MATRIZ FODA}

4. Clima laboral favorable.

5. Desarrollo de actividades académicas, culturales y deportivas

\section{DEBILIDADES - D}

1. Infraestructura alquilada.

2. Capacidad instalada insuficiente para la demanda de estudiantes.

3. Falta de medios para la investigación de mercado.

4. Demora en cobro de mensualidad (Cartera atrasada).

\section{OPORTUNIDADES - 0}

1. Inadecuada aplicación del Currículo Nacional de Educación Básica en las instituciones educativas

2. Incremento de la capacidad de Gasto de los NSE C y D

3. Beneficios tributarios y exoneraciones a empresas del Sector Educación.

4. Deficiencia en la implementación tecnológica en el Sector Público.

5. Implementación del enfoque ambiental para el Sector Educación

\section{AMENAZAS - A}

1. Aparición de nuevas instituciones educativas y corporaciones educativas con más experiencia y capacidad de inversión.

2. Competencia en función a la oferta de precios.

3. Proyecciones de crecimiento de la población en edad escolar se mantiene en el mismo rango desde el 2012, aunque en el distrito de Santiago se incrementa.

4. Ofertas laborales para el sector Público por la Reforma Magisterial Peruana

\section{ESTRATEGIAS -FO}

Desarrollar técnicas personalizadas de enseñanza para fortalecer el modelo educativo de la IEP. (F2, O1, O4). Realizar capacitación a los docentes con convenios y

programas de educación con nuevos enfoques de

$$
\text { enseñanza. (F3, F4, O1). }
$$

Adicionar al currículo vigente talleres extra curriculares

de acuerdo a los intereses particulares del estudiante,

con el fin de desarrollar sus competencias. (F2, F5, O1,

$$
\mathrm{O} 2)
$$

\section{ESTRATEGIAS -FA}

Realizar promociones de descuentos a familiares de los egresados (F2, F5, A1, A3)

Desarrollar formación técnica productiva en los

estudiantes mediante convenios con institutos superiores (F2, F3, A1, A2).

Crear convenios de capacitación con Universidades para los docentes (F3, F4, A4)

\section{ESTRATEGIAS -DO}

Mejorar los procesos internos de la IEP optimizando la distribución de costos y gastos (D1. D4, O2, O3).

Creación de una nueva institución educativa en la periferia del distrito de Santiago (D1, D2, D3,O2, O3 )

Creación del nivel inicial de estudiantes (D2, D3, O2, O4)

Crear una base de datos para realizar seguimiento a la

satisfacción de los padres de familia y alumnos. (D3, O $\mathrm{O} 2)$

\section{ESTRATEGIAS -DA}

Alquilar un local más amplio en beneficio de los estudiantes. (D1, D2, D3, A1, A3). 


\section{FORMULACIÓN DE ESTRATEGIAS:}

\section{ESTRATEGIAS -FO}

1) Desarrollar técnicas personalizadas de enseñanza para fortalecer el modelo educativo de la IEP. (F2, O1, O4).

2) Realizar capacitación a los docentes con convenios y programas de educación con nuevos enfoques de enseñanza. (F3, F4, O1).

3) Adicionar al currículo vigente talleres extra curriculares de acuerdo a los intereses particulares del estudiante, con el fin de desarrollar sus competencias. (F2, F5, O1, O2) ESTRATEGIAS -DO

1) Mejorar los procesos internos de la IEP optimizando la distribución de costos y gastos. (D1. D4, O2, O3).

2) Creación de una nueva institución educativa en la periferia del distrito de Santiago (D1, $\mathrm{D} 2, \mathrm{D} 3, \mathrm{O} 2, \mathrm{O} 3$ )

3) Creación del nivel inicial de estudiantes (D2, D3, O2, O4)

4) Crear una base de datos para realizar seguimiento a la satisfacción de los padres de familia y alumnos. (D3, O1 O2).

\section{ESTRATEGIAS -FA}

1) Realizar promociones de descuentos a familiares de los egresados (F2, F5, A1, A3)

2) Desarrollar formación técnica productiva en los estudiantes mediante convenios con institutos superiores. (F2, F3, A1, A2).

3) Crear convenios de capacitación con Universidades para los docentes (F3, F4, A4) ESTRATEGIAS -DA

1) Alquilar un local más amplio en beneficio de los estudiantes. (D1, D2, D3, A1, A3). 


\subsubsection{Matriz PEYEA.}

Según D’Alessio (2006, p. 281) la matriz PEYEA es usada para determinar la apropiada postura estratégica de una organización o de sus unidades de negocio. La matriz PEYEA (SPACE, en inglés) tiene dos ejes que combinan factores relativos a la industria (fortaleza de la industria y estabilidad del entorno) y dos ejes que combinan factores relativos a la organización (fortaleza financiera y ventaja competitiva) en extremos de alto y bajo que forman un marco de cuatro cuadrantes, cada uno asociado con una postura estratégica básica: agresiva, conservadora, defensiva, o competitiva.

Los ejes de la matriz PEYEA representan dos dimensiones internas: las fuerzas financieras (FF) y las ventajas competitivas (VC) y dos dimensiones externas: la estabilidad del entorno (EA) y la fuerza de la industria (FI).

Según David (2013, p. 179) los pasos necesarios para desarrollar una matriz PEYEA son:

Seleccionar un conjunto de variables para definir la fuerza financiera $(\mathrm{FF})$, la ventaja competitiva (VC), la estabilidad del entorno (EE) y la fuerza de la industria (FI).

Asignar un valor numérico de +1 (la peor) a +7 (la mejor) a cada una de las variables que integran las dimensiones FF y FI. Asignar un valor numérico de -1 (la mejor) a -7 (la peor) a cada una de las variables que integran las dimensiones EE y VC. En los ejes FF y VC, hacer una comparación con los competidores. En los ejes FI y EE, hacer una comparación con otras industrias.

- Calcular la puntuación promedio para FF, VC, FI y EE sumando los valores otorgados a las variables en cada dimensión, y dividiendo el resultado entre el número de variables incluidas en la dimensión respectiva. 
- Graficar las puntuaciones promedio para FF, FI, EE y VC sobre el eje correspondiente de la matriz PEYEA.

- Sumar las dos puntuaciones del eje x y trazar el punto resultante en X. Sumar las dos puntuaciones del eje y, y trazar el punto resultante en Y. Trazar la intersección del nuevo punto xy.

- Trazar un vector direccional que vaya desde el origen de la matriz PEYEA hasta el punto de intersección. Este vector indica el tipo de estrategias recomendadas para la organización: agresiva, competitiva, defensiva o conservadora.

En la IEP Santiago Apóstol se han identificado las siguientes dimensiones internas:

- FUERZAS FINANCIERAS (FF)

Para determinar las fuerzas financieras de la IEP Santiago Apóstol se ha tomado en cuenta los factores propuestos por David (2013) que se adaptan en cierta medida al estudio, para su mejor compresión se han obtenido los resultados aplicados según ratios financieros de los estados financieros al 31 de diciembre de 2017 de la IEP Santiago Apóstol y criterios técnicos determinados y realizados con apoyo del director de la institución, parte administrativa, docentes y estudiantes. 
Tabla 38

Fuerzas Financieras FF

\begin{tabular}{cc}
\hline Fuerza financiera (FF) & Rating \\
\hline El rendimiento sobre la inversión ROI = 0.15, por cada sol invertido en los activos produjo en el & 3 \\
período 2017 un rendimiento de 15\% sobre la inversión, a comparación del 2016 que fue 19\%. & 3 \\
El apalancamiento es 0.40, el 40\% de los activos totales es financiado por los acreedores y de & \\
liquidarse estos activos totales al precio en libros quedaría un saldo de 60\% de su valor, después del & 4 \\
pago de las obligaciones vigentes, el año 2016 fue de 52\%. & \\
La liquidez es 2.10 quiere decir que el activo corriente es 2.10 veces más grande que el pasivo & 5 \\
corriente; o que, por cada sol de deuda, la IEP cuenta con S/ 2.10 para pagarla, se mantuvo constante & 5 \\
entre el 2016 y 2017. & 4 \\
El capital de trabajo es S/ 7,909 & 4 \\
El flujo de efectivo es S/ 44,937 & 5 \\
el Distrito de Santiago. & 5 \\
\hline La facilidad de salir del mercado es un 20\% ya que existe la necesidad de educación básica regular en & 30 \\
\hline Pos riesgos implícitos en el negocio serian un 10\% ya que los servicios de educación son rentables. & \\
\hline
\end{tabular}

- VENTAJAS COMPETITIVAS (VC)

Para determinar las ventajas competitivas de la IEP Santiago Apóstol se ha tomado en cuenta los factores propuestos por David (2013) que se adaptan en cierta medida al estudio, para su mejor compresión se han trabajado con criterios técnicos del estudio de la industria.

Tabla 39

Ventaja Competitiva VC

\begin{tabular}{cc}
\hline Ventaja Competitiva (VC) & Rating \\
\hline La participación en el mercado es 7\% & -4 \\
La calidad del servicio es 67\% según encuesta (anexos 5 y 6) & -3 \\
El ciclo de vida del servicio & -3 \\
La lealtad de los clientes & -4 \\
La utilización de la capacidad de la competencia & -4 \\
Los conocimientos tecnológicos prácticos & -3 \\
El control sobre los proveedores y distribuidores & -4 \\
\hline Promedio = -25/7 =-3.57 & -25 \\
\hline
\end{tabular}

- ESTABILIDAD DEL AMBIENTE (EA)

Según el análisis realizado del entorno de la IEP Santiago Apóstol se ha tomado en cuenta los factores propuestos por David (2013) que se adaptan en cierta medida al estudio, se han trabajado con los siguientes resultados obtenidos del estudio del ambiente. 
Tabla 40

Estabilidad del entorno EE

\begin{tabular}{ccc}
\hline Estabilidad del entorno (EE) & Rating \\
\hline Los cambios tecnológicos en educación & -3 \\
La tasa inflacionaria en el país que cerro el período 2017 es $1.36 \%$ & -4 & -4 \\
La variabilidad de la demanda en educación & -5 & -5 \\
El rango de precios de la competencia & -6 & -5 \\
Las barreras de ingreso al Mercado & La Presión competitiva & -32 \\
La elasticidad precio de la demanda respecto a sus competidores es una demanda inelástica. & \\
Promedio $=-32 / 7=-4.57$ &
\end{tabular}

- FUERZA DE LA INDUSTRIA (FI)

Durante el período 2011-2017, la tasa de crecimiento de las matrículas ha sido de 3.53\% en los niveles de Primaria y Secundaria para el distrito de Santiago. Pasando de 3,115 matrículas es 2011 a 3,770 al 2017 (véase tabla 9). Ya que las utilidades dependen del número de matrículas se espera un potencial creciente en el futuro. La industria tiene estabilidad financiera ya que no se han realizado inversiones importantes en el sector en los últimos años. Por otro lado, no se tiene facilidad de ingreso al mercado ya que los costos de inversión promedios de la industria son muy altos, limitando el acceso de nuevos colegios. En la tabla 41, se han tomado en cuenta los factores propuestos por David (2013) para hallar el promedio de la fuerza de la industria. 
Tabla 41

Fuerza de la industria

\begin{tabular}{cc}
\hline Fuerza de la industria (FI) & Rating \\
\hline El potencial de crecimiento & 4 \\
El potencial de utilidades & 4 \\
La estabilidad financiera & 5 \\
El grado de apalancamiento & 5 \\
La utilización de los recursos & 4 \\
La facilidad de ingreso al mercado & 1 \\
La productividad, utilización de la capacidad & 3 \\
\hline Promedio $=26 / 7=3.71$ & 26 \\
\hline
\end{tabular}

En conclusión:

El promedio para la EE es $-4.57 \quad$ El promedio para la FI es 3.71

El promedio para la VC es $-3.57 \quad$ El promedio para la FF es 4.29

El vector direccional coordina: eje $\mathrm{x}:-4.57+4.29=-0.28$

eje $y:-3.57+3.71=0.14$

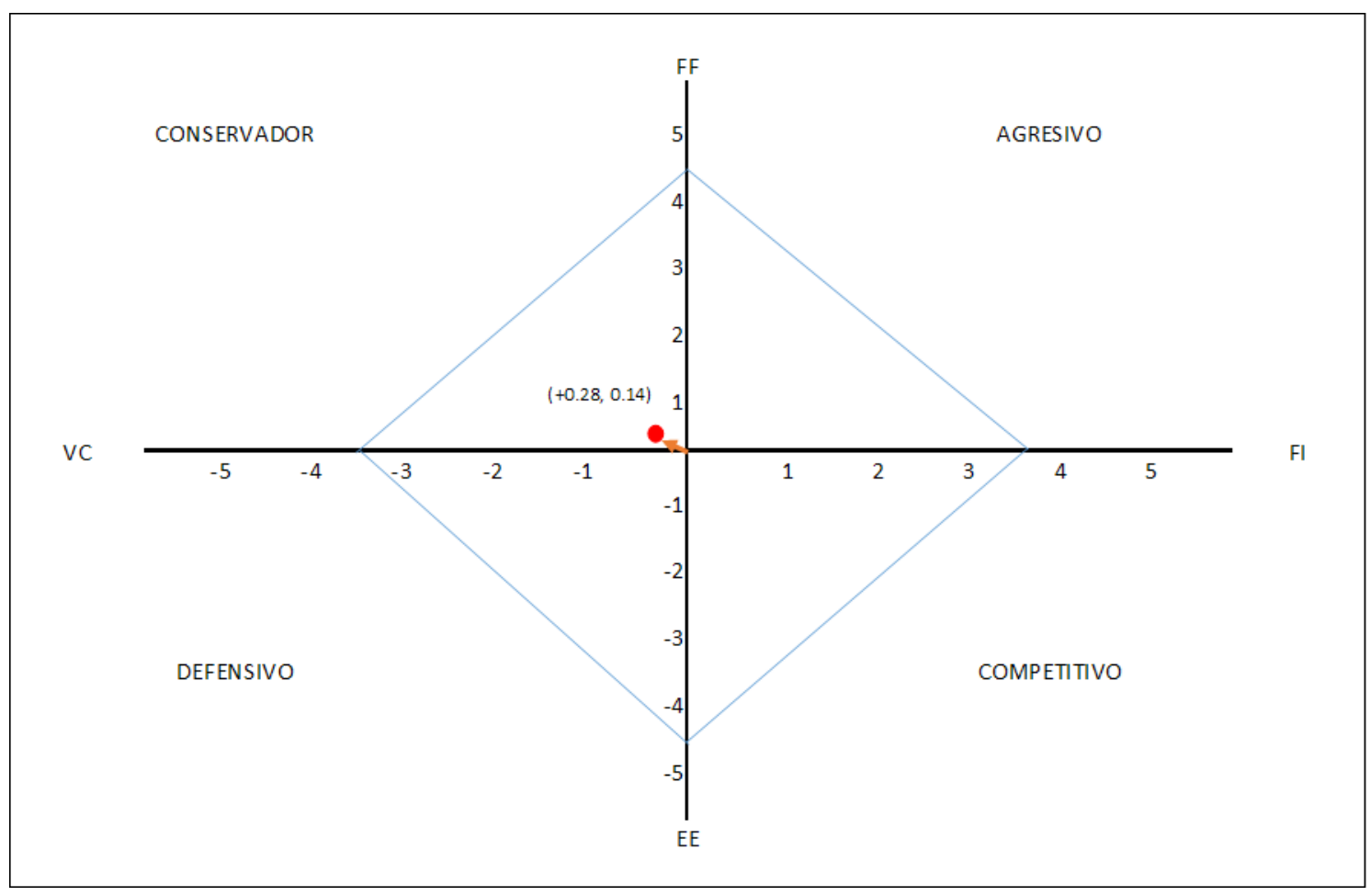

Figura 10. Matriz PEYEA de la IEP Santiago Apóstol. Elaboración propia. 
La IEP Santiago Apóstol tiene un perfil conservador que adolece de ventajas competitivas importantes en una industria tecnológicamente estable, ha logrado cierta solidez financiera, pero sin crecimiento en ventas.

\subsubsection{Matriz interna y externa.}

Para la creación de la matriz IE se tomaron los valores obtenidos de la matriz EFI de valor 2.44 y de la Matriz EFE de valor 2.72 estos se agruparon de la siguiente forma en el plano Cartesiano:

- Eje X estará definido por la Matriz EFE

- Eje Y estará definido por la Matriz EFI

- Los rangos mínimos y máximo serán 1 y 4 respectivamente

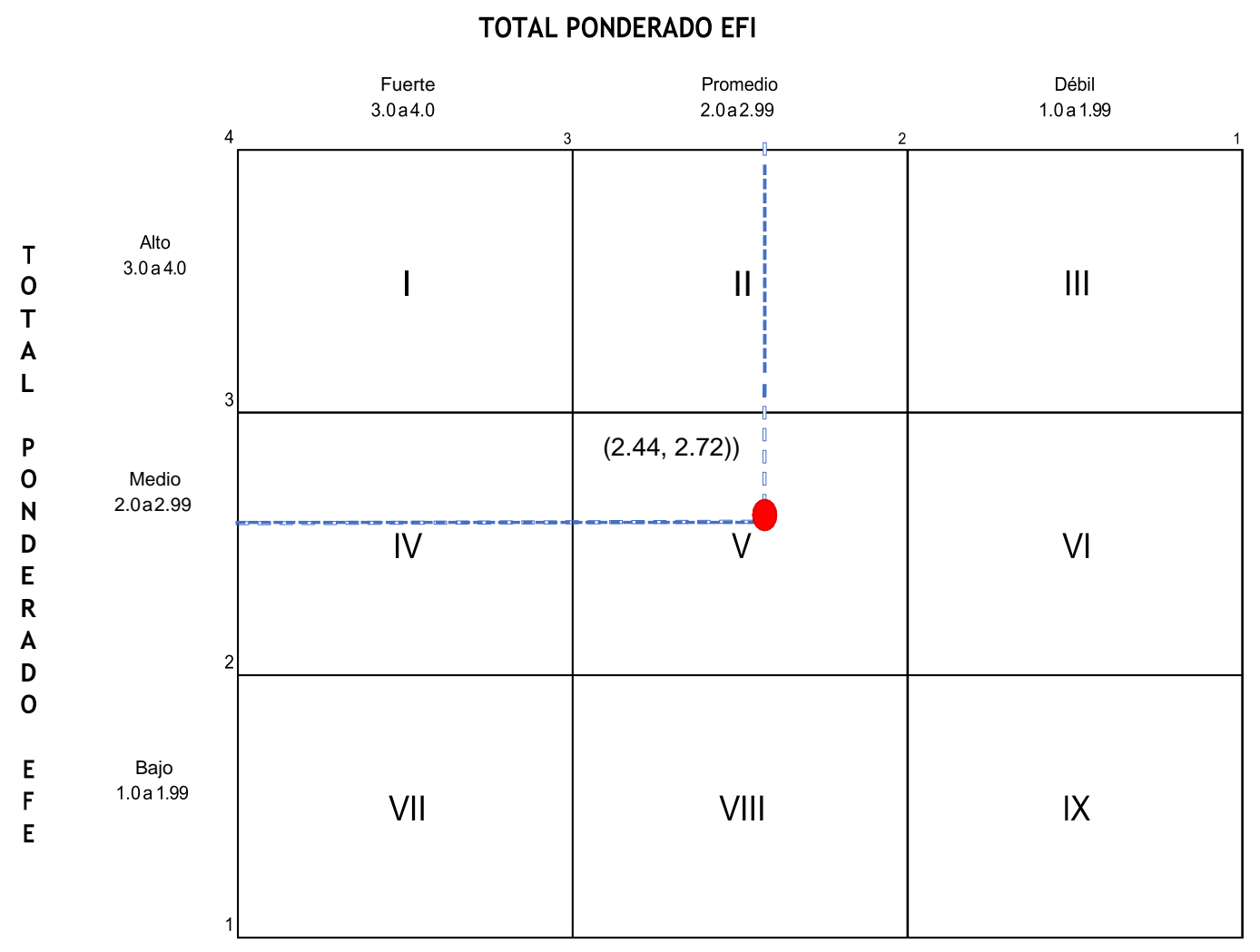

Figura 11. Matriz interna y externa de la IEP Santiago Apóstol. Elaboración propia 
La ubicación de la IEP Santiago Apóstol en la matriz está ubicado en prescripción "retener y mantener", lo que significa que las decisiones correspondientes deben ser: mejorar los procesos y aumentar moderadamente las ventas, por encontrarse en un mercado de alta competencia. Sin embargo, la IEP Santiago Apóstol se encuentra en una buena posición en relación a los competidores, adicionalmente también es recomendable mejorar los procesos internos para reducir los costos y ello se refleje en los resultados financieros.

\subsubsection{Matriz de la gran estrategia.}

El propósito de esta matriz considera evaluar el crecimiento del mercado y la posición competitiva de la empresa.

Según ESCALE, el número de matrículas dentro de la educación básica regular del sector privado asciende al $0.4 \%$ en los últimos tres años.

En lo concerniente al departamento del Cusco, para los años 2014, 2015 y 2016 el número de las matrículas dentro de la educación primaria de la gestión privada, el promedio de crecimiento fue de 4.4\%. Mientras que el número de Matrículas dentro de la educación secundaria privada, mostró un descenso promedio de $1.5 \%$,

Por otro lado, en la gestión pública del sector se observa un crecimiento en las matrículas del nivel secundario, demostrando la posibilidad de poder atraer nuevos clientes para la IEP Santiago Apóstol. 


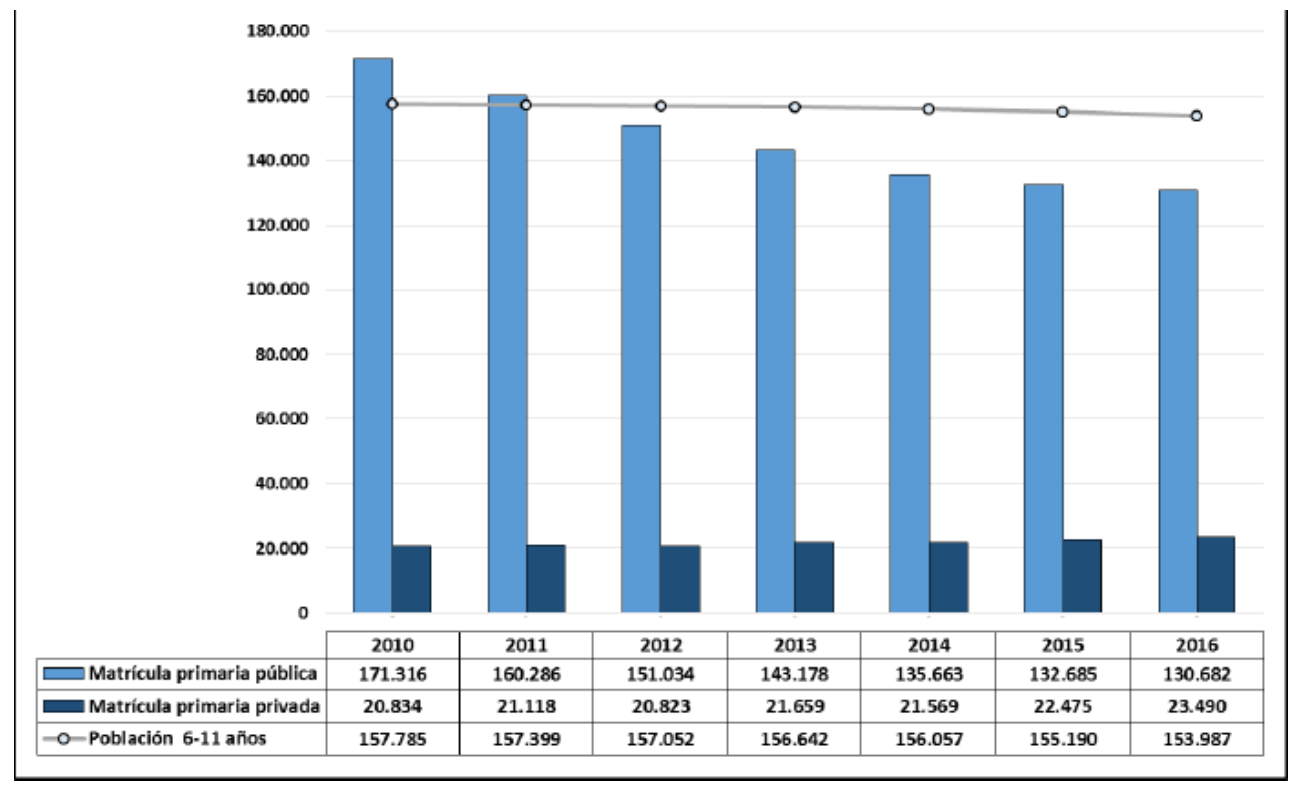

Figura 12. Población y matrícula en edad escolar de educación primaria en Cusco, 2010 - 2016.

Proyecciones población INEI 2016 y Censo Escolar del Ministerio de Educación.

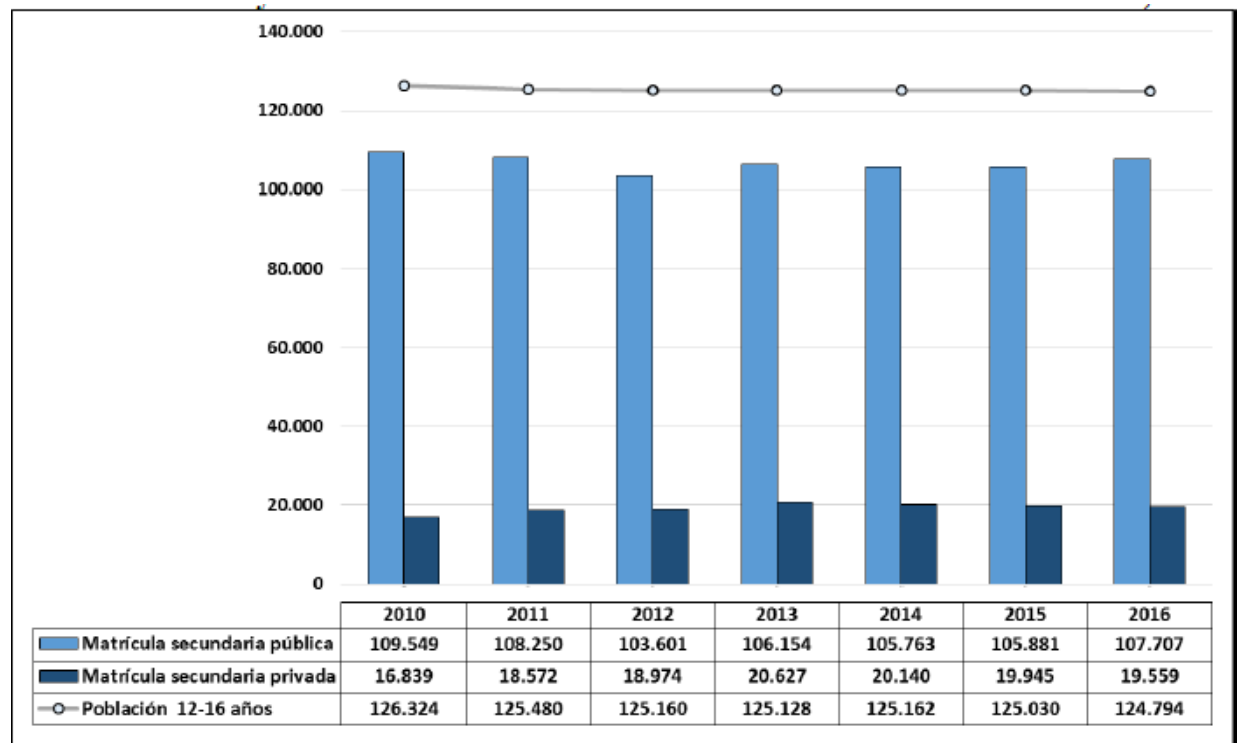

Figura 13. Población y matrícula en edad escolar de educación secundaria en Cusco, 2010-2016.

Proyecciones población INEI, 2016 y Censo Escolar del Ministerio de Educación. Elaboración propia 
La IEP Santiago Apóstol, actualmente ofrece un servicio de educación básica regular dentro de los estándares promedio, de acuerdo a la Unidad de Gestión Educativa Local Cusco, por lo tanto, no se tiene atributos que logren diferenciar su servicio, no ha variado los precios de pensiones durante los tres últimos años. Debido a su capacidad instalada insuficiente para cubrir la demanda de estudiantes no se ha logrado obtener estrategias para abaratar costos.

La IEP Santiago Apóstol, ha orientado su servicio a un segmento específico, únicamente buscan brindar su servicio a los niños que viven en el distrito de Santiago que pertenecen al nivel socio económico C y D.

Por lo expuesto, se concluye que la IEP Santiago Apóstol está ubicada en el cuadrante II, requiere evaluar seriamente su posición en el mercado, a pesar que su sector está en crecimiento no tiene capacidad de competir debe evaluar y realizar estrategias para cambiar estos resultados.

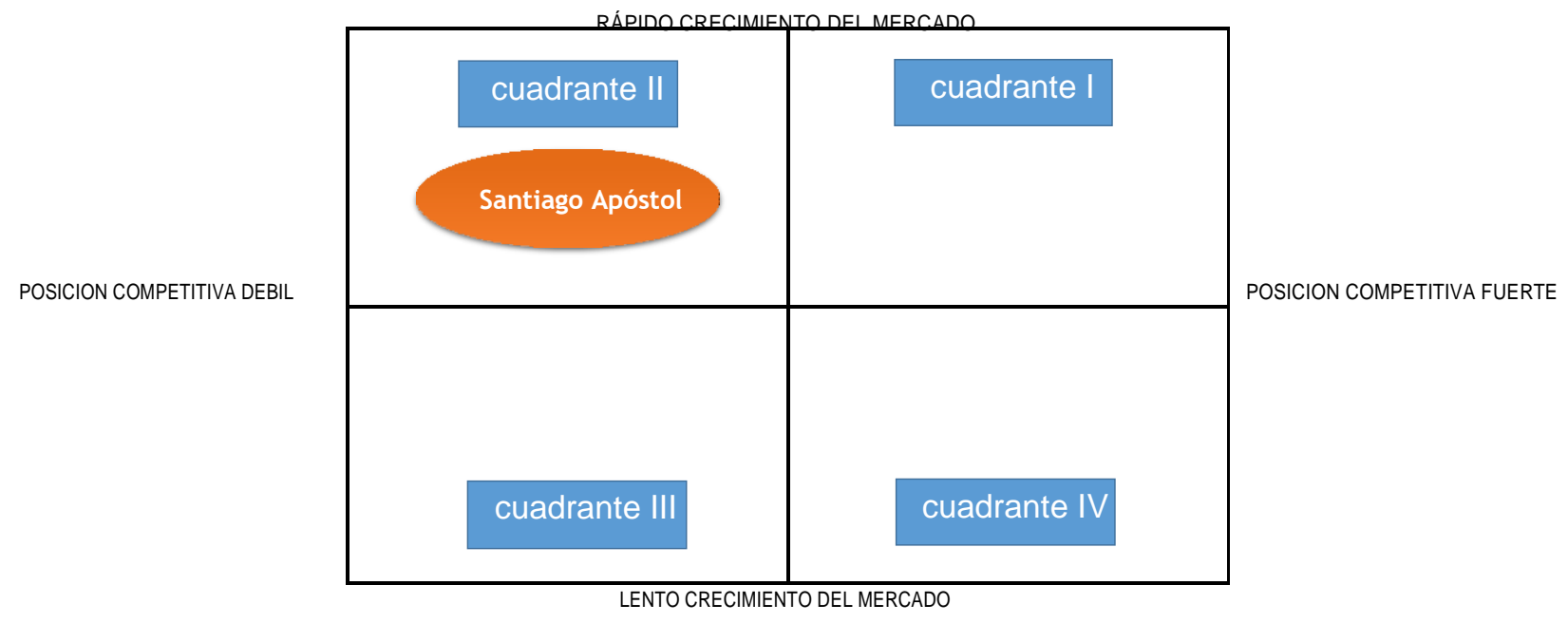

Figura 14. Posición de la IEP Santiago Apóstol. Elaboración propia 


\section{Capítulo VII. Selección de la Estrategia}

Se formularán las estrategias para el desarrollo de la IEP. Santiago Apóstol, siguiendo con el proceso estratégico recomendado por D'Alessio (2006). El estudio expondrá la necesidad de establecer un plan estratégico educativo de calidad considerando la visión y misión.

El proceso estratégico, se trabaja con cuatro matrices:

- MFODA (Matriz de fortalezas, oportunidades, debilidades y amenazas)

- MPEYEA (Matriz de la posición estratégica y evaluación de la acción)

- IE (Matriz de factores internos - externos), y

- GE (Matriz de la gran estrategia).

Como resultado se obtendrán las estrategias competitivas de mayor atractivo para la institución, las que serán seleccionadas utilizando la matriz de decisión estratégica (MDE) que resume los resultados de las matrices del proceso estratégico, luego se procederá a la selección de las estrategias que serán evaluadas en la matriz cuantitativa de planeamiento estratégico (MCPE).

\subsection{Método Factores Estratégicos Clave.}

En este punto se escogerán las estrategias más convenientes de acuerdo a los análisis de lo anteriormente expuesto.

\subsubsection{Criterios de selección.}

Del resultado del análisis obtenido de las matriz FODA se han determinado 11 estrategias, que serán calificadas según el tipo de estrategia de las matrices PEYEA, IE y GE y la que obtenga mayor puntaje por su repetición.

\subsubsection{Matriz de la decisión}


Según D’Alessio (2006, p. 332), la matriz de la decisión permite apreciar las repeticiones de las estrategias que se aplican en las diferentes matrices como FODA, PEYEA, IE y GE, de estas estrategias se elegirán las que se repitan por lo menos en 2 matrices.

En la tabla 42 se puede observar que existen 2 estrategias que se repiten en tres de las matrices efectuadas obteniendo un puntaje de 3. De estas se seleccionará la estrategia principal y la contingente y las de puntajes menores complementaran la estrategia principal.

- Adicionar al currículo vigente talleres extra curriculares de acuerdo a los intereses particulares del estudiante, con el fin de desarrollar mayores competencias.

- Mejorar los procesos internos de la IEP optimizando la distribución de costos y gastos.

Tabla 42

Matriz de decisión de la Estrategia

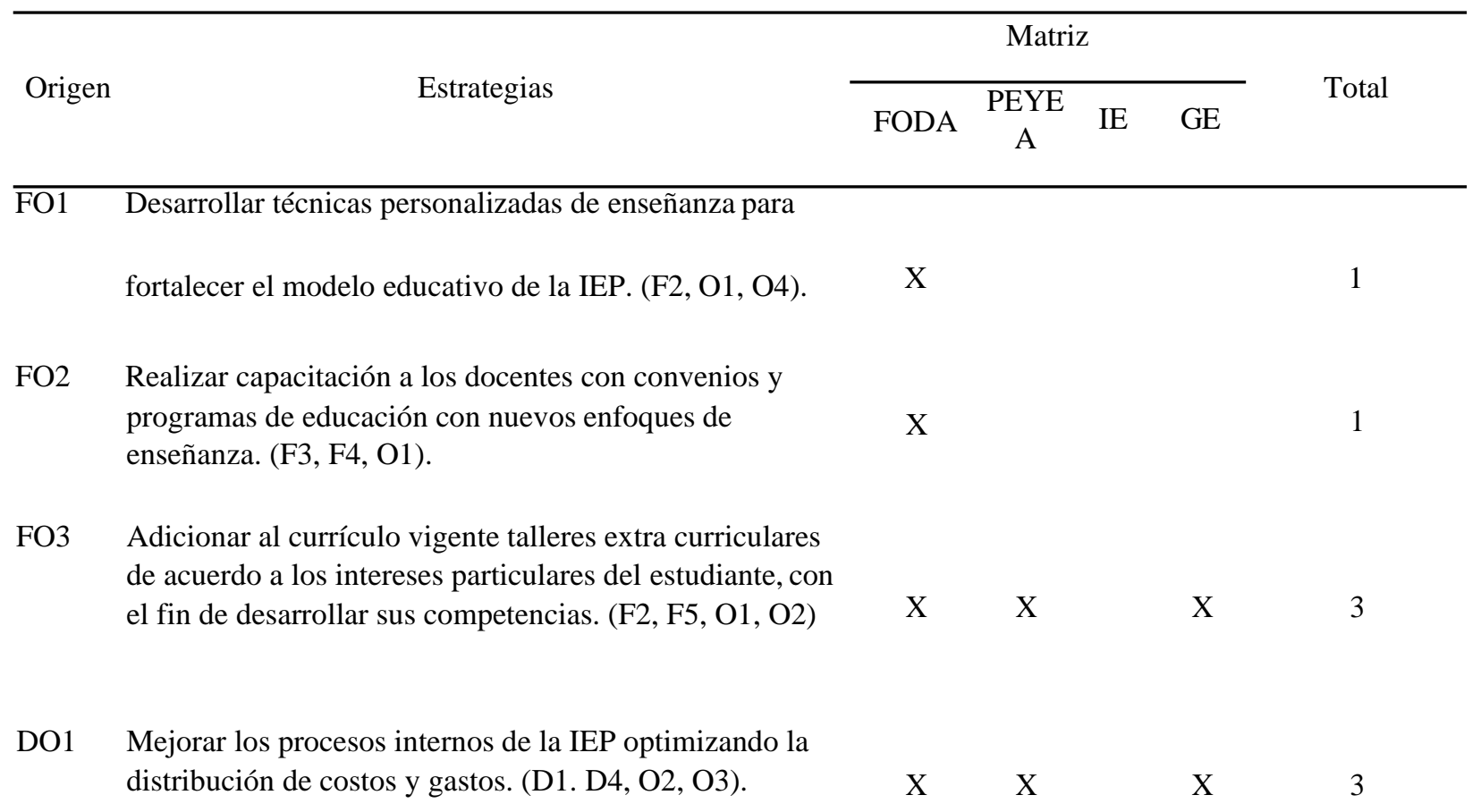


DO2 Creación de una nueva institución educativa en la periferia del distrito de Santiago (D1, D2, D3,O2, O3 )

X $\quad \mathrm{X}$

2

DO3 Creación del nivel inicial de estudiantes (D2, D3, O2, O4)

DO4 Crear una base de datos para realizar seguimiento a la satisfacción de los padres de familia y alumnos. (D3, O1 $\mathrm{O} 2)$.

FA1 Realizar promociones de descuentos a familiares de los egresados (F2, F5, A1, A3)

FA2 Desarrollar formación técnica productiva en los estudiantes mediante convenios con institutos superiores. $\quad \mathrm{X}$ (F2, F3, A1, A2).

FA3 Crear convenios de capacitación con Universidades para los docentes (F3, F4, A4)

DA1 Alquilar un local más amplio en beneficio de los estudiantes. (D1, D2, D3, A1, A3).
X $\quad \mathrm{X}$

$\begin{array}{lll}\mathrm{X} & 2\end{array}$

$\mathrm{X}$

1

X 2
X 1

X 1

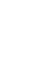

Nota. Elaboración propia

Para calificar las estrategias es conveniente desarrollarlas de acuerdo a los criterios de selección de Rumelt (matriz de Rumelt) Tabla 43, quien propuso los siguientes criterios:

- Congruencia, significa que la estrategia no debe presentar metas y objetivos incongruentes.

- Consonancia, en este caso la estrategia debe mostrar adaptabilidad y estar acorde con el entorno externo y los cambios críticos que sucedan.

- Ventaja, la estrategia debe asegurar la creación y el mantenimiento de una ventaja competitiva en un área de actividad seleccionada.

- Factibilidad, la estrategia a aplicar no debe generar sobrecostos en los recursos que se encuentran disponibles ni crear problemas que no puedan solucionarse.

- De acuerdo a estos criterios construiremos la matriz de RUMELT. 
Tabla 43

Matriz de RUMELT

\begin{tabular}{|c|c|c|c|c|c|}
\hline Estrategias & Consistencia & Consonancia & Factibilidad & Ventaja & Se Acepta \\
\hline $\begin{array}{l}\text { Adicionar al currículo vigente talleres extra } \\
\text { curriculares de acuerdo a los intereses } \\
\text { particulares del estudiante, con el fin de } \\
\text { desarrollar sus competencias. (F2, F5, O1, O2) }\end{array}$ & $\mathrm{Si}$ & $\mathrm{Si}$ & $\mathrm{Si}$ & $\mathrm{Si}$ & $\mathrm{Si}$ \\
\hline $\begin{array}{c}\text { Mejorar los procesos internos de la IEP } \\
\text { optimizando la distribución de costos y gastos. } \\
\text { (D1. D4, O2, O3). }\end{array}$ & $\mathrm{Si}$ & $\mathrm{Si}$ & $\mathrm{Si}$ & $\mathrm{Si}$ & $\mathrm{Si}$ \\
\hline
\end{tabular}

Nota. Elaboración propia

\subsubsection{Matriz cuantitativa del planeamiento estratégico.}

Para crear una lista jerarquizada, existe una técnica analítica para determinar el atractivo relativo de las posibles acciones alternativas. (David, 2013) Esta técnica es la matriz cuantitativa de la planificación estratégica (MCPE) que permite efectuar una elección objetiva de las estrategias alternativas.

La Matriz de Selección cuenta con los factores de éxito claves siguientes:

- Factores estratégicos

- Factores financieros

- Factores tecnológicos

- Factores de proceso

- Factores humanos

- Factores ambientales

Cada Factor se le asignará un peso como calificación de acuerdo a la ponderación para la IEP Santiago Apóstol.

E1: Adicionar al currículo vigente talleres extra curriculares de acuerdo a los intereses particulares del estudiante, con el fin de desarrollar mayores competencias. 


\section{E2: Mejorar los procesos internos de la IEP optimizando la distribución de costos y gastos}

\section{Tabla 44}

\section{Matriz cuantitativa del planeamiento estratégico}

\begin{tabular}{|c|c|c|c|c|c|}
\hline \multirow{2}{*}{ Factores Internos y Externos Clave } & \multirow{2}{*}{ Peso } & \multicolumn{2}{|c|}{ E1 } & \multicolumn{2}{|c|}{ E2 } \\
\hline & & Puntaje & Ponderación & Puntaje & Ponderación \\
\hline \multicolumn{6}{|l|}{ Oportunidades } \\
\hline $\begin{array}{c}\text { Inadecuada aplicación del Currículo Nacional } \\
\text { de Educación Básica en las instituciones } \\
\text { educativas. }\end{array}$ & 0.14 & 2 & 0.28 & 2 & 0.28 \\
\hline $\begin{array}{l}\text { Incremento de la capacidad de Gasto de los } \\
\text { NSE C y D }\end{array}$ & 0.15 & 2 & 0.3 & 3 & 0.45 \\
\hline $\begin{array}{l}\text { Beneficios tributarios y exoneraciones a } \\
\text { empresas del Sector Educación. }\end{array}$ & 0.08 & 1 & 0.08 & 1 & 0.08 \\
\hline $\begin{array}{c}\text { Deficiencia en la implementación tecnológica } \\
\text { en el Sector Público. }\end{array}$ & 0.09 & 1 & 0.09 & 2 & 0.18 \\
\hline $\begin{array}{l}\text { Implementación del enfoque ambiental para el } \\
\text { Sector Educación }\end{array}$ & 0.06 & 2 & 0.12 & 3 & 0.18 \\
\hline \multicolumn{6}{|l|}{ Amenazas } \\
\hline $\begin{array}{l}\text { Aparición de nuevas instituciones educativas y } \\
\text { corporaciones educativas con más experiencia y } \\
\text { capacidad de inversión. }\end{array}$ & 0.09 & 3 & 0.27 & 4 & 0.36 \\
\hline Competencia en función a la oferta de precios. & 0.13 & 3 & 0.39 & 4 & 0.52 \\
\hline $\begin{array}{l}\text { Proyecciones de crecimiento de la población en } \\
\text { edad escolar se mantiene en el mismo rango } \\
\text { desde el 2012, aunque en el distrito de Santiago } \\
\text { se incrementa. }\end{array}$ & 0.14 & 2 & 0.28 & 3 & 0.42 \\
\hline $\begin{array}{c}\text { Ofertas laborales para el sector Público por la } \\
\text { Reforma Magisterial Peruana }\end{array}$ & 0.12 & 2 & 0.24 & 4 & 0.48 \\
\hline \multicolumn{6}{|l|}{ Fortalezas } \\
\hline Ubicación geográfica estratégica. & 0.13 & 2 & 0.26 & 4 & 0.52 \\
\hline Lealtad de clientes. & 0.10 & 4 & 0.4 & 4 & 0.4 \\
\hline Docentes calificados. & 0.12 & 4 & 0.48 & 3 & 0.36 \\
\hline Clima laboral favorable. & 0.14 & 2 & 0.28 & 4 & 0.56 \\
\hline $\begin{array}{l}\text { Desarrollo de actividades académicas, culturales } \\
\text { y deportivas }\end{array}$ & 0.09 & 4 & 0.36 & 3 & 0.27 \\
\hline \multicolumn{6}{|l|}{ Debilidades } \\
\hline Infraestructura alquilada. & 0.14 & 2 & 0.28 & 4 & 0.56 \\
\hline $\begin{array}{c}\text { Capacidad instalada insuficiente para la } \\
\text { demanda de estudiantes. }\end{array}$ & 0.12 & 3 & 0.36 & 4 & 0.48 \\
\hline $\begin{array}{l}\text { Falta de medios para la investigación de } \\
\text { mercado. }\end{array}$ & 0.09 & 3 & 0.27 & 3 & 0.27 \\
\hline $\begin{array}{c}\text { Demora en cobro de mensualidad (Cartera } \\
\text { atrasada). }\end{array}$ & 0.07 & 1 & 0.07 & 3 & 0.21 \\
\hline Total & 2.00 & & 4.81 & & 6.58 \\
\hline
\end{tabular}

Nota. Elaboración propia 
De acuerdo a la Matriz cuantitativa del planeamiento estratégico (tabla 40), la estrategia más adecuada es la estrategia 2 Mejorar los procesos internos de la IEP optimizando la distribución de costos y gastos, cuya puntuación es de 6.58. Por su parte, la estrategia 1: Adicionar al currículo vigente talleres extra curriculares de acuerdo a los intereses particulares del estudiante, con el fin de desarrollar nuevos productos que generen mayores ingresos, obtuvo una puntuación de 4.81. Teniendo en cuenta dicho análisis, es posible implementar ambas estrategias para que el Plan Estratégico tenga éxito en el período 2018 - 2023. La estrategia 1 será nuestra estrategia alterna.

\subsection{Método de Escenarios}

Según Johnson, Scholes, \& Whittington (2006, p. 76):

"Los escenarios son descripciones detalladas y posibles de cómo se puede desarrollar el entorno empresarial de una organización en el futuro, a partir de la agrupación de influencias claves del entorno y de los motores de cambio sobre los que hay gran incertidumbre"

Se ha tomado en consideración los factores externos más representativos para la institución educativa y considerar su impacto, los cuales son:

1) Aplicación de la Currículo Nacional Vigente en las instituciones educativas.

2) Ofertas laborales sector público por Reforma magisterial

3) Capacidad de gasto de los NSE C y D

4) Población en edad escolar en el distrito de Santiago.

\subsubsection{Descripción de Escenarios considerados.}

De acuerdo a las estrategias es importante analizar y plantear los diferentes escenarios en los que puede desenvolverse. Estos pueden ser: 


\section{A. Escenario Optimista.}

Se considera un escenario optimista para la IEP Santiago Apóstol en la que aplica correctamente el Currículo Nacional Vigente, complementando con un avance tecnológico en las aulas. El $90 \%$ de docentes se quedan en sus puestos laborales porque es reconocida su trayectoria y estudios superiores. Los niveles socioeconómicos C y D incrementan su porcentaje poblacional hasta en un 54\% en el distrito de Santiago creciendo la población en edad escolar en un $4 \%$ por año, y aumentando su capacidad de gasto.

\section{B. Escenario Conservador.}

Se considera un escenario conservador para la IEP Santiago Apóstol en el que aplica el currículo Nacional Vigente mantiene su tecnología como en el año base. El $70 \%$ de docentes se quedan en sus puestos laborales. Los niveles socioeconómicos $\mathrm{C}$ y D incrementan su porcentaje poblacional hasta en un 51\% en el distrito de Santiago manteniéndose la población en edad manteniéndose la capacidad de gasto.

\section{Escenario Pesimista.}

Se considera un escenario pesimista para la IEP Santiago Apóstol en el que se aplica el currículo Nacional Vigente no actualiza su tecnología. El 50\% de docentes se quedan en sus puestos laborales. Los niveles socioeconómicos C y D no incrementan su porcentaje poblacional en el distrito de Santiago disminuye la población en edad no se incrementa la capacidad de gasto. 


\section{Comparación de Estrategias con escenarios.}

Según la tabla 45 se puede ver que en el escenario optimista el desarrollo de las estrategias es altamente favorable.

Tabla 45

Impactos en las Estrategias

\begin{tabular}{|c|c|c|c|}
\hline \multirow{2}{*}{ Estrategias } & \multicolumn{3}{|c|}{ Escenarios } \\
\hline & Optimista & Conservador & Pesimista \\
\hline $\begin{array}{l}\text { Mejorar los procesos internos de la IEP } \\
\text { optimizando la distribución de costos y } \\
\text { gastos }\end{array}$ & Altamente Favorable & Favorable & $\begin{array}{c}\text { Poco } \\
\text { Favorable }\end{array}$ \\
\hline $\begin{array}{l}\text { Adicionar al currículo actual talleres } \\
\text { extra curriculares de acuerdo a los } \\
\text { intereses particulares del estudiante, con } \\
\text { el fin de desarrollar nuevos productos } \\
\text { que generen mayores ingresos. }\end{array}$ & Altamente Favorable & Favorable & $\begin{array}{c}\text { Poco } \\
\text { Favorable }\end{array}$ \\
\hline
\end{tabular}

\subsection{Descripción de Estrategia Seleccionada}

Después de haber analizado la matriz MPEC y la matriz de selección,

Se ha determinado como estrategia principal la $\mathrm{N}^{\circ} 1$ y contingente la $\mathrm{N}^{\circ} 2$

1. Mejorar los procesos internos de la IEP optimizando la distribución de costos y gastos.

Para ello se considerará la naturaleza de cada costo y gasto de la IEP, mediante una adecuada planificación, control y evaluación de impacto de cada uno y cómo se relacionan con la eficacia, eficiencia y rentabilidad de la empresa, de esta manera justificar su realización.

2. Adicionar al currículo actual talleres extra curriculares de acuerdo a los intereses particulares del estudiante, con el fin de desarrollar nuevos productos que generen mayores ingresos.

Mediante el focus group efectuado (anexo 6), se pudo observar que los padres de familia y alumnos desearían que la institución educativa tenga contemplado como parte de su oferta talleres extracurriculares que permitan desarrollar las 
habilidades personales de los estudiantes, quienes mencionaron su interés por actividades artísticas como, danza y música. Los padres de familia también indicaron que sus hijos desarrollan actividades extra curriculares durante las vacaciones y ofrecer cursos de acuerdo a los intereses de los alumnos, facilitaría el desarrollo de sus capacidades. Por ello, ofrecer talleres extra curriculares, permitiría lograr un mayor nivel de satisfacción del cliente. 


\section{Capítulo VIII. Implementación de la estrategia}

\subsection{Mapa de la Estrategia}

El mapa estratégico del Balanced Scorecard, de Kaplan \& Norton (2001) proporciona el marco ideal para que las empresas puedan comunicar lo que están realizando, alinear el trabajo de día a día con la estrategia, priorizar proyectos, productos y servicios, medir y monitorear el progreso hacia las metas estratégicas. La estrategia seleccionada en el capítulo anterior fue establecer una política de racionalización de gastos administrativos en todos los niveles de la institución educativa.

El sistema permitirá conectar los elementos estratégicos como la misión, visión, estrategias principales y los objetivos operacionales o iniciativas. Se utilizarán las cuatro perspectivas tradicionales (Financiera, Procesos Internos, Aprendizaje y del Cliente) para implementar la estrategia en la IEP Santiago Apóstol. La figura 15 muestra las perspectivas de desarrollo de la IEP Santiago Apóstol.

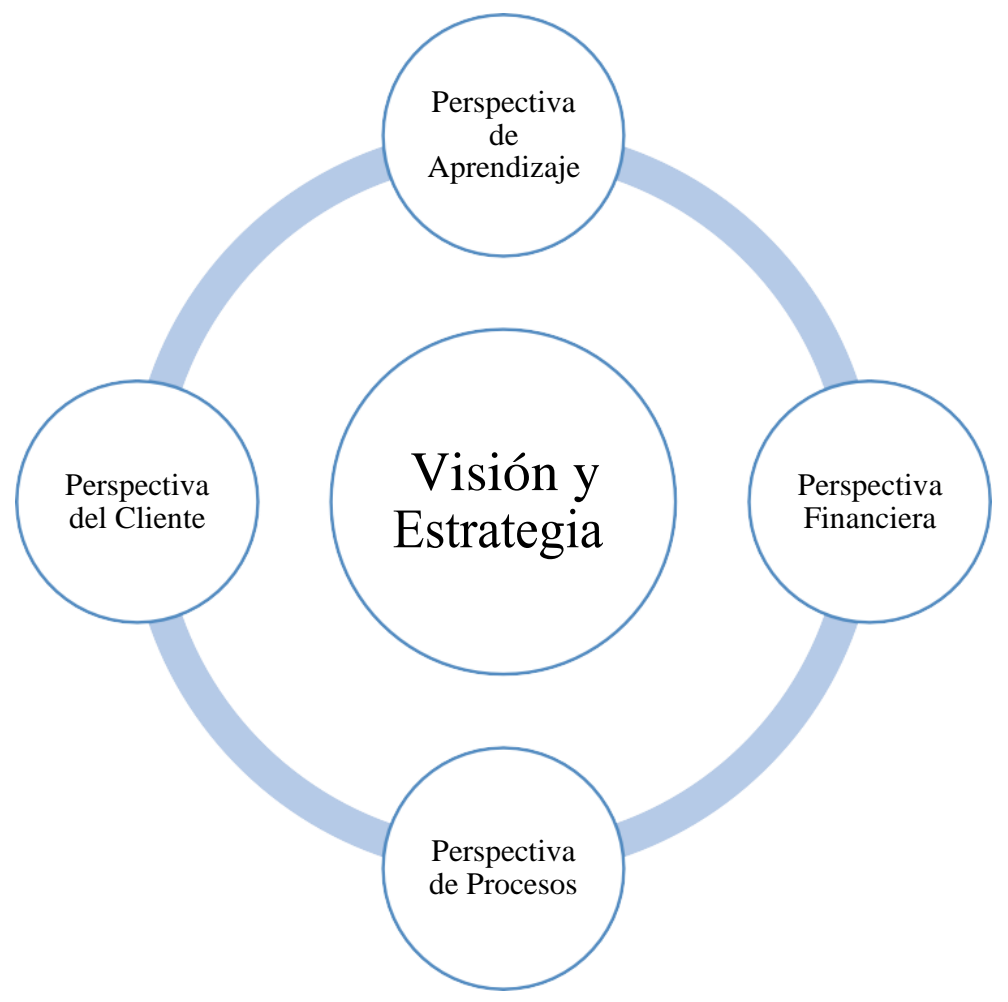

Figura 15. Perspectivas de desarrollo. Elaboración Propia. 
La figura 16 muestra el mapa del Balanced Scorecard para la estrategia seleccionada.

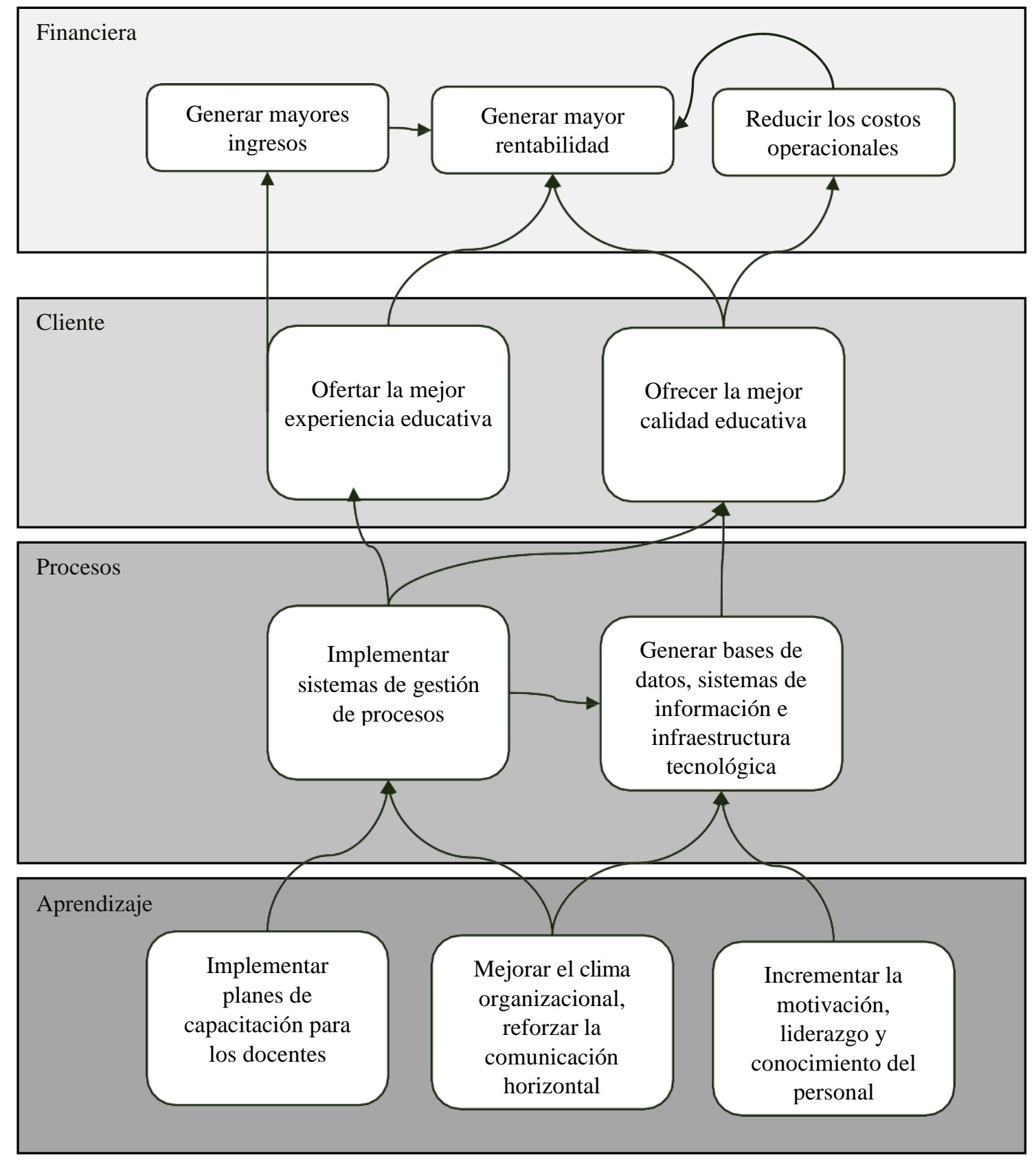

Figura 16. Mapa del Balanced Scorecard. Elaboración Propia.

\subsection{Objetivos Específicos}

Esta sección muestra un resumen del mapa estratégico y los objetivos específicos de acuerdo a su pertenencia a las perspectivas del Balanced Scorecard 


\subsubsection{Perspectiva Financiera.}

- O1: Generar mayor rentabilidad

- O2: Reducir los costos operacionales

- O3: Generar mayores ingresos

\subsubsection{Perspectiva del Cliente.}

- O4: Ofertar la mejor experiencia educativa

- O5: Ofrecer la mejor calidad educativa

\subsubsection{Perspectiva de Procesos.}

- O6: Implementar sistemas de gestión de procesos

- O7: Generar bases de datos, sistemas de información e infraestructura tecnológica

\subsubsection{Perspectiva de Aprendizaje.}

- O8: Implementar planes de capacitación para los docentes

- O9: Incrementar la motivación, liderazgo y conocimiento de las estrategias del personal

- O10: Mejorar el clima organizacional, reforzar la comunicación horizontal 
Tabla 46

Objetivos del Balanced Scorecard

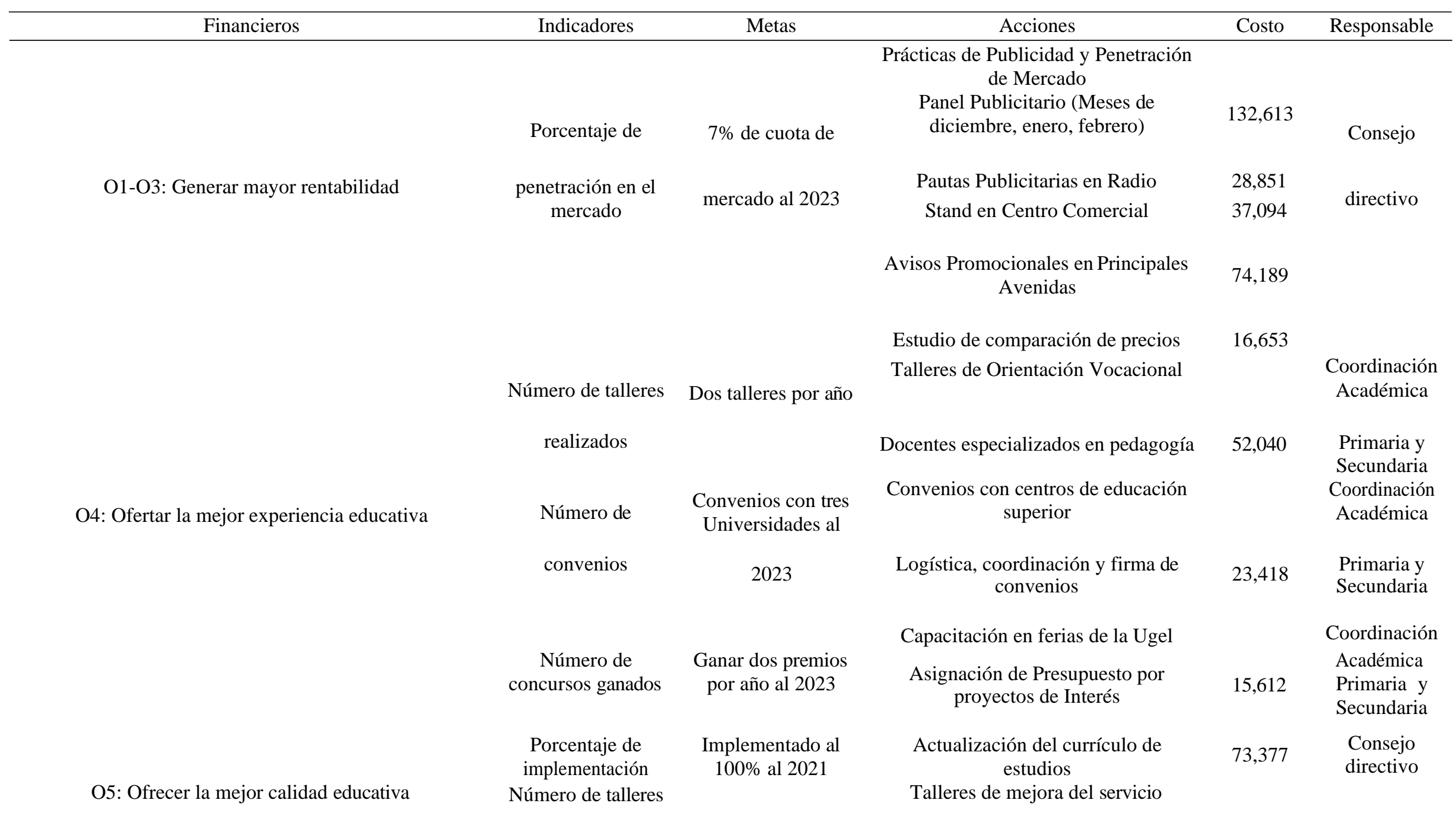


realizados

Porcentaje de

avance
Dos talleres por año educativo

Capacitadores

23,418

Entidad

Consultoría en gestión de procesos

Promotora 


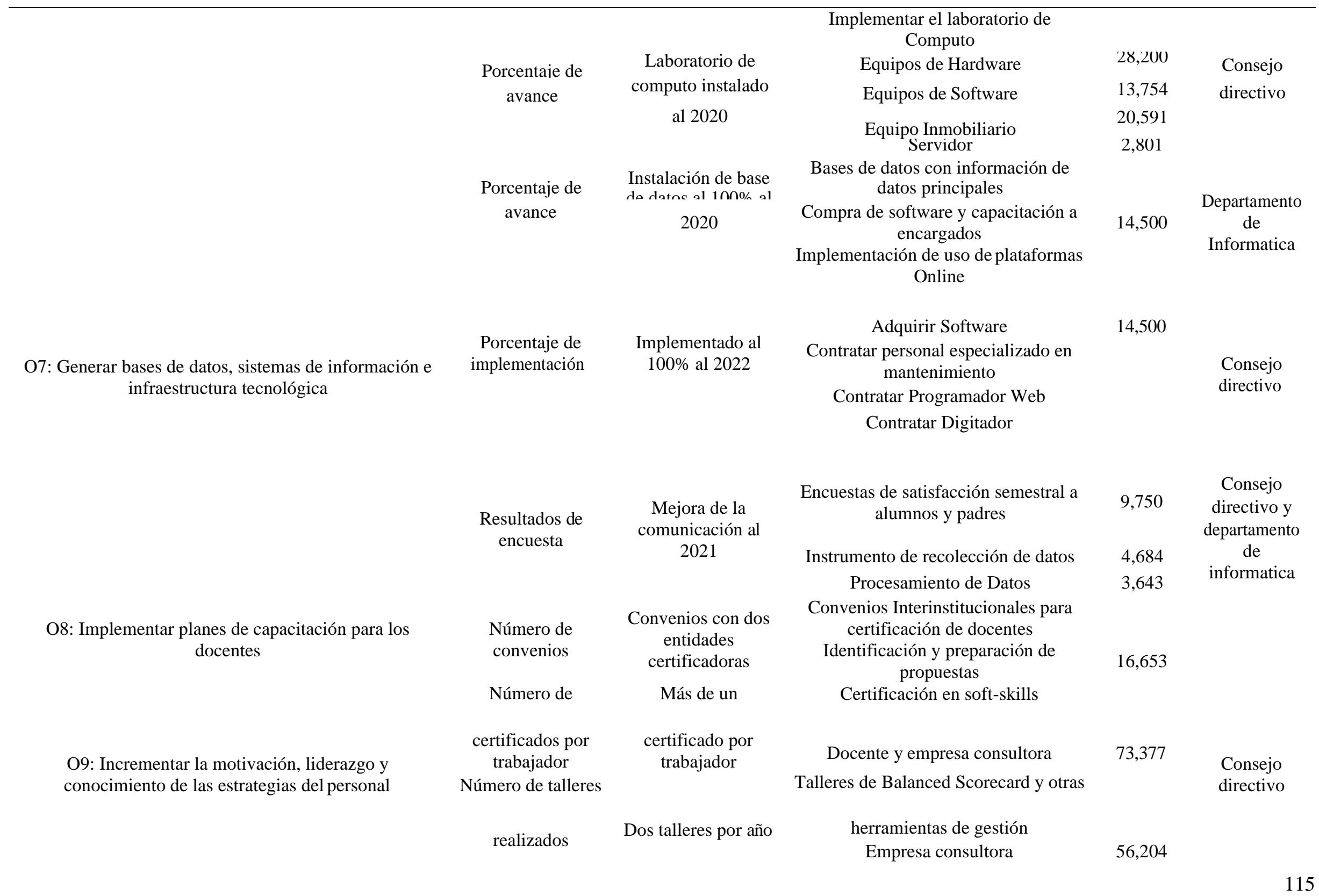




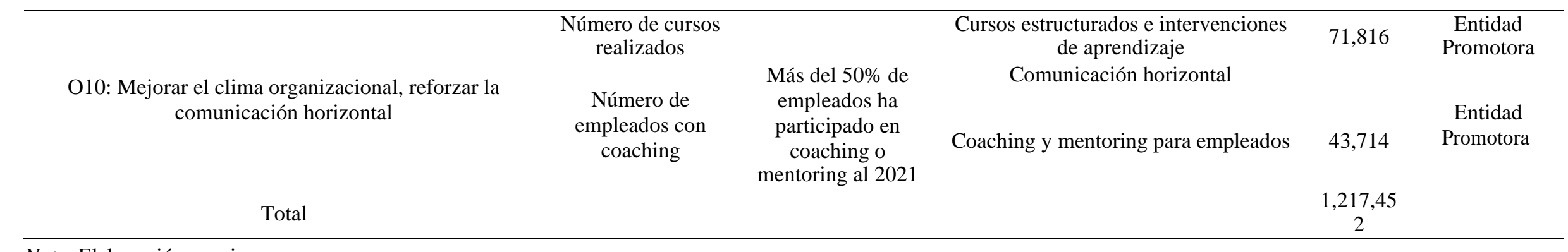

Nota. Elaboración propia. 


\section{Capítulo IX. Evaluación}

En el presente capítulo se realiza un análisis financiero de los objetivos propuestos en el Plan Estratégico, así como la evaluación de la viabilidad del proyecto utilizando los indicadores del Valor Actual Neto (VAN), la Tasa Interna de Retorno (TIR) y el período de recuperación del capital.

\subsection{Evaluación Financiera de la Estrategia}

A continuación, se evalúa la situación financiera de la IEP Santiago Apóstol en base al estado de resultados histórico para los años 2014, 2015, 2016, 2017 y 2018; posteriormente se proyecta el flujo de ventas, el estado de resultados y el flujo de caja para la estrategia principal identificada en el Capítulo IX - Implementación de la estrategia (con estrategia) y sin estrategia.

\subsubsection{Análisis de los estados financieros históricos.}

En la tabla 46 se muestra el estado de resultados histórico de los años 2014, 2015, 2016 y 2017. Durante este período tanto la utilidad bruta como los gastos operativos se han incrementado en forma progresiva, en $65 \%$ y $55 \%$ respectivamente. Uno de los objetivos planteados se enfoca en reducir los gastos de operación y contar con una ganancia neta mayor durante la duración del proyecto. 
Tabla 47

Estado de Resultados histórico (en soles)

\begin{tabular}{|c|c|c|c|c|c|}
\hline & 2014 & 2015 & 2016 & 2017 & 2018 \\
\hline Ventas & 482,970 & 617,840 & 719,013 & 797,194 & 813,137 \\
\hline Total Ingresos & 482,970 & 617,840 & 719,013 & 797,194 & 813,137 \\
\hline \multicolumn{6}{|l|}{ Costo de ventas } \\
\hline Utilidad Bruta & 482,970 & 617,840 & 719,013 & 797,194 & 813,137 \\
\hline Gastos de ventas & $-393,575$ & $-454,718$ & $-522,326$ & -611.504 & $-623,734$ \\
\hline Gastos de administración & $-69,454$ & $-80,244$ & $-91,547$ & $-107,912$ & $-110,07$ \\
\hline Otros ingresos & & 1,010 & & & \\
\hline Total gastos de operación & $-463,030$ & $-533,952$ & $-613,874$ & $-719,416$ & $-733,804$ \\
\hline Ganancia por actividad de operación & 19,939 & 83,887 & 105,138 & 77,778 & 79,333 \\
\hline \multicolumn{6}{|l|}{ Ingresos financieros } \\
\hline Gastos financieros & & $-29,146$ & $-21,944$ & $-18,559$ & $-18,93$ \\
\hline Resultado antes de impuesto a la renta & 19,939 & 54,740 & 83,193 & 59,219 & 60,403 \\
\hline Gasto por impuesto a la renta & $-3,044$ & $-15,428$ & $-23,294$ & $-5,922$ & $-6,044$ \\
\hline Ganancia neta del ejercicio & 16,895 & 39,312 & 59,899 & 53,297 & 54,364 \\
\hline
\end{tabular}

\subsubsection{Proyección de los ingresos anuales (sin estrategia y con estrategia).}

A continuación, se muestran los ingresos anuales y estados financieros para el proyecto con y sin estrategia. En la tabla 48 se detallan los ingresos por ventas anuales sin estrategia, se proyecta un ingreso total que muestra una tendencia a la baja entre los años 2019 y 2023, el ingreso calculado toma en cuenta una variación mínima en las matrículas de los estudiantes, a causa de la mayor competencia generada por los colegios. Se estima un porcentaje de ingreso en efectivo de $93.25 \%$ para el primer año debido a los estudiantes que no logran pagar la mensualidad a tiempo en los últimos meses del año. 
Tabla 48

Ingresos por ventas anuales sin estrategia(en soles)

\begin{tabular}{cccccc}
\hline Producto & 2019 & 2020 & 2021 & 2022 & 2023 \\
\hline Matricula & 140,500 & 142,000 & 143,500 & 145,500 & 147,000 \\
Mensualidad & 758,700 & 766,800 & 774,900 & 785,700 & 793,800 \\
\hline Total & 899,200 & 908,800 & 918,400 & 931,200 & 940,800 \\
\hline Ingreso en Efectivo & 838,504 & 847,456 & 856,408 & 868,344 & 877,296 \\
\% en efectivo & $93.25 \%$ & & & &
\end{tabular}

Nota. Elaboración Propia; el costo de la mensualidad es de 280 soles y el costo de la matrícula es de 500 soles.

En la tabla 49 se proyecta un crecimiento (penetración de mercado) de $9.26 \%$ en base a la proyección realizada en el capítulo II - La Empresa. El incremento responde a la inversión inicial que se realizará en la infraestructura y calidad de servicio durante la implementación de la estrategia principal. Por otro lado, el mercado puede absorber el incremento de 13 alumnos en promedio por año, ya que representa el $16 \%$ del total de matrículas proyectadas en colegios privados del distrito de Santiago (176 matrículas, véase Capítulo II - La Empresa).

Tabla 49

Ingresos por ventas anuales con estrategia (en soles)

\begin{tabular}{cccccc}
\hline Producto & 2019 & 2020 & 2021 & 2022 & 2023 \\
\hline Matrícula & 158,601 & 188,000 & 195,000 & 202,000 & 208,500 \\
Mensualidad & $1,005,200$ & $1,052,800$ & $1,092,000$ & $1,131,200$ & $1,167,600$ \\
\hline Total & $1,163,801$ & $1,240,800$ & $1,287,000$ & $1,333,200$ & $1,376,100$ \\
\hline
\end{tabular}

Nota. Elaboración Propia; el costo de la mensualidad es de 280 soles y el costo de la matrícula es de 500 soles respectivamente.

La tabla 50 muestra el flujo de efectivo para los 6 primeros meses. Se tiene un déficit de S/ 51,372 durante los dos primeros meses, monto que se incluye en la inversión pre-operativa como capital de trabajo.

Tabla 50

Flujo de efectivo (Primeros 6 meses del 2019)

\begin{tabular}{ccccccc}
\hline & Mes 1 & Mes 2 & Mes 3 & Mes 4 & Mes 5 & Mes 6 \\
\hline Préstamo & 5,219 & 5,219 & 5,219 & 5,219 & 5,219 & 5,219 \\
IGV & 4,681 & 4,681 & 4,681 & 4,681 & 4,681 & 4,681 \\
Total de egresos en efectivo & 78,107 & 78,107 & 78,107 & 78,107 & 78,107 & 78,107 \\
Saldo de caja (Ingresos - Egresos) & $-38,345$ & 25,318 & 57,931 & 2,309 & 17,387 & 12,361 \\
\hline
\end{tabular}




\begin{tabular}{|c|c|c|c|c|c|c|}
\hline Saldo de caja inicial & & $-38,345$ & $-13,027$ & 44,904 & 47,213 & 64,600 \\
\hline Saldo de caja final (Acumulado) & $-38,345$ & $-13,027$ & 44,904 & 47,213 & 64,600 & 76,961 \\
\hline
\end{tabular}

\subsubsection{Servicio a la deuda.}

El préstamo requerido para el cumplimiento de los objetivos estratégicos es de S/ 200,000 respectivamente. Se cotizó con un representante de la Caja Cusco (2018) para determinar la tasa de interés y las condiciones del préstamo, la TCEA ofrecida por la Caja es de $16.43 \%$. El financiamiento es tomado a 60 meses ( 5 años), sin períodos de gracia. La cuota mensual a pagar es de S/. 5,219. En la tabla 51 se visualiza la tabla de amortización del préstamo. En los requisitos del préstamo, se menciona que se requieren los documentos de casa o fiador con casa propia o local comercial propio; respecto a este punto, la promotora de la IEP Santiago Apóstol cuenta con un inmueble propio, ubicado en una zona comercial del distrito de Wanchaq; asimismo, cabe indicar que la IEP Santiago Apóstol es un cliente regular de la Caja Cusco desde el 2008, la cual provee servicios como la captación de las matrículas y mensualidades de los estudiantes; cuentas sueldo para los trabajadores de la IEP y préstamos para mejoras. Se propone utilizar al inmueble propio ubicado en la zona comercial como distrito de Wanchaq como garantía para acceder al préstamo de la Caja Cusco.

Tabla 51

Amortización del préstamo

\begin{tabular}{cccccccc}
\hline $\mathrm{N}^{\circ}$ & Deuda & Capital & Intereses & $\begin{array}{c}\text { Cuota Sin } \\
\text { Desgravamen }\end{array}$ & Desgravamen & Cuota & $\begin{array}{c}\text { Escudo } \\
\text { Fiscal }\end{array}$ \\
\hline & 200,000 & & & & & & \\
1 & 197,761 & 2,239 & 2,551 & 4,790 & 428 & 5,219 & 753 \\
2 & 195,493 & 2,268 & 2,523 & 4,790 & 428 & 5,219 & 744 \\
3 & 193,197 & 2,296 & 2,494 & 4,790 & 428 & 5,219 & 736 \\
4 & 190,871 & 2,326 & 2,465 & 4,790 & 428 & 5,219 & 727 \\
5 & 188,516 & 2,355 & 2,435 & 4,790 & 428 & 5,219 & 718 \\
6 & 186,130 & 2,386 & 2,405 & 4,790 & 428 & 5,219 & 709 \\
7 & 183,714 & 2,416 & 2,375 & 4,790 & 428 & 5,219 & 700 \\
8 & 181,268 & 2,447 & 2,344 & 4,790 & 428 & 5,219 & 691 \\
9 & 178,790 & 2,478 & 2,312 & 4,790 & 428 & 5,219 & 682 \\
10 & 176,280 & 2,510 & 2,281 & 4,790 & 428 & 5,219 & 673 \\
\hline
\end{tabular}




\begin{tabular}{cccccccc}
\hline 11 & 173,738 & 2,542 & 2,249 & 4,790 & 428 & 5,219 & 663 \\
$\ldots$ & & & & & & \\
54 & 27,502 & 4,384 & 407 & 4,790 & 428 & 5,219 & 120 \\
55 & 23,062 & 4,440 & 351 & 4,790 & 428 & 5,219 & 104 \\
56 & 18,566 & 4,496 & 294 & 4,790 & 428 & 5,219 & 87 \\
57 & 14,012 & 4,554 & 237 & 4,790 & 428 & 5,219 & 70 \\
58 & 9,401 & 4,612 & 179 & 4,790 & 428 & 5,219 & 53 \\
59 & 4,730 & 4,671 & 120 & 4,790 & 428 & 5,219 & 35 \\
60 & 0 & 4,730 & 60 & 4,790 & 428 & 5,219 & 18 \\
\hline Total & 200,000 & 87,428 & 287,428 & 25,695 & 313,123 & 25,791 \\
\hline Nota. Elaboración propia.
\end{tabular}

10.1.4 Gastos Administrativos, Operativos y de Implementación.

La tabla 52 muestra el pronóstico para los gastos de personal y administrativos.

Tabla 52

Gastos de personal y administrativos

\begin{tabular}{|c|c|c|c|c|c|}
\hline Gastos de personal & 2019 & 2020 & 2021 & 2022 & 2023 \\
\hline Docencia & 228,000 & 232,560 & 237,211 & 241,955 & 246,795 \\
\hline Administración y gerencia & 156,000 & 159,120 & 162,302 & 165,548 & 168,859 \\
\hline Seguimiento y monitoreo del proyecto & 120,000 & 122,400 & 124,848 & 127,345 & 129,892 \\
\hline Total Personal & 504,000 & 514,080 & 524,362 & 534,849 & 545,546 \\
\hline \multicolumn{6}{|l|}{ Gastos administrativos } \\
\hline \multicolumn{6}{|l|}{ Transporte } \\
\hline Luz & 5,400 & 5,508 & 5,618 & 5,731 & 5,845 \\
\hline Agua & 3,840 & 3,917 & 3,995 & 4,075 & 4,157 \\
\hline Teléfono e internet & 5,400 & 5,508 & 5,618 & 5,731 & 5,845 \\
\hline Alquiler de sucursal de ventas & 57,000 & 58,140 & 59,303 & 60,489 & 61,699 \\
\hline Celular & 4,968 & 5,067 & 5,169 & 5,272 & 5,378 \\
\hline Contador & 30,000 & 30,600 & 31,212 & 31,836 & 32,473 \\
\hline Limpieza Publica & 840 & 857 & 874 & 891 & 909 \\
\hline Seguridad & 20,480 & 20,890 & 21,308 & 21,734 & 22,168 \\
\hline Limpieza & 26,780 & 27,315 & 27,862 & 28,419 & 28,987 \\
\hline Total gastos administrativos & 154,708 & 157,802 & 160,958 & 164,177 & 167,461 \\
\hline IGV Gastos administrativos & 27,847 & 28,404 & 28,972 & 29,552 & 30,143 \\
\hline Total Gastos administrativos con IGV & 182,555 & 186,206 & 189,931 & 193,729 & 197,604 \\
\hline
\end{tabular}

La tabla 53 muestra los costos de la implementación de la estrategia señalada en el Capítulo XI - Implementación de la estrategia, no se incluyen los costos de inversión (véase estructura de inversiones en anexo 8). 


\section{Tabla 53}

Costos de implementación de la estrategia (Años 1 al 5)

\begin{tabular}{|c|c|c|c|c|c|}
\hline & 2019 & 2020 & 2021 & 2022 & 2023 \\
\hline \multicolumn{6}{|l|}{ Prácticas de Publicidad y Penetración de Mercado } \\
\hline $\begin{array}{l}\text { Panel Publicitario (Meses de diciembre, enero, } \\
\text { febrero) }\end{array}$ & 32,175 & 32,819 & 33,475 & 34,144 & \\
\hline Pautas Publicitarias en Radio & 7,000 & 7,140 & 7,283 & 7,428 & \\
\hline Stand en Centro Comercial & 9,000 & 9,180 & 9,364 & 9,551 & \\
\hline Avisos Promocionales en Principales Avenidas & 18,000 & 18,360 & 18,727 & 19,102 & \\
\hline Estudio de comparación de precios & 3,200 & 3,264 & 3,329 & 3,396 & 3,464 \\
\hline \multicolumn{6}{|l|}{ Talleres de Orientación Vocacional } \\
\hline $\begin{array}{l}\text { Docente especializado en pedagogía y orientación } \\
\text { vocacional }\end{array}$ & 10,000 & 10,200 & 10,404 & 10,612 & 10,824 \\
\hline Convenios con centros de educación superior & & & & & \\
\hline Logística, coordinación y firma de convenios & 4,500 & 4,590 & 4,682 & 4,775 & 4,871 \\
\hline \multicolumn{6}{|l|}{ Capacitación en ferias de la Ugel } \\
\hline Asignación de Presupuesto por proyectos de Interés & 3,000 & 3,060 & 3,121 & 3,184 & 3,247 \\
\hline $\begin{array}{l}\text { Actualización del currículo de estudios } \\
\text { Talleres de mejora del servicio educativo }\end{array}$ & 14,100 & 14,382 & 14,670 & 14,963 & 15,262 \\
\hline Capacitadores & 4,500 & 4,590 & 4,682 & 4,775 & 4,871 \\
\hline $\begin{array}{l}\text { Convenios Interinstitucionales para certificación de } \\
\text { docentes } \\
\text { Identificación y preparación de propuestas }\end{array}$ & 3,200 & 3,264 & 3,329 & 3,396 & 3,464 \\
\hline Contratar personal especializado en mantenimiento & & 30,000 & 30,600 & 31,212 & 31,836 \\
\hline Contratar Programador Web & & 51,600 & 1,224 & 1,248 & 1,273 \\
\hline Contratar Digitador & & 1,500 & 1,224 & 1,248 & 1,273 \\
\hline \multicolumn{6}{|l|}{$\begin{array}{l}\text { Encuestas de satisfacción semestral a alumnos y } \\
\text { padres }\end{array}$} \\
\hline Instrumento de recolección de datos & 900 & 918 & 936 & 955 & 974 \\
\hline Procesamiento de Datos & 700 & 714 & 728 & 743 & 758 \\
\hline \multicolumn{6}{|l|}{ Certificación en soft-skills } \\
\hline Docente y empresa consultora & 14,100 & 14,382 & 14,670 & 14,963 & 15,262 \\
\hline \multicolumn{6}{|l|}{$\begin{array}{l}\text { Talleres de Balanced Scorecard y otras herramientas } \\
\text { de gestión }\end{array}$} \\
\hline Empresa consultora & 10,800 & 11,016 & 11,236 & 11,461 & 11,690 \\
\hline \multicolumn{6}{|l|}{ Clima organizacional } \\
\hline $\begin{array}{l}\text { Cursos estructurados e intervenciones de aprendizaje } \\
\text { Comunicación horizontal }\end{array}$ & 13,800 & 14,076 & 14,358 & 14,645 & 14,938 \\
\hline Coaching y mentoring para empleados & 8,400 & 8,568 & 8,739 & 8,914 & 9,092 \\
\hline Total & $\begin{array}{c}157,37 \\
5\end{array}$ & $\begin{array}{c}243,62 \\
3\end{array}$ & $\begin{array}{c}196,78 \\
1\end{array}$ & $\begin{array}{c}200,71 \\
7\end{array}$ & $\begin{array}{c}133,10 \\
1\end{array}$ \\
\hline
\end{tabular}

Nota. Elaboración propia.

La tabla 54 muestra la inversión inicial a ser realizada como parte del proyecto:

Tabla 54

Inversión Inicial (Año 0)

\begin{tabular}{lc}
\hline Inversión Inicial & 2018 \\
\hline Consultoría en gestión de procesos & 366,000 \\
Equipos de Hardware & 28,200 \\
\hline
\end{tabular}




\begin{tabular}{lc}
\hline Equipo Inmobiliario & 20,591 \\
Servidor & 2,801 \\
Compra de software y capacitación a encargados & 14,500 \\
Adquirir Software & 14,500 \\
Encuestas de satisfacción semestral a alumnos y padres & 9,750 \\
\hline \multicolumn{1}{c}{ Total } & 417,592 \\
\hline
\end{tabular}

\subsubsection{Proyección del estado de resultados (sin estrategia y con estrategia).}

En la tabla 55 se detalla el estado de resultados sin estrategia para el período 2019-2023, para simplificar el análisis se estima una variación de 2\% en los gastos administrativos y gastos de venta año a año. Se observa que la utilidad operativa se reduce entre el 2019 y 2023 principalmente debido al incremento de la competencia directa (mencionada en el capítulo IV - Análisis Externo).

Tabla 55

Estado de Resultados sin Estrategia (en soles)

\begin{tabular}{cccccc}
\hline & 2019 & 2020 & 2021 & 2022 & 2023 \\
\hline Ingresos por enseñanza y matricula & 899,200 & 908,800 & 918,400 & 931,200 & 940,800 \\
Total ingresos & 899,200 & 908,800 & 918,400 & 931,200 & 940,800 \\
Cargas de Personal & $-522,000$ & $-532,440$ & $-543,089$ & $-553,951$ & $-565,030$ \\
Servicios prestados por terceros & $-150,628$ & $-153,640$ & $-156,713$ & $-159,848$ & $-163,044$ \\
Depreciación del ejercicio & $-6,017$ & $-6,017$ & $-6,017$ & $-6,017$ & $-6,017$ \\
Utilidad Operativa & 220,555 & 216,703 & 212,581 & 211,385 & 206,709 \\
Gastos financieros & & & & & \\
Utilidad antes del impuesto & 220,555 & 216,703 & 212,581 & 211,385 & 206,709 \\
Impuesto a la renta & $-65,064$ & $-63,927$ & $-62,711$ & $-62,359$ & $-60,979$ \\
\hline Utilidad Neta & 155,491 & 152,775 & 149,870 & 149,026 & 145,730 \\
\hline
\end{tabular}

Nota. Elaboración propia

La tabla 56 detalla el estado de resultados con estrategia, los ingresos por enseñanza y matrícula tienen una tendencia positiva. También se observa un incremento en la utilidad neta, debido principalmente a la tasa de matrícula escolar y las nuevas instalaciones de la IEP. Asimismo, los gastos financieros van disminuyendo en cada año; debido a la estructura del préstamo, otorgado por la Caja Cusco (2018). 
Tabla 56

Estado de Resultados con Estrategia (en soles)

\begin{tabular}{cccccc}
\hline & 2019 & 2020 & 2021 & 2022 & 2023 \\
\hline Ingresos por enseñanza y matricula & $1,163,801$ & $1,240,800$ & $1,287,000$ & $1,333,200$ & $1,376,100$ \\
Total ingresos & $1,163,801$ & $1,240,800$ & $1,287,000$ & $1,333,200$ & $1,376,100$ \\
Cargas de Personal & $-504,000$ & $-514,080$ & $-524,362$ & $-534,849$ & $-545,546$ \\
Servicios prestados por terceros & $-312,083$ & $-401,425$ & $-357,739$ & $-364,894$ & $-300,562$ \\
Depreciación del ejercicio & $-46,409$ & $-46,409$ & $-46,409$ & $-46,409$ & $-46,409$ \\
& & & & & \\
Utilidad Operativa & 301,309 & 278,886 & 358,490 & 387,048 & 483,583 \\
Gastos financieros & $-28,650$ & $-23,912$ & $-18,396$ & $-11,974$ & $-4,496$ \\
Utilidad antes del impuesto & 272,659 & 254,974 & 340,094 & 375,074 & 479,087 \\
Impuesto a la renta & $-80,434$ & $-75,217$ & $-100,328$ & $-110,647$ & $-141,331$ \\
\hline Utilidad Neta & 192,224 & 179,757 & 239,766 & 264,427 & 337,756 \\
\hline Escudo Fiscal & 8,452 & 7,054 & 5,427 & 3,532 & 1,326 \\
\hline
\end{tabular}

Nota. Elaboración propia.

\subsubsection{Proyección del estado de situación}

Tabla 57

Estado de situación proyectado

\begin{tabular}{cccccc}
\hline Conceptos & 2019 & 2020 & 2021 & 2022 & 2023 \\
\hline Activo & & & & & \\
Efectivo y equivalente de efectivo & 209,798 & 192,593 & 247,086 & 265,325 & 331,176 \\
Activo Inmovilizado & 492,759 & 492,759 & 492,759 & 492,759 & 492,759 \\
Depreciación Acumulada & 46,409 & 92,819 & 139,228 & 185,637 & 232,047 \\
Impuestos, gastos anticipados y otros activos & 88,886 & 82,271 & 105,755 & 114,179 & 142,657 \\
Total Activo & 837,852 & 860,441 & 984,827 & $1,057,900$ & $1,198,638$ \\
\hline Pasivo & & & & & \\
\hline Tributos por pagar & 56,175 & 72,256 & 64,393 & 65,681 & 54,101 \\
Remuneraciones y beneficios sociales por pagar & 504,000 & 514,080 & 524,362 & 534,849 & 545,546 \\
Obligaciones Financieras & 62,625 & 62,625 & 62,625 & 62,625 & 62,625 \\
Total Pasivo & 622,800 & 648,961 & 651,379 & 663,154 & 662,272 \\
\hline Patrimonio & & & & & \\
\hline Capital social & 406,085 & 406,085 & 406,085 & 406,085 & 406,085 \\
Resultado del ejercicio & $-191,033$ & $-194,605$ & $-72,637$ & $-11,340$ & 130,282 \\
Total patrimonio neto & 215,053 & 211,480 & 333,448 & 394,746 & 536,367 \\
\hline Total pasivo y patrimonio & 837,852 & 860,441 & 984,827 & $1,057,900$ & $1,198,638$
\end{tabular}

Nota. Elaboración propia.

\subsubsection{Proyección del Flujo de caja con y sin estrategia.}

Por último, se realiza la proyección del flujo de caja para la IEP con o sin estrategia. La tabla 58 muestra el flujo de Caja sin estrategia, el flujo es positivo durante los cinco años. 
Tabla 58

Flujo de caja sin estrategia (en soles)

\begin{tabular}{|c|c|c|c|c|c|c|}
\hline & 2014 & 2019 & 2020 & 2021 & 2022 & 2023 \\
\hline Ingresos por enseñanza y matricula & & 899,200 & 908,800 & 918,400 & 931,200 & 940,800 \\
\hline Servicios prestados por terceros & & $-150,628$ & $-153,640$ & $-156,713$ & $-159,848$ & $\begin{array}{c}- \\
163,044\end{array}$ \\
\hline Cargas de Personal & & $-522,000$ & $-532,440$ & $-543,089$ & $-553,951$ & $\begin{array}{c}- \\
565,030\end{array}$ \\
\hline Depreciación & & $-6,017$ & $-6,017$ & $-6,017$ & $-6,017$ & $-6,017$ \\
\hline Beneficio antes de impuestos & & 220,555 & 216,703 & 212,581 & 211,385 & 206,709 \\
\hline Impuestos & & $-65,064$ & $-63,927$ & $-62,711$ & $-62,359$ & $-60,979$ \\
\hline Depreciación & & 6,017 & 6,017 & 6,017 & 6,017 & 6,017 \\
\hline Flujo de Caja operativo & & 161,508 & 158,792 & 155,887 & 155,043 & 151,747 \\
\hline \multicolumn{7}{|l|}{ Flujo de Capital o Inversión } \\
\hline Inversión de Activos Fijos & 56,720 & & & & & \\
\hline Flujo de Capital o Inversión & $-56,720$ & & & & & \\
\hline Pago IGV & & 27,113 & 27,655 & 28,208 & 28,773 & 29,348 \\
\hline Flujo de Caja Económico & $-56,720$ & 188,621 & 186,448 & 184,095 & 183,816 & 181,095 \\
\hline Flujo de Caja Económico & $-56,720$ & 188,621 & 186,448 & 184,095 & 183,816 & 181,095 \\
\hline
\end{tabular}

Nota. Elaboración propia.

En la tabla 59 se presenta el flujo de caja con estrategia. Tanto el flujo de caja financiero como el flujo de caja económico muestran una tendencia al alza durante la implementación de la estrategia.

Tabla 59

Flujo de caja con estrategia (en soles)

\begin{tabular}{|c|c|c|c|c|c|c|}
\hline & 2018 & 2019 & 2020 & 2021 & 2022 & 2023 \\
\hline $\begin{array}{c}\text { Ingresos por enseñanza y } \\
\text { matrícula }\end{array}$ & & $\begin{array}{c}1,163,80 \\
1\end{array}$ & $\begin{array}{c}1,240,80 \\
0\end{array}$ & $\begin{array}{c}1,287,00 \\
0\end{array}$ & $\begin{array}{c}1,333,20 \\
0\end{array}$ & $\begin{array}{c}1,376,10 \\
0\end{array}$ \\
\hline Cargas de Personal & & $-504,000$ & $-514,080$ & $-524,362$ & $-534,849$ & $-545,546$ \\
\hline Servicios prestados por terceros & & $-312,083$ & $-401,425$ & $-357,739$ & $-364,894$ & $-300,562$ \\
\hline Depreciación & & $-46,409$ & $-46,409$ & $-46,409$ & $-46,409$ & $-46,409$ \\
\hline Beneficio antes de impuestos & & 301,309 & 278,886 & 358,490 & 387,048 & 483,583 \\
\hline Impuestos & & $-88,886$ & $-82,271$ & $-105,755$ & $-114,179$ & $-142,657$ \\
\hline Depreciación & & 46,409 & 46,409 & 46,409 & 46,409 & 46,409 \\
\hline Flujo de Caja operativo & & 258,832 & 243,024 & 299,145 & 319,278 & 387,335 \\
\hline
\end{tabular}

Flujo de Capital o Inversión 


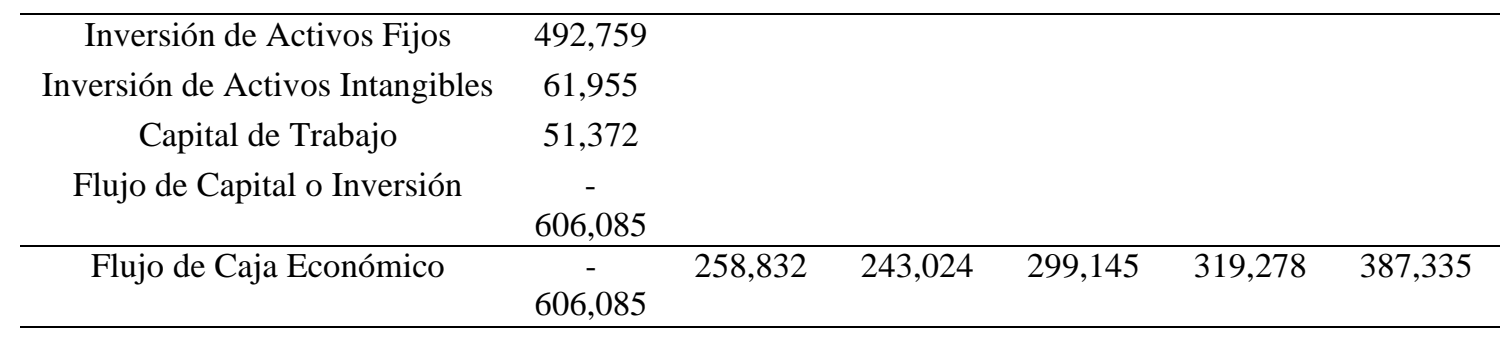

Flujo del Servicio de la Deuda

Préstamo 200,000 Interes

Amortizacion Escudo Fiscal

Flujo del Servicio de la Deuda$$
200,000
$$

$\begin{array}{rccccc} & -28,650 & -23,912 & -18,396 & -11,974 & -4,496 \\ & -28,836 & -33,573 & -39,090 & -45,512 & -52,990 \\ 200,000 & 8,452 & 7,054 & 5,427 & 3,532 & 1,326 \\ & -49,034 & -50,432 & -52,059 & -53,953 & -56,159\end{array}$

Flujo de Caja Financiero

$406^{-}, 085$

Nota. Elaboración propia.

\subsubsection{Evaluación Financiera (VAN, TIR, y ratios financieros).}

En la presente sección, se realiza la evaluación financiera del proyecto utilizando los indicadores del VANE, VANF, TIR y TIRE para conocer la rentabilidad. Se utiliza el modelo Capital Asset Pricing Model (CAPM) para calcular el costo de oportunidad del capital (COK), el cual define la rentabilidad exigida por los accionistas.

Se identifica el sector al que pertenece la IEP Santiago Apóstol, según Damodaran (2018), la industria es Educación, con una beta apalancado de 1.15. El ratio deuda/patrimonio para este sector en EEUU es de 38.83\%; Mientras que la Tax rate para el sector es de $8.24 \%$. Con los tres datos; se desapalanca el Beta utilizando la fórmula de Hamada (1972). La beta obtenida es de 0.85. Posteriormente se realiza el reapalancamiento del Beta con los datos del Perú; de acuerdo a (SUNAT, 2018), el impuesto a la renta es de $29.5 \%$. Utilizando los datos del estado de situación proyectado al 2019 se calcula el ratio Deuda Patrimonio.

Tabla 60

Cálculo del beta para el proyecto

\begin{tabular}{lc}
\hline Ítems & Valor \\
\hline
\end{tabular}




\begin{tabular}{lc}
\hline Beta sector educación EEUU & 1.15 \\
Ratio Deuda/Patrimonio EEUU & $38.83 \%$ \\
Tax rate EEUU & $8.24 \%$ \\
Beta desapalancada & 0.85 \\
\hline Beta apalancada (datos Perú) & \\
\hline Impuesto a la renta & $29.5 \%$ \\
Ratio Deuda / Pasivo y Patrimonio & 0.74 \\
Ratio Patrimonio/ Pasivo y Patrimonio & 0.26 \\
\hline Beta Apalancado & 2.58 \\
\hline Nota. Elaboración propia. &
\end{tabular}

Con los datos mencionados se calcula la beta del proyecto, siendo esta de 2.58 .

Con la beta del proyecto se procede a calcular el costo de oportunidad del capital utilizando el enfoque del CAPM, se utiliza el riesgo país para el 14 de mayo del 2018 (Ambito, 2018), el promedio de la inflación de los últimos cinco años en Perú y EE.UU. Banco Central de Reserva del Perú (2019), United States Department of Labor (2019), el promedio del rendimiento a 10 años de los Bonos del tesoro de EE.UU, y el promedio aritmético del retorno S\&P500.

Tabla 61

Cálculo del CAPM

\begin{tabular}{lc}
\hline Ítems & Valor \\
\hline Beta Apalancado & 2.58 \\
Tasa libre de riesgo (Promedio de rendimiento a 10 años) Bonos del tesoro & $5.15 \%$ \\
Promedio aritmético de retorno S\&P500 & $11.53 \%$ \\
Prima de riesgo & $6.38 \%$ \\
Riesgo País (15.05.18) & $1.28 \%$ \\
Inflación Perú & $2.88 \%$ \\
Inflación EE.UU. & $1.90 \%$ \\
COK Nominal EE.UU. & $21.60 \%$ \\
COK Real EE.UU. & $19.33 \%$ \\
COK Nominal Perú & $23.49 \%$ \\
COK Real Perú & $20.61 \%$ \\
\hline
\end{tabular}

Nota. Elaboración propia.

A continuación, se calcula el Weighted Average Cost of Capital (WACC). De acuerdo con (Miles \& Ezzell, 1980) se calcula con la siguiente formula, cuando la empresa se financia con deuda y patrimonio: 


$$
W A C C=\frac{D}{D} \frac{P}{+P} K_{d}+\frac{P}{D+P} K_{e} *(1-T)
$$

Donde $\mathrm{D}$ es la deuda total, E es el patrimonio total de la empresa, T es la tasa de impuesto a la renta, $K_{d}$ el costo de la deuda (la tasa de interés) y $K_{e}$ el costo del capital; para nuestro caso es el COK.

Tabla 62

Cálculo del WACC

\begin{tabular}{lc}
\hline Ítems & Valor \\
\hline Impuesto a la renta & $29.5 \%$ \\
Ratio Deuda / Pasivo y Patrimonio & 0.74 \\
Ratio Patrimonio/ Pasivo y Patrimonio & 0.26 \\
Kd & $16.43 \%$ \\
Ke & $23.49 \%$ \\
\hline WACC & $14.64 \%$ \\
\hline
\end{tabular}

Nota. Elaboración propia.

Con el COK y el WACC, se procede a calcular los principales indicadores

financieros en base al flujo de caja proyectado.

Tabla 63

Indicadores Financieros

\begin{tabular}{cc}
\hline Indicador Financiero & Valor \\
\hline VANE & 193,818 \\
TIRE & $36.96 \%$ \\
VANF & 408,326 \\
TIRF & $48.26 \%$ \\
\hline
\end{tabular}

Nota. Elaboración propia.

Tanto el VANE como el VANF son positivos; con valores de 193,818 y 408,326 esto nos indica que los flujos actualizados al período actual son mayores que los costos de inversión inicial, el pago de la deuda y los costos operativos en ambos casos, sin embargo, el VANF es superior al VANE por el costo de la inversión inicial cuando no se accede a un préstamo. Por otro lado, la TIRE y TIRF son positivas y superiores al COK y WACC respectivamente. La TIRF es superior a la TIRE, indicando que el esquema de préstamo es el deseable, ya que permite cubrir los costos operativos el primer año; así como el costo de inversión. 
El payback descontado, representa el tiempo que tarda en recuperarse la inversión, tomando en cuenta el año en los que se producen los flujos de caja. Asimismo, es adecuado para complementar el análisis financiero con los criterios rentabilidad VAN y TIR. La formula para calcular el payback es la siguiente:

$$
\text { Payback }=a+\frac{I_{0}-b}{F_{t}}
$$

Donde:

a: Es el número del período anterior hasta recuperar el desembolso inicial $I_{0}$ : Es la inversión inicial del proyecto

$b$ : Es la suma de los flujos hasta el final del período $a$

$F_{t}$ : Es el valor del flujo de caja del año en el que se recupera la inversión

Tabla 64

Payback descontado

\begin{tabular}{ccccccc}
\hline & 2018 & 2019 & 2020 & 2021 & \multicolumn{1}{c}{2022} & 2023 \\
\hline Flujo de caja & $-606,085$ & 258,832 & 243,024 & 299,145 & 319,278 & 387,335 \\
Flujo de caja descontado & & 225,778 & 184,916 & 198,550 & 184,850 & 195,614 \\
Flujo de caja acumulado & $-606,085$ & $-380,308$ & $-195,392$ & 3,158 & 188,008 & 383,623 \\
Período de recupero: & 3.98 & años & & & & \\
\hline
\end{tabular}

Nota. Elaboración propia.

Se tiene que el período de recuperación del capital es de 3.98 años (tabla 59); se calculó descontando los flujos en base al WACC, posteriormente se halla el flujo de caja acumulado, así obteniendo el período de recupero. 


\subsection{Análisis de riesgo}

\subsubsection{Análisis del punto de equilibrio}

El análisis del punto de equilibrio nos permitirá conocer la cantidad de matriculados y el nivel de ingresos que se necesita para no incurrir en pérdidas ni ganancias. Para ello, se calculan los gastos administrativos, de operación, de venta y financieros; es decir, los costos fijos y se divide entre el ingreso obtenido anualmente por alumno (3,200 soles). Obteniendo la cantidad de equilibrio. (ver Tabla 65)

Tabla 65

Estimación de punto de equilibrio (soles y cantidades)

\begin{tabular}{cccccc}
\hline & 2019 & 2020 & 2021 & 2022 & 2023 \\
\hline Costo fijo & & & & & \\
Cargas de Personal & $-492,000$ & $-501,840$ & $-511,877$ & $-522,114$ & $-532,557$ \\
Servicios prestados por terceros & $-80,469$ & $-91,386$ & $-93,214$ & $-107,972$ & $-167,461$ \\
Gastos financieros & $-54,605$ & $-41,105$ & $-31,623$ & $-20,583$ & $-7,729$ \\
\hline Total & 301,309 & 278,886 & 358,490 & 387,048 & 483,583 \\
\hline Punto de Equilibrio en S/ & & & & \\
\hline Total Ventas (soles) & 301,309 & 278,886 & 358,490 & 387,048 & 483,583 \\
\hline Punto de Equilibrio - Q & & & & \\
\hline Matrícula + Mensualidad & 91 & 85 & 109 & 117 \\
\hline
\end{tabular}

Nota. Elaboración propia.

\subsubsection{Análisis de sensibilidad}

El análisis de sensibilidad nos permitirá conocer la influencia sobre el TIR y VAN (variables de salida) al aumentar o disminuir el precio de la mensualidad, los costos fijos y la demanda de alumnado en el colegio (variables de entrada). Estas variables varían en diferentes porcentajes para realizar el análisis de sensibilidad (ver Tablas 66 ). Las variables de salida son el VAN económico (VANE), la tasa interna de retorno económico (TIRE), el VAN financiero (VANF) y la tasa interna de retorno financiero (TIRF), que ayudaran a medir cuánto afecta las variables de entrada al proyecto. 
Tabla 66

Análisis de sensibilidad Unidimensional

\begin{tabular}{cccc}
\hline & Precio & Demanda & Costos \\
\hline \% Variación & -13.37 & -15.68 & 19.43 \\
VANE & $-333,832$ & $-340,358$ & $-345,701$ \\
TIRE & $13.4 \%$ & $13.4 \%$ & $13.4 \%$ \\
VANF & 0 & 0 & 0 \\
TIRF & $15.1 \%$ & $15.1 \%$ & $15.1 \%$ \\
\hline
\end{tabular}

Nota. Elaboración propia.

Del análisis unidimensional se observa que el VAN Financiero se vuelve 0 cuando el precio de la matrícula disminuye en $13.37 \%$, cuando la demanda disminuye en $15.68 \%$ o cuando el costo del proyecto se incrementa en $19.43 \%$.

\subsubsection{Mitigación del riesgo}

Luego de identificar y analizar las posibles situaciones de riesgo del proyecto tomando como herramienta el análisis de sensibilidad, se concluye que las variables "precio de la mensualidad" y "cantidad demandada" representan un riesgo para el proyecto debido a su alta sensibilidad, siendo la situación más riesgosa la disminución del precio de la mensualidad. Se utiliza el análisis FODA junto a las variables identificadas en el capítulo XIII - Elaboración de la Estrategia. Se consideran dos variables para evaluar el nivel de riesgo. La primera es la probabilidad, que determina el nivel de ocurrencia de riesgo; la segunda es el impacto, que determina la importancia de los indicadores financieros de la IE Santiago Apóstol; ambas categorías son categóricas y se evalúan con una puntuación del 1 al 5. Finalmente, el nivel de riesgo se halla con la formula Nivel de Riesgo $=$ Probabilidad $*$ Impacto. El nivel de riesgo tiene una puntuación del 1 al 4: Bajo, Moderado, Alto y Extremo. La tabla 67 muestra las puntuaciones para los riesgos identificados. 
Tabla 67

Matriz de riesgos

\begin{tabular}{|c|c|c|c|}
\hline Riesgos Identificados & Probabilidad & Impacto & $\begin{array}{l}\text { Nivel de } \\
\text { riesgo }\end{array}$ \\
\hline Transición de docentes a la carrera pública magisterial & 4 & 4 & Extremo \\
\hline $\begin{array}{l}\text { Crecimiento de la oferta privada escolarizada (colegios y } \\
\text { academias pre-universitarias) y no escolarizada }\end{array}$ & 3 & 2 & Moderado \\
\hline Reducción del nivel de ingresos de los padres & 2 & 4 & Moderado \\
\hline Falta de estrategias de Marketing y publicidad & 1 & 3 & Bajo \\
\hline $\begin{array}{l}\text { Reducción en la tasa de crecimiento de la población en edad } \\
\text { escolar }\end{array}$ & 2 & 2 & Bajo \\
\hline $\begin{array}{l}\text { Tendencia a la baja en el crecimiento mundial (EE.UU, } \\
\text { China y Europa) }\end{array}$ & 3 & 3 & Moderado \\
\hline Crecimiento de la incidencia de trabajo infantil & 2 & 4 & Moderado \\
\hline Obsolescencia tecnológica de los materiales de computación & 4 & 2 & Moderado \\
\hline Reducción en la tasa de crecimiento del PBI Peruano & 3 & 2 & Moderado \\
\hline Reacción de la competencia invirtiendo en publicidad. & 4 & 3 & Alto \\
\hline
\end{tabular}

Nota. Elaboración propia.

Una de las variables con nivel de riesgo extremo se identifica a la transición de docentes a la carrera pública magisterial, debido principalmente a la Ley de Reforma Magisterial, que incorpora beneficios sociales, mejora de las remuneraciones y plazas para la carrera pública magisterial. Esta es la única variable que influirá significativamente en la rentabilidad de la empresa. Por otro lado, una variable tiene el riesgo alto es la reacción de la competencia invirtiendo en publicidad. Se espera que los colegios privados respondan de esta manera ante el proyecto y la construcción del nuevo local en general. Por último, entre las variables con riesgo moderado se tiene al crecimiento de la oferta privada escolarizada, la reducción del nivel de ingresos de los padres, la tendencia a la baja en el crecimiento mundial, la obsolescencia tecnológica de los materiales de computación y la reducción en la tasa de crecimiento del PBI peruano. 


\section{Tabla 68}

\section{Matriz de mitigaciones}

\begin{tabular}{|c|c|c|c|c|c|c|c|}
\hline & $\begin{array}{l}\text { Creación de una } \\
\text { base de datos para } \\
\text { reconocer el perfil } \\
\text { del consumidor. }\end{array}$ & $\begin{array}{l}\text { Implementación de } \\
\text { una estrategia de } \\
\text { marketing agresiva. }\end{array}$ & $\begin{array}{l}\text { Crear un } \\
\text { programa de } \\
\text { fidelización del } \\
\text { cliente }\end{array}$ & $\begin{array}{c}\text { Campaña publicitaria } \\
\text { masiva en diferentes } \\
\text { medios de } \\
\text { comunicación y redes } \\
\text { sociales. }\end{array}$ & $\begin{array}{l}\text { Becas para } \\
\text { alumnos } \\
\text { destacados. }\end{array}$ & $\begin{array}{c}\text { Ofertas en } \\
\text { mensualidades para } \\
\text { alumnos con vínculo } \\
\text { de hermanos. }\end{array}$ & $\begin{array}{c}\text { Ofrecer talleres } \\
\text { modelo gratuitos } \\
\text { durante el primer } \\
\text { trimestre para } \\
\text { demostrar la calidad } \\
\text { educativa. }\end{array}$ \\
\hline $\begin{array}{c}\text { Crecimiento de la oferta } \\
\text { privada escolarizada } \\
\text { (colegios y academias } \\
\text { pre-universitarias) y no } \\
\text { escolarizada }\end{array}$ & & & $X$ & & $X$ & & \\
\hline $\begin{array}{l}\text { Reducción del nivel de } \\
\text { ingresos de los padres }\end{array}$ & $x$ & & & & & & $x$ \\
\hline $\begin{array}{l}\text { Meducción en la tasa de } \\
\text { crecimiento de la } \\
\text { población en edad escolar }\end{array}$ & $x$ & $\boldsymbol{\Lambda}$ & $\boldsymbol{\Lambda}$ & 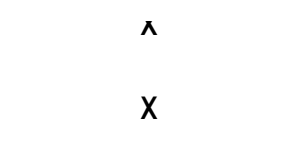 & & & $\wedge$ \\
\hline $\begin{array}{l}\text { Tendencia a la baja en el } \\
\text { crecimiento mundial } \\
\text { (EE.UU, China y Europa) }\end{array}$ & $X$ & & & & $X$ & $X$ & $X$ \\
\hline $\begin{array}{c}\text { Crecimiento de la } \\
\text { incidencia de trabajo } \\
\text { infantil }\end{array}$ & & & & & $x$ & & $X$ \\
\hline $\begin{array}{l}\text { Reducción en la tasa de } \\
\text { crecimiento del PBI } \\
\text { Peruano }\end{array}$ & & $x$ & & & $x$ & & \\
\hline $\begin{array}{l}\text { Reacción de la } \\
\text { competencia invirtiendo } \\
\text { en publicidad. }\end{array}$ & & $x$ & $X$ & $x$ & & & \\
\hline
\end{tabular}

Nota. Elaboración propia 


\section{CONCLUSIONES Y RECOMENDACIONES CONCLUSIONES}

Se han llegado a las siguientes conclusiones al diseñar el plan estratégico para la IEP Santiago Apóstol:

1) La IEP Santiago Apóstol ha identificado que responde de manera regular a las oportunidades y amenazas en lo que respecta a los factores externos; sin embargo, no se están aprovechando con eficacia las oportunidades existentes, ni minimizando los posibles efectos negativos de las amenazas externas.

2) La IEP Santiago Apóstol tiene una posición interna desfavorable; porque no posee una ventaja competitiva que le permita afrontar los desafíos de su industria.

3) Se han planteado dos estrategias para la IEP Santiago Apóstol, para mejorar la eficacia, eficiencia con la formulación de una estrategia principal: "mejorar los procesos internos de la IEP optimizando la distribución de costos y gastos" y como estrategia contingente "Adicionar al currículo vigente talleres extra curriculares de acuerdo a los intereses particulares del estudiante, con el fin de desarrollar nuevos productos que generen mayores ingresos".

4) La implementación del plan estratégico es viable, debido a que el VANE y VANF muestran resultados positivos con S/ 193,818 y $\mathrm{S} / 408,326$ respectivamente; los indicadores de la TIRE y TIRF tienen valores superiores al COK Y WACC respectivamente, con $36.96 \%$ y $48.26 \%$ 


\section{RECOMENDACIONES}

1) La IEP Santiago Apóstol debe de tomar en cuenta las oportunidades y amenazas identificadas en el análisis externo, para así poder minimizar los efectos negativos y maximizar las oportunidades presentadas a la institución.

2) La IEP Santiago Apóstol al reconocer sus fortalezas y debilidades del análisis interno y al aplicar las estrategias internas planteadas, desarrollará ventajas para hacer frente a la competencia.

3) Se recomienda que la IEP Santiago Apóstol considere la implementación de las estrategias planteadas para ganar una mayor representatividad en el distrito de Santiago, a través de la diferenciación del servicio educativo ofrecido a los estudiantes.

4) Se recomienda implementar el plan estratégico ya que los indicadores financieros tienen resultados positivos, demostrando su viabilidad; asimismo, se logrará una mejor posición competitiva en el mercado educativo del distrito de Santiago e incremento de la rentabilidad. 


\section{BIBLIOGRAFÍA}

Ambito. (14 de Mayo de 2018). Riesgo pais para el Perú. Obtenido de Ambito.com: http://www.ambito.com/economia/mercados/riesgo-pais/info/?id=13

APEIM. (15 de Julio de 2018). Niveles Socioeconomicos 2018. Obtenido de Asociación Peruana de Investigación de Mercados: http://www.apeim.com.pe/wpcontent/themes/apeim/docs/nse/APEIM-NSE-2017.pdf

Banco Interamericano de Desarrollo. (2017). Aprender Mejor - Políticas Públicas para el desarrollo de habilidades. Washington D.C.: Biblioteca Felipe Herrera.

C. Hax, A., \& Majluf, N. (2004). Estrategias para el Liderazgo Competitivo. Buenos Aires: Granica.

Caja Cusco. (15 de Julio de 2018). Simultador de Créditos. Obtenido de Caja Cusco Web Site: https://zonasegura.cmac-cusco.com.pe/simuladorweb/fmSimuladorCredito.aspx

Daft, R. L. (2011). Teoria y Diseño Organizacional. Santa Fe, Mexico DF: Cengage Learning Editores SA de CV.

Damodaran, A. (14 de Mayo de 2018). Implied Equity Risk Premium . Obtenido de Damoradan Online: http://pages.stern.nyu.edu/ adamodar/

David, F. R. (2013). Conceptos de Administración Estrátegica. Ciudad de México: Pearson Educación de México.

ESCALE. (15 de Julio de 2018). Resultados de la Evaluaci'on Censal de Estudiantes - ECE 2016. Obtenido de Sitio Web del Ministerio de Educación: http://umc.minedu.gob.pe/wp-content/uploads/2017/04/Descargarpresentaci\%C3\%B3n-Cusco.pdf

Hamada, R. (1972). The Effect of the Firm's Capital Structure on the Systematic Risk of Common Stocks. The Journal of Finance, 435-452.

Hill, C. W., \& Jones, G. R. (2014). Strategic Management: An Integrated Approach. Boston: Houghton Mifflin Company.

INEI. (2018). Censos Nacionales 2017: XII de Población, VII de Vivienda y III de Comunidades Indígenas. Obtenido de Sitio Web del Instituto Nacional de Estadística e Informática: http://censos2017.inei.gob.pe/redatam/

Johnson, G. S. (2006). Direccion Estrategica. Madrid: Pearson Educación.

Jopen, G., Gomez, W., \& Olivera, H. (2014). Sistema Educativo Peruano: Balance y Agenda Pendiente. Lima: Documento de Trabajo 379 - Departamento de Economía PUCP.

Kaplan, R. S., \& Norton, D. P. (2001). The Strategy-Focused Organization: How Balanced Scorecard Companies Thrive in the New Business Environment. Boston: Harvard Business School Press.

Kim, W. C., \& Mauborgne, R. (2005). Blue Ocean Strategy: How to Create Uncontested Market Space and Make Competition Irrelevant. Boston: Harvard Business School Press.

Kotler, P., \& Keller, K. (2012). Dirección de Marketing. Ciudad de México: Pearson Educación.

Levitt, T. (1965). Exploit the Product Life Cycle. Harvard Business Review. 
Luque, A., Barrientos, S., \& Pérez, I. (2017). La Educación Peruana y el Desarrollo Sostenible. Ciencia \& Desarrollo $n .^{\circ} 8,44-48$.

Martinez, E., C., Ledesma, J. S., \& Russo, A. O. (2014). Modelos de cálculo de las betas a aplicar en el Capital Asset Pricing Model. Estudios Gerenciales, 200-208.

Miles, J. A., \& Ezzell, J. R. (1980). The Weighted Average Cost of Capital, Perfect Capital Markets, and Project Life: A Clarification. The Journal of Financial and Quantitative Analysis, 719-730.

Ministerio de Educación. (2016). Plan Nacional de Educación Ambiental 2017-2022. Lima: Nacional.

Ministerio de Educacion. (23 de Mayo de 2018). ESCALE Tendencias 2016. Obtenido de ESCALE: http://escale.minedu.gob.pe/ueetendencias 2016

Pearce, J. (1982). Problems facing first-time managers. Human Resource Management Volume 21, 35-38.

Porter, M. (1979). How Competitive Forces Shape Strategy . Harvard Business Review, 137145.

Prahalad, C., \& Hamel, G. (1990). The Core Competence of the Corporation. Harvard Bussiness Review, 25-30.

Serna, H. (2008). Gerencia Estratégica. Bogotá: DC 3R Editores.

SUNAT. (14 de Mayo de 2018). Acerca del Impuesto a la Renta. Obtenido de SUNAT: http://www.sunat.gob.pe/legislacion/renta/index.html

Thompson, A., Gamble, J., Peteraf, M., \& Strickland III, A. (2012). Administración Estratégica. Ciudad de México: McGraw Hill.

UNESCO. (2017). Revisión de las políticas educativas 2000-2015. Continuidades en las políticas públicas en educación en Perú: aprendizajes, docentes y gestión descentralizada. Lima: Biblioteca Nacional del Perú.

W., P. M. (2014). Global Strategy (Onceava ed.). México D.F.: Cengage Learning. 


\section{Anexos}

\section{Anexo 1}

\section{Procedimiento Autorización de Apertura Institución Educativa}

Según el nuevo Reglamento de las Instituciones Privadas de Educación Básica y Educación Técnico Productiva de la Ley 26549 Ley de los Centros Educativos Privados en sus artículos 4,5 y 6 nos hablan del procedimiento que debe seguir la empresa que desea acceder a la autorización de funcionamiento de su Centro Educativo debiendo presentar una solicitud escrita con copia digital hasta el último día hábil del mes de octubre del año anterior a la apertura. La solicitud debe contener lo siguiente:

a. Nombre o Razón Social e identificación del propietario o promotor, incluyendo el número de su Registro Único del Contribuyente (RUC).

b. Nombre propuesto para la Institución educativa.

c. Nombre del director.

d. Integrantes del Comité Directivo de ser el caso y número de personal docente y administrativo.

e. Información sobre los niveles y modalidades que atenderá la Institución educativa.

f. Fecha prevista para el inicio de las actividades académicas, periodicidad y término del año escolar en el marco de la calendarización flexible y el cumplimiento del mínimo de horas de trabajo pedagógico. El inicio de la forma escolarizada debe coincidir con el inicio del próximo año lectivo establecido a nivel nacional y/o regional según corresponda. 
g. Número probable de alumnos y secciones que funcionarán al inicio del servicio educativo.

h. Proyecto Educativo Institucional (PEI), Proyecto Curricular de Centro (PCC) conforme a las normas específicas, sobre la base del Diseño Curricular Nacional y su diversificación correspondiente y el Reglamento Interno (RI).

i. Inventario de mobiliario escolar, material educativo pertinente, equipos y bienes con que contará la Institución educativa al iniciar sus actividades.

j. Plano de ubicación de la Institución educativa por crearse.

k. Plano de distribución del local que ocupará la Institución educativa, acompañado del respectivo informe sobre la idoneidad de las instalaciones en relación al número previsto de alumnos, suscrito por un Arquitecto o Ingeniero Civil colegiado, así como el informe de Defensa Civil.

1. Copia del título de propiedad del terreno o local o copia del contrato de alquiler del local que ocupará la Institución educativa. 


\section{Anexo 2 \\ Encuesta para padres de familia de la Institución Educativa Santiago Apóstol del distrito de Santiago-Cusco}

Estimado Padre/Madre de Familia:

A continuación, encontrará algunas preguntas sobre la Institución Educativa en la que estudia(n) su(s) hijo(s) o hija(s).

Le pedimos que responda con la mayor sinceridad. No hay respuestas correctas o incorrectas. Se trata de recoger información sobre el colegio, para que pueda mejorar. Muchas gracias por su colaboración.

INSTRUCCIONES: Marque con una equis $(X)$ sobre la opción que se parezca más a lo que sucede en la IEP Santiago Apóstol del Distrito de Santiago.

Debe marcar la escala 1 calificación baja al 5 calificación alta en todas las opciones de las preguntas.

1. Como es la calidad de servicio respecto a la enseñanza que reciben sus hijos (as);
Excelente Muy Bueno 5 4
Bueno
3
Regular
2
Deficiente
1

2. Los costes respecto al derecho de enseñanza son accesibles para la educación de sus hijos (as);

$\begin{array}{lllll}\text { Excelente } & \text { Muy Bueno } & \text { Bueno } & \text { Regular } & \text { Deficiente } \\ 5 & 4 & 3 & 2 & 1\end{array}$

3. El material de enseñanza que utilizan los docentes en la formación de sus hijos (as) es;

$\begin{array}{lllll}\text { Excelente } & \text { Muy Bueno } & \text { Bueno } & \text { Regular } & \text { Deficiente } \\ 5 & 4 & 3 & 2 & 1\end{array}$

4. Los docentes que enseñan en la IEP Santiago Apóstol tienen una formación y capacitación;

$\begin{array}{lllll}\text { Excelente } & \text { Muy Bueno } & \text { Bueno } & \text { Regular } & \text { Deficiente } \\ 5 & 4 & 3 & 2 & 1\end{array}$


5. Considera que la puntualidad en el inicio y finalización de las clases es;
Excelente
Muy Bueno
Bueno
Regular
Deficiente
5
4
3
2
1

6. Como considera la disciplina de los docentes y trabajadores administrativos en la IEP Santiago Apóstol;
Excelente
Muy Bueno
Bueno
Regular
Deficiente
5
4
3
2
1

7. Como considera el aula (infraestructura) donde recibe enseñanza su hijo(a);
Excelente
Muy Bueno
Bueno
Regular
Deficiente
5
4
3
2
1

8. El mobiliario educativo que utiliza su hijo(a) es;

$\begin{array}{lllll}\text { Excelente } & \text { Muy Bueno } & \text { Bueno } & \text { Regular } & \text { Deficiente } \\ 5 & 4 & 3 & 2 & 1\end{array}$

9. Las vacantes que oferta la IEP Santiago Apóstol es;

$\begin{array}{lllll}\text { Excelente } & \text { Muy Bueno } & \text { Bueno } & \text { Regular } & \text { Deficiente } \\ 5 & 4 & 3 & 2 & 1\end{array}$




\section{Anexo 3}

\section{Tabulación de la encuesta para padres de familia de las instituciones educativas privadas del distrito de Santiago-Cusco}

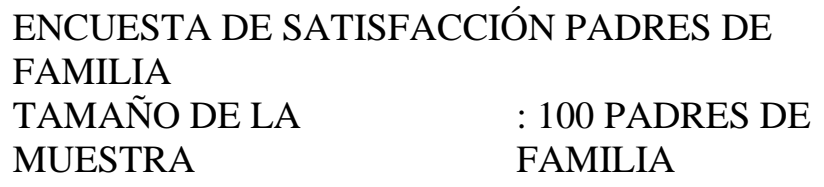

CALIFICACIÓN PREGUNTAS DEL 1 AL 9

\begin{tabular}{|r|l|}
\hline 5 & Excelente \\
\hline 4 & Muy Bueno \\
\hline 3 & Bueno \\
\hline 2 & Regular \\
\hline 1 & Malo \\
\hline & \\
\hline
\end{tabular}

\begin{tabular}{|c|c|c|c|c|c|c|c|c|c|}
\hline Numero de encuesta & $\begin{array}{c}\text { Como es la calidad de } \\
\text { servicio respecto a la } \\
\text { enseñanza que reciben sus } \\
\text { hijos (as); }\end{array}$ & $\begin{array}{l}\text { Los costes } \\
\text { respecto al derecho } \\
\text { de enseñanza son } \\
\text { accesibles para la } \\
\text { educación de sus } \\
\text { hijos (as); }\end{array}$ & $\begin{array}{c}\text { El material de } \\
\text { enseñanza } \\
\text { que utilizan } \\
\text { los docentes } \\
\text { en la } \\
\text { formación de } \\
\text { sus hijos (as) } \\
\text { es; }\end{array}$ & $\begin{array}{c}\text { Los } \\
\text { docentes que } \\
\text { enseñan en } \\
\text { la IEP } \\
\text { Santiago } \\
\text { Apóstol } \\
\text { tienen una } \\
\text { formación y } \\
\text { capacitación } \\
\text {; }\end{array}$ & $\begin{array}{l}\text { Considera } \\
\text { que la } \\
\text { puntualida } \\
\text { d en el } \\
\text { inicio y } \\
\text { finalizació } \\
\text { n de las } \\
\text { clases es; }\end{array}$ & $\begin{array}{c}\text { Como } \\
\text { considera la } \\
\text { disciplina de } \\
\text { los docentes y } \\
\text { trabajadores } \\
\text { administrativo } \\
\text { s en la IEP } \\
\text { Santiago } \\
\text { Apóstol; }\end{array}$ & $\begin{array}{c}\text { Como } \\
\text { considera el } \\
\text { aula } \\
\text { (infraestructura } \\
\text { ) donde recibe } \\
\text { enseñanza su } \\
\text { hijo(a) }\end{array}$ & $\begin{array}{c}\text { El } \\
\text { mobiliari } \\
\text { o } \\
\text { educativo } \\
\text { que } \\
\text { utiliza su } \\
\text { hijo(a) es; }\end{array}$ & $\begin{array}{c}\text { Las } \\
\text { vacantes } \\
\text { que } \\
\text { oferta la } \\
\text { IEP } \\
\text { Santiag } \\
\text { o } \\
\text { Apóstol } \\
\text { es; }\end{array}$ \\
\hline 1 & 4 & 3 & 5 & 3 & 3 & 3 & 3 & 4 & 3 \\
\hline 2 & 5 & 3 & 5 & 4 & 3 & 5 & 3 & 3 & 2 \\
\hline 3 & 4 & 3 & 5 & 3 & 3 & 3 & 3 & 4 & 3 \\
\hline
\end{tabular}




\begin{tabular}{|c|c|c|c|c|c|c|c|c|c|}
\hline 4 & 4 & 3 & 5 & 4 & 3 & 4 & 3 & 3 & 2 \\
\hline 5 & 4 & 3 & 5 & 5 & 3 & 3 & 3 & 3 & 2 \\
\hline 6 & 4 & 3 & 5 & 5 & 3 & 3 & 3 & 3 & 2 \\
\hline 7 & 4 & 3 & 5 & 4 & 3 & 3 & 3 & 3 & 2 \\
\hline 8 & 4 & 4 & 5 & 3 & 3 & 3 & 3 & 3 & 2 \\
\hline 9 & 4 & 4 & 4 & 4 & 3 & 3 & 3 & 3 & 2 \\
\hline 10 & 4 & 4 & 5 & 4 & 3 & 3 & 3 & 4 & 2 \\
\hline 11 & 4 & 4 & 4 & 4 & 3 & 3 & 4 & 4 & 2 \\
\hline 12 & 5 & 4 & 4 & 3 & 3 & 3 & 3 & 2 & 1 \\
\hline 13 & 4 & 4 & 5 & 5 & 3 & 3 & 3 & 2 & 2 \\
\hline 14 & 4 & 4 & 4 & 3 & 4 & 4 & 3 & 3 & 2 \\
\hline 15 & 5 & 4 & 4 & 3 & 4 & 4 & 3 & 3 & 2 \\
\hline 16 & 4 & 4 & 4 & 3 & 3 & 4 & 2 & 3 & 2 \\
\hline 17 & 4 & 3 & 4 & 4 & 3 & 4 & 3 & 3 & 2 \\
\hline 18 & 4 & 3 & 5 & 5 & 3 & 4 & 3 & 3 & 3 \\
\hline 19 & 4 & 3 & 5 & 5 & 3 & 3 & 3 & 3 & 2 \\
\hline 20 & 4 & 3 & 5 & 5 & 3 & 3 & 3 & 3 & 2 \\
\hline 21 & 4 & 3 & 3 & 4 & 3 & 3 & 3 & 3 & 2 \\
\hline 22 & 4 & 3 & 3 & 5 & 4 & 4 & 3 & 3 & 1 \\
\hline 23 & 4 & 4 & 3 & 5 & 3 & 4 & 3 & 3 & 2 \\
\hline 24 & 5 & 3 & 5 & 4 & 3 & 4 & 3 & 3 & 2 \\
\hline 25 & 5 & 3 & 5 & 4 & 3 & 3 & 3 & 4 & 2 \\
\hline 26 & 5 & 3 & 5 & 4 & 3 & 4 & 3 & 4 & 2 \\
\hline 27 & 5 & 3 & 3 & 4 & 3 & 3 & 3 & 4 & 2 \\
\hline 28 & 4 & 3 & 5 & 5 & 4 & 4 & 3 & 4 & 3 \\
\hline 29 & 4 & 3 & 5 & 5 & 4 & 5 & 3 & 4 & 3 \\
\hline 30 & 5 & 3 & 3 & 4 & 4 & 4 & 3 & 4 & 3 \\
\hline
\end{tabular}




\begin{tabular}{|c|c|c|c|c|c|c|c|c|c|}
\hline 31 & 5 & 3 & 3 & 4 & 4 & 4 & 3 & 4 & 3 \\
\hline 32 & 4 & 3 & 3 & 4 & 3 & 4 & 3 & 4 & 3 \\
\hline 33 & 4 & 3 & 3 & 5 & 4 & 4 & 3 & 3 & 3 \\
\hline 34 & 4 & 3 & 5 & 5 & 4 & 4 & 3 & 4 & 3 \\
\hline 35 & 4 & 3 & 5 & 4 & 3 & 4 & 3 & 3 & 2 \\
\hline 36 & 4 & 3 & 4 & 4 & 3 & 4 & 3 & 3 & 1 \\
\hline 37 & 4 & 4 & 4 & 5 & 3 & 4 & 3 & 3 & 2 \\
\hline 38 & 4 & 4 & 5 & 4 & 3 & 4 & 3 & 3 & 2 \\
\hline 39 & 3 & 3 & 4 & 3 & 3 & 3 & 3 & 3 & 2 \\
\hline 40 & 3 & 3 & 5 & 3 & 3 & 3 & 3 & 4 & 3 \\
\hline 41 & 3 & 3 & 5 & 4 & 3 & 3 & 3 & 3 & 2 \\
\hline 42 & 3 & 4 & 4 & 4 & 3 & 3 & 3 & 4 & 2 \\
\hline 43 & 3 & 4 & 4 & 4 & 3 & 3 & 2 & 3 & 2 \\
\hline 44 & 4 & 4 & 4 & 4 & 3 & 3 & 2 & 3 & 2 \\
\hline 45 & 3 & 4 & 4 & 4 & 4 & 4 & 3 & 4 & 3 \\
\hline 46 & 3 & 4 & 5 & 4 & 3 & 4 & 2 & 3 & 2 \\
\hline 47 & 3 & 5 & 5 & 5 & 3 & 4 & 2 & 3 & 2 \\
\hline 48 & 3 & 3 & 4 & 5 & 3 & 4 & 3 & 3 & 1 \\
\hline 49 & 4 & 3 & 3 & 5 & 3 & 3 & 3 & 3 & 3 \\
\hline 50 & 4 & 3 & 5 & 4 & 3 & 3 & 3 & 3 & 3 \\
\hline 51 & 4 & 3 & 5 & 4 & 3 & 3 & 3 & 3 & 3 \\
\hline 52 & 3 & 3 & 5 & 4 & 3 & 3 & 3 & 3 & 3 \\
\hline 53 & 4 & 3 & 5 & 4 & 3 & 3 & 3 & 3 & 3 \\
\hline 54 & 3 & 3 & 4 & 4 & 3 & 3 & 3 & 4 & 3 \\
\hline 55 & 4 & 4 & 5 & 4 & 3 & 3 & 3 & 4 & 3 \\
\hline 56 & 5 & 3 & 4 & 3 & 3 & 3 & 3 & 4 & 3 \\
\hline 57 & 3 & 3 & 4 & 4 & 4 & 4 & 3 & 4 & 3 \\
\hline
\end{tabular}




\begin{tabular}{|c|c|c|c|c|c|c|c|c|c|}
\hline 58 & 3 & 3 & 5 & 4 & 4 & 4 & 3 & 3 & 2 \\
\hline 59 & 3 & 3 & 4 & 4 & 3 & 3 & 2 & 2 & 1 \\
\hline 60 & 5 & 3 & 5 & 5 & 3 & 4 & 3 & 3 & 2 \\
\hline 61 & 4 & 3 & 4 & 4 & 3 & 4 & 3 & 3 & 2 \\
\hline 62 & 4 & 3 & 5 & 4 & 3 & 4 & 3 & 3 & 2 \\
\hline 63 & 4 & 3 & 5 & 3 & 3 & 3 & 2 & 2 & 1 \\
\hline 64 & 4 & 3 & 4 & 4 & 3 & 3 & 3 & 3 & 2 \\
\hline 65 & 4 & 3 & 4 & 4 & 3 & 4 & 3 & 3 & 2 \\
\hline 66 & 4 & 4 & 4 & 5 & 3 & 4 & 3 & 3 & 3 \\
\hline 67 & 4 & 3 & 4 & 4 & 4 & 4 & 3 & 3 & 2 \\
\hline 68 & 3 & 4 & 4 & 4 & 4 & 4 & 3 & 3 & 2 \\
\hline 69 & 3 & 3 & 3 & 4 & 3 & 4 & 2 & 2 & 1 \\
\hline 70 & 3 & 3 & 3 & 5 & 3 & 4 & 2 & 2 & 2 \\
\hline 71 & 3 & 4 & 5 & 5 & 4 & 4 & 3 & 3 & 3 \\
\hline 72 & 3 & 4 & 4 & 4 & 3 & 4 & 2 & 3 & 2 \\
\hline 73 & 3 & 3 & 4 & 5 & 3 & 4 & 3 & 3 & 2 \\
\hline 74 & 3 & 3 & 4 & 3 & 3 & 4 & 3 & 3 & 2 \\
\hline 75 & 3 & 3 & 4 & 3 & 3 & 4 & 2 & 3 & 2 \\
\hline 76 & 3 & 3 & 4 & 3 & 3 & 4 & 2 & 3 & 2 \\
\hline 77 & 3 & 3 & 4 & 3 & 4 & 4 & 3 & 3 & 3 \\
\hline 78 & 3 & 3 & 5 & 4 & 3 & 3 & 2 & 3 & 2 \\
\hline 79 & 3 & 3 & 3 & 4 & 3 & 4 & 2 & 3 & 2 \\
\hline 80 & 3 & 3 & 4 & 4 & 4 & 4 & 3 & 2 & 2 \\
\hline 81 & 3 & 3 & 4 & 3 & 3 & 3 & 3 & 2 & 1 \\
\hline 82 & 3 & 3 & 5 & 4 & 4 & 4 & 2 & 2 & 2 \\
\hline 83 & 3 & 3 & 5 & 4 & 3 & 4 & 2 & 2 & 1 \\
\hline 84 & 3 & 3 & 4 & 4 & 4 & 4 & 2 & 2 & 2 \\
\hline
\end{tabular}




\begin{tabular}{|c|c|c|c|c|c|c|c|c|c|}
\hline 85 & 3 & 3 & 4 & 5 & 3 & 4 & 3 & 2 & 2 \\
\hline 86 & 4 & 3 & 4 & 4 & 4 & 4 & 3 & 2 & 2 \\
\hline 87 & 3 & 3 & 5 & 4 & 4 & 5 & 3 & 2 & 2 \\
\hline 88 & 3 & 3 & 4 & 3 & 4 & 4 & 3 & 2 & 2 \\
\hline 89 & 3 & 3 & 4 & 3 & 4 & 4 & 4 & 2 & 2 \\
\hline 90 & 4 & 3 & 5 & 4 & 4 & 4 & 4 & 2 & 2 \\
\hline 91 & 4 & 3 & 5 & 4 & 4 & 5 & 3 & 2 & 1 \\
\hline 92 & 4 & 3 & 4 & 4 & 4 & 4 & 3 & 2 & 2 \\
\hline 93 & 4 & 3 & 4 & 3 & 3 & 4 & 3 & 2 & 2 \\
\hline 94 & 4 & 3 & 5 & 3 & 3 & 4 & 3 & 3 & 2 \\
\hline 95 & 4 & 3 & 5 & 4 & 4 & 4 & 3 & 3 & 2 \\
\hline 96 & 4 & 3 & 5 & 3 & 3 & 5 & 3 & 3 & 2 \\
\hline 97 & 5 & 3 & 4 & 3 & 3 & 3 & 3 & 3 & 2 \\
\hline 98 & 4 & 3 & 4 & 4 & 4 & 3 & 3 & 2 & 2 \\
\hline 99 & 4 & 3 & 4 & 4 & 4 & 4 & 3 & 2 & 3 \\
\hline 100 & 5 & 3 & 4 & 4 & 3 & 3 & 3 & 2 & 3 \\
\hline
\end{tabular}




\section{Anexo 4}

\section{ENCUESTA DE CLIMA ORGANIZACIONAL}

La presente encuesta tiene como fin conocer su opinión del clima y cultura organizacional en su institución educativa para un trabajo de investigación. Esta encuesta es anónima y su opinión será preservada.

\begin{tabular}{|c|c|c|c|c|c|}
\hline \multirow[t]{2}{*}{$\mathbf{N}^{\circ}$} & \multirow[t]{2}{*}{ PREGUNTAS } & $\begin{array}{c}\text { Totalmente } \\
\text { en } \\
\text { desacuerdo }\end{array}$ & $\begin{array}{c}\text { En } \\
\text { desacuerdo }\end{array}$ & $\begin{array}{c}\text { De } \\
\text { acuerdo }\end{array}$ & $\begin{array}{l}\text { Totalmente } \\
\text { de acuerdo }\end{array}$ \\
\hline & & 1 & 2 & 3 & 4 \\
\hline 1 & $\begin{array}{l}\text { Mi jefe me indica con claridad los } \\
\text { resultados que espera de mi trabajo }\end{array}$ & & & & \\
\hline 2 & $\begin{array}{l}\text { Estoy informado de los } \\
\text { acontecimientos importantes } \\
\text { relacionados al colegio. }\end{array}$ & & & & \\
\hline 3 & $\begin{array}{l}\text { Existe coordinación eficaz con las } \\
\text { demás áreas para cumplir mis metas } \\
\text { oportunamente }\end{array}$ & & & & \\
\hline 4 & $\begin{array}{l}\text { Puedo iniciar una conversación con } \\
\text { mi jefe fácilmente }\end{array}$ & & & & \\
\hline 5 & $\begin{array}{l}\text { En mi área se conoce la visión del } \\
\text { colegio y sabemos cómo actuar para } \\
\text { hacerla realidad. }\end{array}$ & & & & \\
\hline 6 & $\begin{array}{l}\text { Conozco cuáles son los valores que } \\
\text { se practican en la organización }\end{array}$ & & & & \\
\hline 7 & $\begin{array}{l}\text { Las actividades que realizo son las } \\
\text { que corresponden a mi puesto de } \\
\text { trabajo }\end{array}$ & & & & \\
\hline 8 & $\begin{array}{l}\text { Las metas y estrategias de la } \\
\text { empresa son conocidas por todos }\end{array}$ & & & & \\
\hline 9 & $\begin{array}{l}\text { Mi trabajo es importante para la } \\
\text { institución. }\end{array}$ & & & & \\
\hline 10 & $\begin{array}{l}\text { Puedo hacer uso de mis habilidades } \\
\text { en esta organización }\end{array}$ & & & & \\
\hline 11 & $\begin{array}{l}\text { Recibo reconocimientos cuando } \\
\text { realizo bien mi trabajo. }\end{array}$ & & & & \\
\hline 12 & $\begin{array}{l}\text { Participo en capacitaciones } \\
\text { organizadas por la institución para } \\
\text { desarrollarme como profesional }\end{array}$ & & & & \\
\hline 13 & $\begin{array}{l}\text { Considero que mi remuneración está } \\
\text { acorde al trabajo que realizo }\end{array}$ & & & & \\
\hline 14 & $\begin{array}{l}\text { Mi trabajo permite que tenga un } \\
\text { balance entre mi vida personal y } \\
\text { laboral. }\end{array}$ & & & & \\
\hline 15 & $\begin{array}{l}\text { Me tratan bien, sin importar mis } \\
\text { condiciones socio económicas }\end{array}$ & & & & \\
\hline 16 & $\begin{array}{l}\text { La empresa me ofrece beneficios } \\
\text { adicionales a los de ley. }\end{array}$ & & & & \\
\hline
\end{tabular}




\begin{tabular}{|c|l|l|l|l|l|}
\hline 17 & $\begin{array}{l}\text { Siento que puedo contar con el } \\
\text { apoyo de mis colegas. }\end{array}$ & & & \\
\hline 18 & $\begin{array}{l}\text { Mi jefe trata a su equipo sin } \\
\text { preferencias. }\end{array}$ & & & & \\
\hline 19 & $\begin{array}{l}\text { El colegio me brinda las } \\
\text { herramientas para cumplir con los } \\
\text { resultados que me pide }\end{array}$ & & & & \\
\hline 20 & $\begin{array}{l}\text { Mi jefe me permite participar en } \\
\text { decisiones importantes. }\end{array}$ & & & & \\
\hline
\end{tabular}




\section{Anexo 5}

\section{Tabulación de encuesta de clima laboral}

ENCUESTA DE SATISFACCIÓN CLIMA LABORAL

TAMAÑO DE LA MUESTRA : 25 Colaboradores

AÑO DE APLICACIÓN 2017

\section{CALIFICACIÓN PREGUNTAS DEL 1 AL 9}

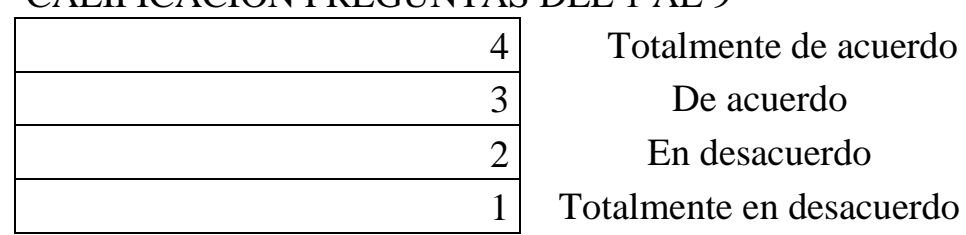

\begin{tabular}{|c|c|c|c|c|c|c|c|c|c|c|c|c|c|c|c|c|c|c|c|c|}
\hline Preguntas & $\mathbf{1}$ & $\mathbf{2}$ & $\mathbf{3}$ & $\mathbf{4}$ & $\mathbf{5}$ & $\mathbf{6}$ & $\mathbf{7}$ & $\mathbf{8}$ & $\mathbf{9}$ & $\mathbf{1 0}$ & $\mathbf{1 1}$ & $\mathbf{1 2}$ & $\mathbf{1 3}$ & $\mathbf{1 4}$ & $\mathbf{1 5}$ & $\mathbf{1 6}$ & $\mathbf{1 7}$ & $\mathbf{1 8}$ & $\mathbf{1 9}$ & $\mathbf{2 0}$ \\
\hline 1 & 4 & 3 & 3 & 4 & 3 & 4 & 4 & 3 & 4 & 3 & 3 & 3 & 4 & 3 & 3 & 4 & 3 & 3 & 3 & 3 \\
\hline 2 & 2 & 3 & 3 & 4 & 3 & 3 & 3 & 3 & 3 & 2 & 2 & 3 & 3 & 3 & 3 & 2 & 2 & 3 & 3 & 2 \\
\hline 3 & 4 & 2 & 3 & 3 & 3 & 4 & 4 & 4 & 4 & 3 & 3 & 1 & 3 & 3 & 3 & 3 & 3 & 1 & 1 & 3 \\
\hline 4 & 3 & 3 & 3 & 3 & 4 & 3 & 3 & 3 & 4 & 4 & 3 & 4 & 3 & 3 & 4 & 3 & 4 & 3 & 4 & 3 \\
\hline 5 & 3 & 3 & 3 & 3 & 3 & 3 & 3 & 3 & 3 & 3 & 3 & 3 & 3 & 3 & 3 & 3 & 3 & 3 & 3 & 3 \\
\hline 6 & 3 & 3 & 3 & 4 & 3 & 4 & 4 & 3 & 4 & 4 & 3 & 4 & 3 & 4 & 4 & 3 & 4 & 3 & 4 & 3 \\
\hline 7 & 4 & 3 & 4 & 4 & 3 & 3 & 3 & 4 & 4 & 3 & 3 & 3 & 3 & 3 & 4 & 3 & 4 & 3 & 3 & 3 \\
\hline 8 & 3 & 4 & 4 & 3 & 4 & 4 & 4 & 4 & 4 & 4 & 2 & 4 & 3 & 4 & 4 & 2 & 4 & 3 & 4 & 3 \\
\hline 9 & 4 & 4 & 3 & 3 & 4 & 4 & 4 & 4 & 4 & 4 & 3 & 4 & 2 & 4 & 4 & 3 & 4 & 4 & 3 & 2 \\
\hline
\end{tabular}




\begin{tabular}{|c|c|c|c|c|c|c|c|c|c|c|c|c|c|c|c|c|c|c|c|c|}
\hline 10 & 3 & 4 & 4 & 4 & 2 & 4 & 4 & 4 & 4 & 3 & 4 & 3 & 3 & 4 & 4 & 3 & 4 & 4 & 4 & 3 \\
\hline 11 & 3 & 4 & 4 & 4 & 2 & 4 & 4 & 4 & 4 & 3 & 4 & 3 & 3 & 4 & 4 & 3 & 4 & 4 & 4 & 3 \\
\hline 12 & 4 & 4 & 3 & 4 & 4 & 4 & 4 & 4 & 4 & 4 & 4 & 4 & 4 & 4 & 4 & 4 & 4 & 4 & 4 & 4 \\
\hline 13 & 3 & 4 & 3 & 4 & 3 & 4 & 4 & 3 & 4 & 4 & 3 & 3 & 3 & 4 & 4 & 3 & 4 & 3 & 4 & 4 \\
\hline 14 & 4 & 4 & 4 & 4 & 4 & 4 & 4 & 3 & 4 & 4 & 3 & 4 & 3 & 4 & 4 & 3 & 4 & 4 & 4 & 4 \\
\hline 15 & 4 & 4 & 3 & 3 & 4 & 4 & 4 & 4 & 4 & 4 & 3 & 3 & 3 & 4 & 4 & 4 & 3 & 3 & 4 & 3 \\
\hline 16 & 3 & 4 & 4 & 2 & 3 & 4 & 4 & 2 & 4 & 3 & 3 & 4 & 3 & 2 & 4 & 3 & 3 & 2 & 3 & 1 \\
\hline 17 & 4 & 3 & 3 & 4 & 4 & 4 & 4 & 4 & 4 & 4 & 3 & 3 & 3 & 4 & 4 & 4 & 4 & 3 & 4 & 3 \\
\hline 18 & 3 & 3 & 3 & 4 & 3 & 3 & 3 & 3 & 3 & 2 & 1 & 3 & 3 & 3 & 4 & 2 & 2 & 2 & 3 & 1 \\
\hline 19 & 3 & 3 & 3 & 3 & 4 & 3 & 3 & 3 & 3 & 3 & 3 & 3 & 3 & 2 & 4 & 3 & 3 & 4 & 4 & 2 \\
\hline 20 & 3 & 3 & 3 & 3 & 4 & 4 & 4 & 3 & 3 & 3 & 3 & 3 & 3 & 3 & 3 & 3 & 3 & 3 & 3 & 3 \\
\hline 21 & 4 & 3 & 3 & 3 & 3 & 4 & 3 & 3 & 4 & 3 & 3 & 3 & 3 & 3 & 4 & 2 & 3 & 3 & 3 & 2 \\
\hline 22 & 3 & 3 & 2 & 3 & 3 & 3 & 2 & 4 & 3 & 3 & 3 & 2 & 2 & 3 & 4 & 3 & 3 & 2 & 3 & 2 \\
\hline 23 & 4 & 4 & 4 & 4 & 4 & 4 & 4 & 4 & 4 & 4 & 4 & 4 & 4 & 4 & 4 & 3 & 4 & 4 & 4 & 3 \\
\hline 24 & 4 & 4 & 2 & 3 & 3 & 3 & 4 & 2 & 4 & 4 & 3 & 2 & 3 & 3 & 3 & 4 & 3 & 3 & 3 & 4 \\
\hline 25 & 4 & 4 & 3 & 3 & 3 & 3 & 4 & 4 & 4 & 4 & 3 & 4 & 3 & 4 & 4 & 3 & 3 & 3 & 2 & 4 \\
\hline
\end{tabular}




\section{Anexo 6}

\section{FOCUS GROUP CLIENTES}

\section{Consideraciones para el Focus Group.}

\section{Muestra:}

Se consideró dos muestras para el desarrollo del Focus Group:

- Primer grupo: Los participantes son los padres de familia de la IEP Santiago Apóstol, pertenecen al nivel socioeconómico C y D.

- Segundo grupo: Los participantes son los alumnos de la IEP IEP Santiago Apóstol.

\section{Metodología:}

Estudio cualitativo para conocer el nivel de satisfacción de los padres de familia.

\section{Participantes:}

Conformado por 10 participantes por cada grupo:

- 10 padres de familia del nivel primaria y secundaria; 8 residen en el distrito de Santiago y 2 en el distrito de Cusco.

Se consideró padres de familia que sepan acerca de la institución educativa, tomando en cuenta que el $100 \%$ de sus hijos son alumnos regulares (4 años promedio), de este modo están familiarizados con el servicio la IEP.

- 10 alumnos: 7 alumnos del nivel secundaria y 3 alumnos del nivel primaria.

\section{FOCUS GROUP IEP SANTIAGO APOSTOL: PADRES DE FAMILIA}

El presente debate tiene fines académicos para identificar cuáles son las preferencias y expectativas de los clientes de la Institución Educativa Santiago Apóstol.

Se realizará una serie de preguntas relacionadas al servicio actual de la institución educativa con el propósito de conocer la opinión de los padres de familia o estudiantes. 


\begin{tabular}{|c|c|c|}
\hline $\begin{array}{c}\text { Factores claves } \\
\text { para la } \\
\text { institución } \\
\text { educativa }\end{array}$ & Preguntas : Focus Group & Respuestas: Focus Group \\
\hline \multirow{4}{*}{ Servicio } & $\begin{array}{l}\text { ¿Qué opinan respecto al servicio } \\
\text { educativo de Santiago Apóstol? }\end{array}$ & $\begin{array}{l}7 \text { participantes consideran que el } \\
\text { servicio de Santiago Apóstol es } \\
\text { favorable para sus hijos, tomando } \\
\text { en cuenta la preocupación de la } \\
\text { promotora, el director y los } \\
\text { docentes para educar a los niños } \\
\text { y jóvenes. } 3 \text { participantes } \\
\text { consideraron que el servicio les } \\
\text { parece aceptable y que se podría } \\
\text { mejorar con espacios físicos más } \\
\text { amplios para los alumnos. }\end{array}$ \\
\hline & $\begin{array}{l}\text { ¿Santiago Apóstol escucha y atiende } \\
\text { al desarrollo personal de su hijo? }\end{array}$ & $\begin{array}{l}\text { todos consideran que la } \\
\text { institución educativa apoya al } \\
\text { desarrollo personal de sus hijos, } \\
\text { sobre todo por el seguimiento de } \\
\text { los tutores de cada sección y la } \\
\text { asesoría del departamento de } \\
\text { Psicología }\end{array}$ \\
\hline & $\begin{array}{l}\text { ¿Santiago Apóstol le comunica } \\
\text { asuntos de importancia relacionados } \\
\text { a la educación de su hijo? }\end{array}$ & $\begin{array}{l}\text { Todos toman en cuenta la } \\
\text { importancia de la comunicación } \\
\text { de los tutores de sección cuando } \\
\text { notifican las actividades y/o } \\
\text { contingencias que podrían darse } \\
\text { con los alumnos. Asimismo, } \\
\text { valoran que en situaciones de } \\
\text { importancia la promotora o el } \\
\text { director se ponen en contacto } \\
\text { mediante una llamada telefónica. }\end{array}$ \\
\hline & $\begin{array}{l}\text { En caso de que la IEP ofrezca } \\
\text { tutorías y/o cursos extra curriculares } \\
\text { que sean de interés para desarrollar } \\
\text { las habilidades de sus hijos, } \\
\text { ¿matricularían a sus hijos? }\end{array}$ & $\begin{array}{l}\text { Todos respondieron que si están } \\
\text { de acuerdo, ya que por lo } \\
\text { general sus hijos asisten } \\
\text { únicamente a academias en } \\
\text { temporada de vacaciones y } \\
\text { ofrecer cursos de acuerdo a los } \\
\text { intereses de cada estudiante } \\
\text { facilitaría el desarrollo de sus } \\
\text { capacidades }\end{array}$ \\
\hline Precio & $\begin{array}{l}\text { ¿Cómo considera la mensualidad } \\
\text { que paga por la educación de su hijo } \\
\text { en la IEP Santiago Apóstol? }\end{array}$ & $\begin{array}{l}9 \text { participantes consideran que el } \\
\text { precio de la mensualidad es justo } \\
\text { y está acorde al servicio que la } \\
\text { IEP ofrece. } 1 \text { participante indicó } \\
\text { que la mensualidad se mantuvo } \\
\text { estable por varios años }\end{array}$ \\
\hline
\end{tabular}




\begin{tabular}{|c|c|c|}
\hline \multirow[t]{2}{*}{ Docentes } & $\begin{array}{l}\text { ¿Cómo considera la labor de los } \\
\text { docentes de la IEP Santiago } \\
\text { Apóstol? }\end{array}$ & $\begin{array}{l}\text { Todos indicaron que los docentes } \\
\text { se interesan por la enseñanza de } \\
\text { sus hijos. Recalcando la } \\
\text { importancia de contar con } \\
\text { maestros que sepan orientar a los } \\
\text { niños y jóvenes con valores y con } \\
\text { experiencia }\end{array}$ \\
\hline & $\begin{array}{l}\text { ¿Por qué es importante que los } \\
\text { docentes de la institución educativa } \\
\text { sean profesionales con experiencia? }\end{array}$ & $\begin{array}{l}\text { Todos indicaron que están } \\
\text { satisfechos porque conocen a los } \\
\text { docentes, } 9 \text { participantes conocen } \\
\text { la labor de los docentes desde el } \\
\text { ingreso de sus hijos a la IEP }\end{array}$ \\
\hline $\begin{array}{l}\text { Material de } \\
\text { enseñanza }\end{array}$ & $\begin{array}{l}\text { ¿Su hijo recibe el material de } \\
\text { aprendizaje para aprender } \\
\text { satisfactoriamente? }\end{array}$ & $\begin{array}{l}7 \text { participantes conocen acerca de } \\
\text { cuáles son los materiales de } \\
\text { enseñanza (libros y páginas web) } \\
\text { que sus hijos reciben por parte } \\
\text { de los docentes y manifestaron su } \\
\text { conformidad } \\
\end{array}$ \\
\hline \multirow[b]{2}{*}{$\begin{array}{l}\text { Formación y } \\
\text { ética }\end{array}$} & $\begin{array}{l}\text { ¿Considera que Santiago Apóstol } \\
\text { incluye en la educación de su hijo la } \\
\text { formación la enseñanza de valores? }\end{array}$ & $\begin{array}{l}\text { Todos afirmaron que la IEP } \\
\text { considera la formación de valores } \\
\text { para sus hijos }\end{array}$ \\
\hline & $\begin{array}{l}\text { ¿Cuáles son los principales valores } \\
\text { que su hijo aprende dentro de la IEP } \\
\text { Santiago Apóstol? }\end{array}$ & $\begin{array}{l}6 \text { participantes mencionaron que } \\
\text { la disciplina es un valor que } \\
\text { imparte Santiago Apóstol. } 4 \\
\text { participantes mencionaron la } \\
\text { relevancia de la puntualidad }\end{array}$ \\
\hline \multirow{3}{*}{$\begin{array}{l}\text { Infraestructura y } \\
\text { mobiliario }\end{array}$} & $\begin{array}{l}\text { ¿Qué opina sobre la infraestructura } \\
\text { de Santiago Apóstol? }\end{array}$ & $\begin{array}{l}5 \text { participantes mencionaron que } \\
\text { las instalaciones son adecuadas, } \\
\text { para la cantidad de alumnado. El } \\
\text { resto de participantes indicó que } \\
\text { sería importante contar con un } \\
\text { local más amplio. También se } \\
\text { mencionó que la ubicación del } \\
\text { colegio es muy favorable por } \\
\text { estar situado en una zona céntrica }\end{array}$ \\
\hline & $\begin{array}{l}\text { ¿Qué opina sobre la cantidad de } \\
\text { aulas? }\end{array}$ & $\begin{array}{l}\text { todos los participantes } \\
\text { manifestaron su conformidad con } \\
\text { las aulas, tomando en cuenta la } \\
\text { cantidad de alumnos por aula } \\
\end{array}$ \\
\hline & $\begin{array}{l}\text { ¿Qué opina sobre las carpetas, } \\
\text { pizarras y demás materiales de } \\
\text { Santiago Apóstol? }\end{array}$ & $\begin{array}{l}8 \text { participantes indicaron que el } \\
\text { mobiliario está en condiciones } \\
\text { óptimas, } 2 \text { participantes } \\
\text { sugirieron la renovación de } \\
\text { carpetas }\end{array}$ \\
\hline
\end{tabular}


FOCUS GROUP IEP SANTIAGO APOSTOL: ALUMNOS.

\begin{tabular}{|c|c|c|}
\hline $\begin{array}{c}\text { Factores claves } \\
\text { para la institución } \\
\text { educativa }\end{array}$ & Preguntas : Focus Group & Respuestas: Focus Group \\
\hline \multirow{4}{*}{ Servicio } & $\begin{array}{l}\text { ¿Qué opinan respecto al servicio } \\
\text { educativo de Santiago Apóstol? }\end{array}$ & $\begin{array}{l}\text { todos los participantes } \\
\text { consideran que el servicio de } \\
\text { Santiago Apóstol satisface sus } \\
\text { necesidades, asimismo } \\
\text { mencionaron de que la IEP } \\
\text { vela por sus intereses y son } \\
\text { escuchados por sus tutores }\end{array}$ \\
\hline & $\begin{array}{l}\text { ¿Santiago Apóstol escucha y } \\
\text { atiende sus necesidades como } \\
\text { alumno? }\end{array}$ & $\begin{array}{l}\text { todos respondieron que si se } \\
\text { sienten escuchados y que } \\
\text { valoran el apoyo del actual } \\
\text { psicólogo por tener la } \\
\text { facilidad de poder conversar } \\
\text { con él cuando lo necesitan }\end{array}$ \\
\hline & $\begin{array}{l}\text { ¿Santiago Apóstol comunica sobre } \\
\text { asuntos importantes durante el año } \\
\text { escolar? }\end{array}$ & $\begin{array}{l}\text { todos los participantes } \\
\text { indicaron que, si existe } \\
\text { comunicación por parte del } \\
\text { director todas las mañanas, así } \\
\text { como por los tutores de clase } \\
\text { y los docentes. Dos } \\
\text { participantes dieron una } \\
\text { sugerencia de tener un buzón } \\
\text { para dar sus opiniones e } \\
\text { inquietudes }\end{array}$ \\
\hline & $\begin{array}{l}\text { ¿qué ventajas obtienen de estudiar } \\
\text { en Santiago Apóstol? }\end{array}$ & $\begin{array}{l}7 \text { participantes indicaron que } \\
\text { una ventaja importante es que } \\
\text { Santiago Apóstol tiene } \\
\text { reconocimiento en el distrito } \\
\text { de Santiago y se sienten } \\
\text { identificados con su centro de } \\
\text { estudios. } 3 \text { participantes } \\
\text { indicaron que Santiago } \\
\text { Apóstol les forma con } \\
\text { educación basada en la } \\
\text { práctica de compañerismo, } \\
\text { solidaridad y puntualidad }\end{array}$ \\
\hline
\end{tabular}




\begin{tabular}{|c|c|c|}
\hline & $\begin{array}{l}\text { ¿Considera importante que } \\
\text { Santiago Apóstol le ofrezca talleres } \\
\text { extras? ¿qué talleres estarían } \\
\text { acorde a su interés? }\end{array}$ & $\begin{array}{l}\text { todos los participantes } \\
\text { manifestaron su interés por } \\
\text { llevar cursos extra } \\
\text { curriculares. } 5 \text { participantes } \\
\text { indicaron que les interesa } \\
\text { actividades artísticas como la } \\
\text { danza folclórica , } 2 \\
\text { participantes mencionaron su } \\
\text { interés por la práctica de } \\
\text { deporte; } 2 \text { participantes } \\
\text { indicaron que les gustaría } \\
\text { aprender a tocar un } \\
\text { instrumento musical y un } \\
\text { participante mencionó su } \\
\text { interés por aprender } \\
\text { gastronomía }\end{array}$ \\
\hline \multirow[t]{2}{*}{ Docentes } & $\begin{array}{l}\text { ¿Cómo considera la labor de los } \\
\text { docentes de Santiago Apóstol? }\end{array}$ & $\begin{array}{l}\text { todos los participantes } \\
\text { consideran la buena } \\
\text { predisposición para consultar } \\
\text { con sus docentes, cada } \\
\text { docente encargado de su } \\
\text { materia conoce sobre los } \\
\text { temas que enseña y brindan su } \\
\text { ayuda cuando tienen dudas } \\
\text { durante las clases }\end{array}$ \\
\hline & $\begin{array}{l}\text { ¿qué cualidades valora en los } \\
\text { docentes de Santiago Apóstol? }\end{array}$ & $\begin{array}{l}6 \text { participantes comentaron } \\
\text { que los docentes son } \\
\text { exigentes con la disciplina y } \\
\text { orden, } 3 \text { participantes } \\
\text { mencionaron la disponibilidad } \\
\text { de sus docentes para ser } \\
\text { escuchados } \\
\end{array}$ \\
\hline $\begin{array}{l}\text { Formación y } \\
\text { ética }\end{array}$ & $\begin{array}{l}\text { ¿Cuáles son los principales valores } \\
\text { que aprende dentro de la IEP } \\
\text { Santiago Apóstol? }\end{array}$ & $\begin{array}{l}\text { el valor mencionado por todos } \\
\text { fue la puntualidad, } 6 \\
\text { participantes mencionaron la } \\
\text { disciplina y } 4 \text { consideraron la } \\
\text { vocación de estudio }\end{array}$ \\
\hline \multirow{2}{*}{$\begin{array}{l}\text { Infraestructura y } \\
\text { mobiliario }\end{array}$} & $\begin{array}{l}\text { ¿Qué opina sobre la infraestructura } \\
\text { de Santiago Apóstol? }\end{array}$ & $\begin{array}{l}\text { todos los participantes } \\
\text { mencionaron que se sentirían } \\
\text { más a gusto con un espacio } \\
\text { físico más amplio para poder } \\
\text { realizar deporte y ocio durante } \\
\text { los recesos }\end{array}$ \\
\hline & $\begin{array}{l}\text { ¿Qué opina sobre la cantidad de } \\
\text { aulas? }\end{array}$ & $\begin{array}{l}8 \text { participantes mencionaron } \\
\text { que las aulas son exactas para } \\
\text { la cantidad de alumnos por } \\
\text { sección, } 2 \text { participantes } \\
\text { indicaron que sería ideal tener } \\
\text { aulas más grandes para poder }\end{array}$ \\
\hline
\end{tabular}




\begin{tabular}{|l|l|l|}
\hline & $\begin{array}{l}\text { realizar dinámicas durante las } \\
\text { clases }\end{array}$ \\
\begin{tabular}{l|l} 
¿ Qué opina sobre las carpetas, \\
pizarras y demás materiales de \\
Santiago Apóstol?
\end{tabular} & $\begin{array}{l}\text { todos los participantes } \\
\text { indicaron sentirse cómodos } \\
\text { con sus carpetas y con las } \\
\text { pizarras que usan sus } \\
\text { docentes. Asimismo dieron } \\
\text { una sugerencia de comprar } \\
\text { más computadoras para } \\
\text { aprender en el laboratorio de } \\
\text { informática }\end{array}$ \\
\hline
\end{tabular}




\section{Anexo 7}

\section{Beneficios Tributarios}

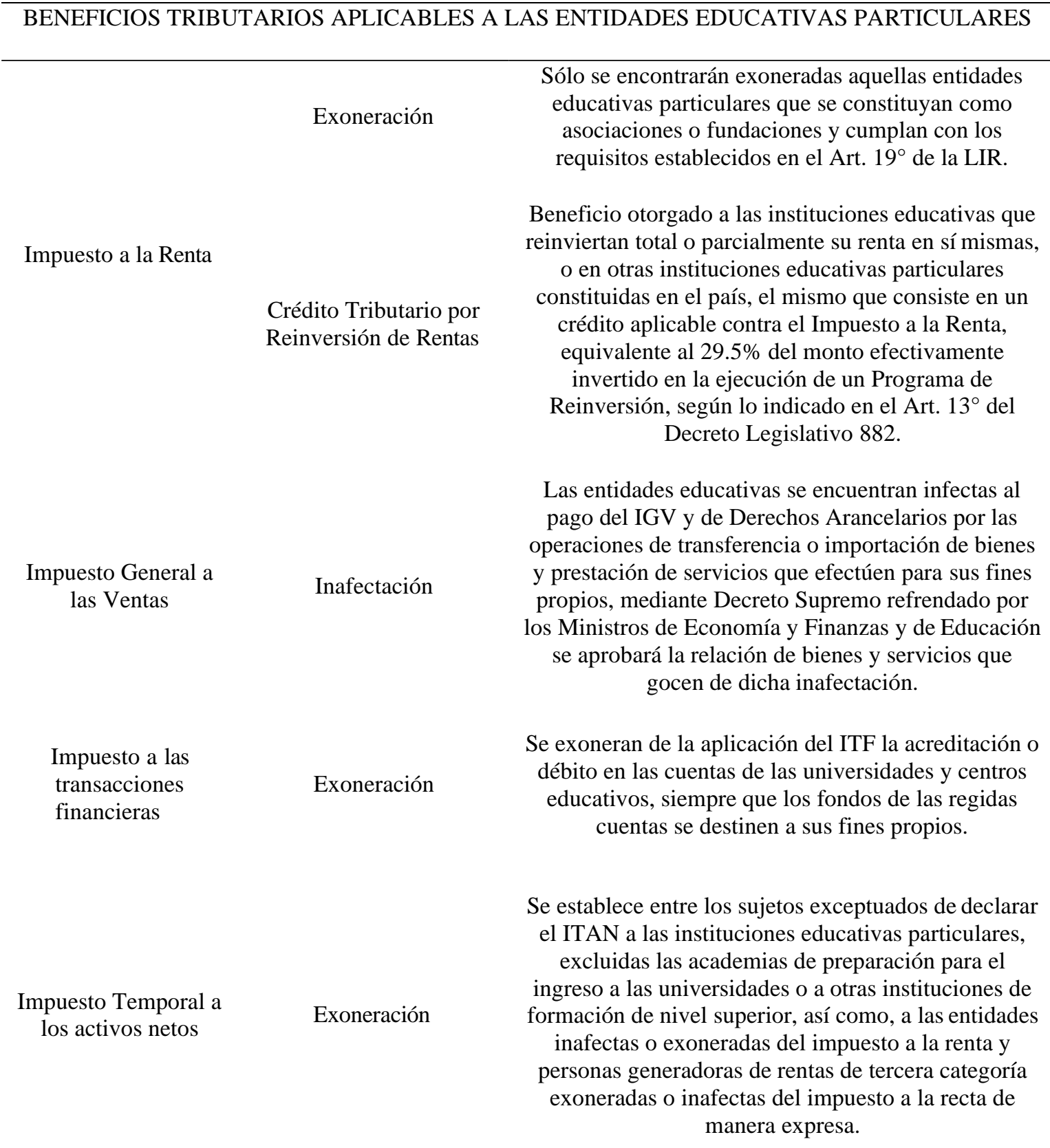

Nota. Recuperado de http://aempresarial.com/web/revitem/1 758 05677.pdf. Revista “Actualidad Empresarial N ${ }^{\circ}$ 
Anexo 8

Estructura de Inversiones

\begin{tabular}{|c|c|c|c|c|c|}
\hline INVERSIONES & INVERSIONES SIN IGV & IGV (18\%) & INVERSIONES CON IGV & CAPITAL PROPIO & DEUDA \\
\hline ACTIVO FIJO TANGIBLE & 741,592 & 133,487 & 875,079 & & \\
\hline ACTIVO FIJO INTANGIBLE & 52,504 & 9,451 & 61,955 & & \\
\hline CAPITAL DE TRABAJO & 45,442 & & 45,442 & & \\
\hline TOTAL & & & & 638,675 & 343,800 \\
\hline
\end{tabular}




\section{Anexo 9}

NÚMERO DE INSTITUCIONES EDUCATIVAS Y PROGRAMAS DEL SISTEMA EDUCATIVO POR TIPO DE

GESTIÓN Y ÁREA GEOGRÁFICA, SEGÚN ETAPA, MODALIDAD Y NIVEL EDUCATIVO

Año 2017

SANTIAGO: NÚMERO DE INSTITUCIONES EDUCATIVAS Y PROGRAMAS DEL SISTEMA EDUCATIVO POR TIPO DE GESTIÓN Y ÁREA GEOGRÁFICA, SEGÚN ETAPA, MODALIDAD Y NIVEL EDUCATIVO, 2017

\begin{tabular}{|c|c|c|c|c|c|c|c|c|c|}
\hline \multirow{2}{*}{$\begin{array}{c}\text { Etapa, modalidad y nivel } \\
\text { educativo }\end{array}$} & \multirow{2}{*}{ Total } & \multicolumn{2}{|c|}{ Gestión } & \multicolumn{2}{|c|}{ Área } & \multicolumn{2}{|c|}{ Pública } & \multicolumn{2}{|c|}{ Privada } \\
\hline & & Pública & Privada & Urbana & Rural & Urbana & Rural & Urbana & Rura \\
\hline Total & $\underline{175}$ & $\underline{106}$ & $\underline{69}$ & $\underline{166}$ & $\underline{9}$ & $\underline{97}$ & $\underline{9}$ & $\underline{69}$ & $=$ \\
\hline Básica Regular & $\underline{161}$ & $\underline{102}$ & $\underline{59}$ & $\underline{152}$ & $\underline{9}$ & $\underline{93}$ & $\underline{9}$ & $\underline{59}$ & $=$ \\
\hline Inicial & 108 & 74 & 34 & 102 & 6 & 68 & 6 & 34 & - \\
\hline Primaria & 34 & 20 & 14 & 31 & 3 & 17 & 3 & 14 & - \\
\hline Secundaria & 19 & 8 & 11 & 19 & - & 8 & - & 11 & - \\
\hline
\end{tabular}

Fuente: MINISTERIO DE EDUCACIÓN - Padrón de Instituciones Educativas

año 2016

SANTIAGO: NÚMERO DE INSTITUCIONES EDUCATIVAS Y PROGRAMAS DEL SISTEMA EDUCATIVO POR TIPO DE GESTIÓN Y ÁREA GEOGRÁFICA, SEGÚN ETAPA, MODALIDAD Y NIVEL EDUCATIVO, 2016 


\begin{tabular}{c|c|c|c|c|c|c|c|c|c}
\hline \multirow{2}{*}{$\begin{array}{c}\text { Etapa, modalidad y nivel } \\
\text { educativo }\end{array}$} & \multirow{2}{*}{ Total } & \multicolumn{2}{|c|}{ Gestión } & \multicolumn{2}{c|}{ Área } & \multicolumn{2}{c|}{ Pública } & \multicolumn{2}{c}{ Privada } \\
\cline { 3 - 10 } & & Pública & Privada & Urbana & Rural & Urbana & Rural & Urbana & Rural \\
\hline Total & $\underline{\mathbf{1 7 4}}$ & $\underline{\mathbf{1 0 5}}$ & $\underline{\mathbf{6 9}}$ & $\underline{\mathbf{1 6 4}}$ & $\underline{\mathbf{1 0}}$ & $\underline{\mathbf{9 5}}$ & $\underline{\mathbf{1 0}}$ & $\underline{\mathbf{6 9}}$ & $=$ \\
Básica Regular & $\underline{\mathbf{1 5 7}}$ & $\underline{\mathbf{1 0 1}}$ & $\underline{\mathbf{5 6}}$ & $\underline{\mathbf{1 4 7}}$ & $\underline{\mathbf{1 0}}$ & $\underline{\mathbf{9 1}}$ & $\underline{\mathbf{1 0}}$ & $\underline{\mathbf{5 6}}$ & $=$ \\
Inicial & 105 & 73 & 32 & 98 & 7 & 66 & 7 & 32 & - \\
Primaria & 34 & 20 & 14 & 31 & 3 & 17 & 3 & 14 & - \\
Secundaria & 18 & 8 & 10 & 18 & - & 8 & - & 10 & - \\
\hline
\end{tabular}

Fuente: MINISTERIO DE EDUCACIÓN - Padrón de Instituciones Educativas

SANTIAGO 2015

SANTIAGO: NÚMERO DE INSTITUCIONES EDUCATIVAS Y PROGRAMAS DEL SISTEMA EDUCATIVO POR TIPO

DE GESTIÓN Y ÁREA GEOGRÁFICA, SEGÚN ETAPA, MODALIDAD Y NIVEL EDUCATIVO, 2015

\begin{tabular}{c|c|c|c|c|c|c|c|c|c}
\hline \multirow{2}{*}{\begin{tabular}{c} 
Etapa, $\begin{array}{c}|c| \\
\text { modalidad y nivel } \\
\text { educativo }\end{array}$ \\
\multirow{2}{*}{ Total }
\end{tabular}} & \multicolumn{2}{|c|}{ Gestión } & \multicolumn{2}{c|}{ Área } & \multicolumn{2}{c|}{ Pública } & \multicolumn{2}{c}{ Privada } \\
\cline { 3 - 9 } & & Pública & Privada & Urbana & Rural & Urbana & Rural & Urbana & Rural \\
\hline Total & $\underline{\mathbf{1 7 7}}$ & $\underline{\mathbf{1 0 9}}$ & $\underline{\mathbf{6 8}}$ & $\underline{\mathbf{1 6 4}}$ & $\underline{\mathbf{1 3}}$ & $\underline{\mathbf{9 6}}$ & $\underline{\mathbf{1 3}}$ & $\underline{\mathbf{6}}$ & $=$ \\
Básica Regular & $\underline{\mathbf{1 6 1}}$ & $\underline{\mathbf{1 0 5}}$ & $\underline{\mathbf{5 6}}$ & $\underline{\mathbf{1 4 8}}$ & $\underline{\mathbf{1 3}}$ & $\underline{\mathbf{9 2}}$ & $\underline{\mathbf{1 3}}$ & $\underline{\mathbf{5 6}}$ & $=$ \\
Inicial & 110 & 77 & 33 & 100 & 10 & 67 & 10 & 33 & - \\
Primaria & 33 & 20 & 13 & 30 & 3 & 17 & 3 & 13 & - \\
Secundaria & 18 & 8 & 10 & 18 & - & 8 & - & 10 & - \\
\hline
\end{tabular}

Fuente: MINISTERIO DE EDUCACIÓN - Padrón de Instituciones Educativas

año 2014

SANTIAGO: NÚMERO DE INSTITUCIONES EDUCATIVAS Y PROGRAMAS DEL SISTEMA EDUCATIVO POR TIPO DE GESTIÓN Y ÁREA GEOGRÁFICA, SEGÚN ETAPA, MODALIDAD Y NIVEL EDUCATIVO, 2014 


\begin{tabular}{|c|c|c|c|c|c|c|c|c|c|}
\hline \multirow{2}{*}{$\begin{array}{c}\text { Etapa, modalidad y nivel } \\
\text { educativo }\end{array}$} & \multirow{2}{*}{ Total } & \multicolumn{2}{|c|}{ Gestión } & \multicolumn{2}{|c|}{ Área } & \multicolumn{2}{|c|}{ Pública } & \multicolumn{2}{|c|}{ Privada } \\
\hline & & Pública & Privada & Urbana & Rural & Urbana & Rural & Urbana & Rura \\
\hline Total & $\underline{180}$ & $\underline{113}$ & $\underline{67}$ & $\underline{169}$ & $\underline{11}$ & $\underline{102}$ & $\underline{11}$ & $\underline{67}$ & $=$ \\
\hline Básica Regular & $\underline{161}$ & $\underline{109}$ & $\underline{52}$ & $\underline{150}$ & $\underline{11}$ & $\underline{98}$ & $\underline{11}$ & $\underline{52}$ & $=$ \\
\hline Inicial & 111 & 81 & 30 & 103 & 8 & 73 & 8 & 30 & - \\
\hline Primaria & 33 & 20 & 13 & 30 & 3 & 17 & 3 & 13 & - \\
\hline Secundaria & 17 & 8 & 9 & 17 & - & 8 & - & 9 & - \\
\hline
\end{tabular}

Fuente: MINISTERIO DE EDUCACIÓN - Padrón de Instituciones Educativas. 